\title{
Orthognathic Surgery for the Maxilla-LeFort I and Anterior Maxillary Osteotomy
}

\author{
Ashok Dabir and Jayesh Vahanwala
}

\subsection{History of Maxillary Osteotomies}

\author{
Maxillary Osteotomies \\ One does not know a science completely without knowing its \\ history.
}

Auguste Comte (1798-1857) [1]

\section{The Le Fort I-Type Maxillary Osteotomy}

The development of modern maxillary orthognathic surgical procedures had diverse historical origins and contributions. The removal of nasal and nasopharyngeal polyps via hemi maxillary osteotomy was being undertaken in Europe in the mid-nineteenth century, notably by the German surgeon Bernhard Rudolf Konrad von Langenbeck (1810-1887) in Berlin [2]. The first maxillary procedure that would today be described as a total Le Fort I-type osteotomy appears to have been undertaken in 1868 by the American surgeon, David Williams Cheever (1831-1915) in Boston City Hospital to provide surgical access for removal of a large nasopharyngeal polyp [3]. One year prior to this, in 1867, Cheever had undertaken a down-fracture of the right hemimaxilla for similar surgical access in another patient, who had made a complete recovery [4]. The total down-fracture of the maxilla at the Le Fort I level performed in 1868, described as Cheever's "double operation," though technically successful, had an unfortunate postoperative outcome in that the patient

Electronic Supplementary Material The online version of this chapter (https://doi.org/10.1007/978-981-15-1346-6_69) contains supplementary material, which is available to authorized users.

A. Dabir $(\bowtie)$

D. Y. Patil University School of Dentistry, Nerul, Navi Mumbai, India

Breach Candy Hospital, Mumbai, India

J. Vahanwala $(\bowtie)$

Department of Oral Surgery, Vaidik Dental College and Research Centre, Nani Daman, Daman, India

Breach Candy Hospital, Mumbai, India subsequently died 5 days later, though probably not as a direct result of the maxillary procedure $[5,6]$.

In 1901, a French surgeon from Lille named René Le Fort (1869-1951) conducted experiments using blunt trauma to intact cadaveric faces, from different directions and varying magnitudes, and thereby described the natural planes of maxillary and facial fractures [7, 8] now known as the Le Fort classification of facial fractures. The names of the Le Fort I-, II-, and III-type osteotomies are due to their similarity to the Le Fort fractures.

In 1927, Wassmund carried out a maxillary osteotomy at the Le Fort I level, without pterygoid plate disjunction or mobilization at the time of surgery [9]. He used elastics to close an anterior open bite, without placing a bone graft, which subsequently relapsed. In 1934, Axhausen in Berlin described advancement of the maxilla at the Le Fort I level, which was incompletely mobilized, again with postoperative elastic traction [10].

Wassmund was the first to apply osteotomies at the Le Fort I level for correction of midfacial deformities [11]. The technique was subsequently modified by several surgeons including Axhausen [12], Schuchardt [13], and Willmar [14]. In 1965, Obwegeser improved the precision of the Le Fort I osteotomy by suggesting complete mobilization of the maxilla so that repositioning was achieved without tension $[15,16]$. The operation was slow to gain popularity until 1973, till Bell's description of the remarkably resilient maxillary blood supply [17]. With advancement in technique and the introduction of safe hypotensive anesthesia, the Le Fort I osteotomy has been increasingly utilized over the last four decades. Over the years, various modifications of the osteotomies, ORIF methods and bone grafting to the mobilized maxilla, have continued to evolve and progress.

\subsection{Surgical Anatomy}

The paired maxillae are made up of a body and four projections: frontal, zygomatic, palatine, and the alveolar process. The maxilla forms the inferior and medial borders of the 
orbits. The infraorbital foramen is located at an average distance of $7.8 \mathrm{~mm}$, positioned inferiorly to the infraorbital rim in women and $8.5 \mathrm{~mm}$ in men [18]. The vascular and sensory supplies to the cheek, lateral aspect of the nose, and upper lip exit the bone from this foramen.

The anterior alveolar processes surround the piriform apertures and join to form the anterior nasal spine in the midline. The anterior nasal spine is the most anterior inferior attachment for the cartilaginous nasal septum, which extends posteriorly along the nasal crest and articulates with the vomer.

The maxillary sinuses are housed in body of maxilla. Anteriorly, palatine process of each maxilla and posteriorly, horizontal lamina of palatine bone form the hard palate. The greater palatine foramen is located on each side approximately $10 \mathrm{~mm}$ posteromedial to the second molar.

The nasolacrimal duct travels within the bony wall between the nasal cavity and the maxillary sinus before terminating below the inferior turbinate. It can be injured during the Le Fort I osteotomy or during an inferior turbinectomy performed to allow superior repositioning of the maxilla (Fig. 69.1) [19, 20].

Posterolaterally, the maxilla articulates with the pyramidal processes of the palatine bones and the pterygoid plates of the sphenoid bone. This pterygomaxillary junction extends superiorly as a fissure, which ends at the pterygopalatine fossa. The terminal portion of the internal maxillary artery traverses the pterygopalatine fossa and gives off several branches that can be encountered during a Le Fort I osteotomy (Fig. 69.2a, b). The average distance between the infe-

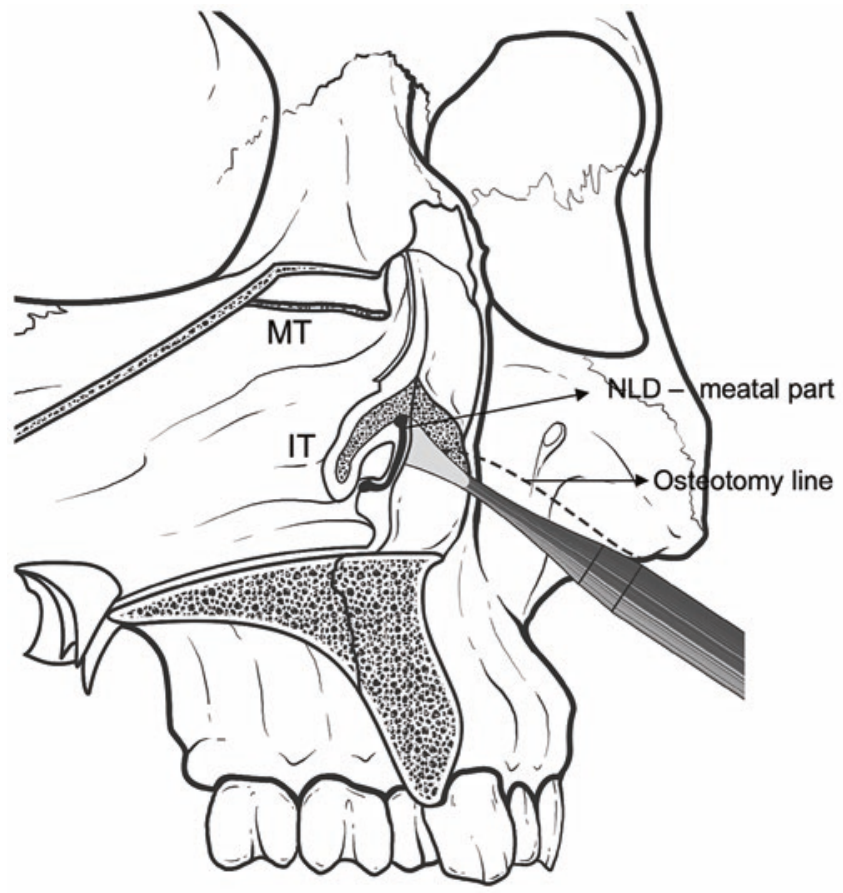

CAssociation of Oral and Maxillofacial Surgeons of India

Fig. 69.1 Relationship of the nasolacrimal duct to the Le Fort I osteotomy cut. The meatus of the nasolacrimal duct is unlikely to be injured if the osteotomy is made just beneath the infraorbital foramen and into the piriform rim at the level of the inferior turbinate (IT). MT middle turbinate
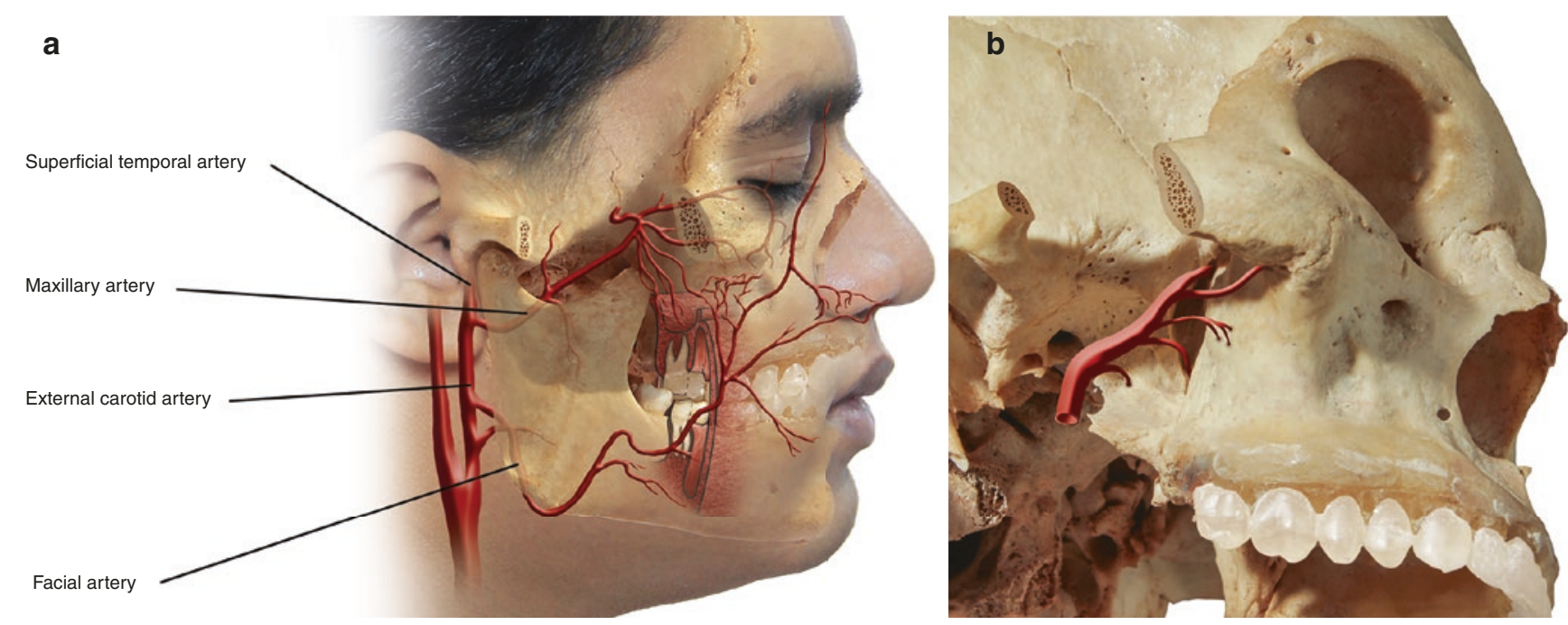

CAssociation of Oral and Maxillofacial Surgeons of India

Fig. 69.2 (a) Branches of external carotid artery, (b) terminal branches of internal maxillary artery 
rior extent of the pterygomaxillary junction and the posterior superior alveolar artery is $15 \mathrm{~mm}$, the infraorbital artery is $32 \mathrm{~mm}$, and the descending palatine artery is $25 \mathrm{~mm}$. The descending palatine arteries travel through the perpendicular plate of the palatine bones and are located approximately $34 \mathrm{~mm}$ posterior to the piriform rims and within $10 \mathrm{~mm}$ medial to the pterygomaxillary fissures [21].

Osteotomies of the lateral nasal walls and at the pterygomaxillary fissures must be completed carefully to avoid injuring these vessels. The internal maxillary artery is 23-25 $\mathrm{mm}$ above the base of the junction of the maxilla with the pterygoid plates, with an average diameter of $2.5 \mathrm{~mm}$. In addition to the direct vascular supply of the maxilla by the descending palatine arteries, there is a rich collateral vascular network from the soft palate supplied by the ascending pharyngeal arteries and the ascending palatine branches of the facial arteries (Fig. 69.3). The risk of damaging the artery can be minimized by ensuring the pterygoid osteotome is directed downward toward the palate and is less than $1.5 \mathrm{~cm}$ above the inferior part of the fissure $[22,23]$.

Bell's work revealed that ligation of the bilateral descending palatine arteries does not compromise the vascularity of the maxilla as long as the soft palate pedicle is preserved [24, 25].

The pterygoid plexus of veins is located between the temporalis and lateral pterygoid muscles and between the medial and lateral pterygoid muscles. It receives tributaries corresponding to the branches of the maxillary artery and drains into the maxillary vein. Venous bleeding from this plexus may be encountered during the posterolateral maxillary dissection and pterygomaxillary disjunction.

The risk of damaging the artery can be minimized by ensuring the pterygoid osteotome is directed downwards towards the palate and is less than $1.5 \mathrm{~cm}$ above the inferior part of the fissure [22, 23].

Bell's work revealed that ligation of the bilateral descending palatine arteries does not compromise the vascularity of the maxilla as long as the soft palate pedicle is preserved [24, 25].

$\mathrm{S}$. Bruneder et al. studied a special type of arterial variation of the Le Fort I segment's blood supply. Individuals with this special arterial anatomy may clinically be at high risk for hypoperfusion and avascular segment necrosis after surgery. Individualized operation planning that takes the patient's arterial anatomy into consideration may help to prevent ischemic vascular complications of the Le Fort I segment and improve operative outcomes in at-risk patients [26].

S. Salmanet et al. studied Dynamic analysis of maxillary perfusion during Le Fort I osteotomy using indocyanine green and concluded that there was a statistically significant decrease in perfusion, as assessed by intraoperative dynamic angiography, to the anterior maxilla following maxillary down-fracture. Patient age, conventional versus segmental Le Fort I osteotomy, changes in mean arterial pressure and/or heart rate, and preservation of the descending palatine vessels had no statistically significant effect on perfusion [27].
Fig. 69.3 The vascular supply of the osteotomised LeFort I segment. The ascending pharyngeal arteries and the ascending palatine branches of the facial artery

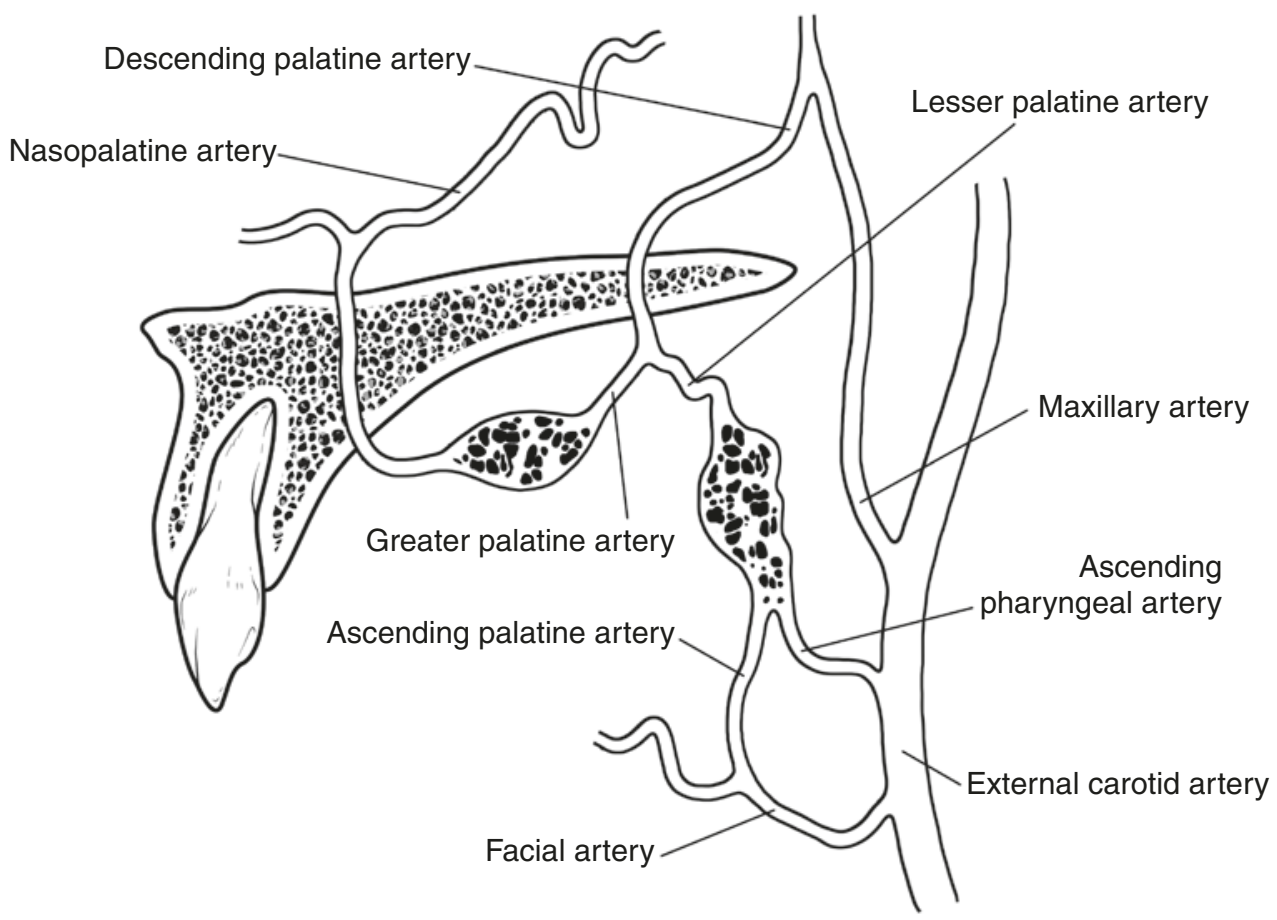

(c)Association of Oral and Maxillofacial Surgeons of India 
The patient's sex and aspects of the skeletal and craniofacial pattern have an influence on the pterygomaxillary area and descending palatine canal anatomy. A preoperative computed tomography analysis involving this evaluation could reduce the risk of surgical complications. A preoperative CT analysis should be performed on an individual basis and should identify the differences between the two sides in the same patient to allow a safer surgical procedure during Le Fort I osteotomy [28].

\subsection{The Anterior Segmental Maxillary Osteotomy}

The first anterior segmental maxillary osteotomy (ASMO) was reported at the beginning of the twentieth century by Günther Cohn-Stock [29], wherein he tried to surgically "correct a marked overjet and overbite of the central maxillary teeth." In his pioneering article in 1921, he described the evolution of his idea to perform an osteotomy of the anterior segment of the maxilla while preserving the vestibular pedicle and, in a later design, also the palatal artery [29].

After Cohn-Stock's original report, three variations of the procedure were developed by Wassmund [9], Wunderer [30], and Cupar [31]. These variations were designed to maintain sufficient blood supply to the maxilla while giving adequate access for instrumentation [32, 33].

In 1927 Wassmund [9] improved Cohn-Stock's design by creating a direct approach to the labial premaxillary cortex using three vertical incisions and subperiosteal tunnelling for completion of the labial osteotomy without reflection of labial or palatal flaps. Both the labial and palatal blood supply are maintained; however, the osteotomy is made in a relatively blind fashion. This method may be indicated for closure of multiple interdental spaces [33] and for anteroposterior repositioning of the premaxilla [34]. It was found to maintain the best vascularity of the repositioned segment in comparison to all other ASMO methods [35].

In 1954 Cupar [31] described a different approach for down-fracture of the anterior maxilla: exposure of the labial aspect of the maxillary bone by a vestibular circumferential cut and labial flap to facilitate the labial osteotomy under direct vision. A palatal osteotomy was performed through a tunnel, maintaining the palatal blood supply. This technique is indicated for superior repositioning of the anterior maxilla in cases of vertical maxillary excess.

In 1963 Wunderer [30] advocated reflection of a palatal flap without fracturing of the anterior maxilla and maintenance of the labial blood supply. Direct access for the palatal osteotomy is the main advantage of this technique, especially if posterior segments of the premaxilla must be removed.
Therefore, this technique may be indicated for setback of the anterior part of the maxilla. Blood flow studies have demonstrated that the transpalatal approach causes the greatest decrease in blood supply to the anterior maxilla [36]. However, transpalatal soft tissue incision and labial osteotomies impair vascular supply to the anterior maxilla from the greater palatine vessels and the superior alveolar vessels, respectively, leaving the labial collaterals as the sole blood supply to the anterior maxilla [37].

In 1977 Epker modified the Cupar technique for downfracture of the anterior maxilla. He used only labial flaps and vertical tunnels labial to the teeth to be extracted, which were usually premolars on both sides [38]. Epker's modification enables repositioning of the anterior maxilla superiorly, posteriorly, and inferiorly. The main advantages of the Epker modification include preservation of the palatal pedicle, ease of placement of internal fixation, provide access to the nasal septal structures to prevent buckling of the nasal septum with superior repositioning of the maxilla, and a direct approach for removal of palatal bone. When required, bone grafting for stabilization of an inferiorly positioned anterior maxilla may also be done using this method.

The segmental Le Fort I osteotomy should not be excluded from the technical armamentarium in orthognathic surgery. On the contrary, the literature consulted suggests it to be a useful tool for the three-dimensional surgical correction of maxillary malposition [39].

\subsubsection{Technique (Video 69.1)}

Anaesthetic and Positioning Considerations: Controlled hypotensive anesthesia has been shown to reduce bleeding from mucosal and bone edges that contain a rich network of small vessels, which cannot easily be identified and controlled with surgical techniques. In healthy patients, a reduction in mean arterial pressure (MAP) of 30\% below the patient's baseline with a minimum MAP of $50 \mathrm{mmHg}$ is safe [40]. In bimaxillary surgery, postoperative blood transfusions are necessary in $13-48 \%$ of patients who do not have controlled hypotension during the operation [41, 42]. The need for transfusion has been nearly eliminated by using this technique. Placement of an indwelling bladder catheter for intraoperative monitoring of urine output as a marker of renal perfusion should be considered when using controlled hypotension. After induction of general anesthesia, the patient is nasally intubated. Because intraoperative maxillomandibular fixation is essential to establish the postoperative position of the anterior maxilla, oral intubation is less desirable and should be avoided. The endotracheal tube must be sufficiently below the level of the vocal cords to prevent 
unintended dislodgement during premaxillary manipulation. A shoulder roll is inserted to extend the neck without creating hyperextension. A sterile preparation and draping is performed, leaving the orbits and nasion exposed. After the planned mucosal incision is marked, local anaesthetic with vasoconstrictor (lidocaine with 1:100,000 epinephrine) is infiltrated in the labial sulcus. Palatal injection should be avoided so as not to induce vasoconstriction in the palatal pedicle.

\subsubsection{Exposure}

A horizontal buccal sulcus incision is made by diathermy or a \#15 scalpel blade in one strike to the bone in the deepest section of the buccal vestibule, circumferentially from right to left second premolar. Next, the periosteum is reflected superiorly to expose the entire canine fossa and piriform aperture bilaterally. Inferiorly, minimum mucoperiosteal stripping should be done, to maximize blood supply to the osteotomized maxilla. The alveolar mucoperiosteum should be undermined to the crestal bone only at preplanned osteotomy or ostectomy sites. The nasal mucoperiosteum should be carefully separated from the nasal cavity floor to prevent intraoperative bleeding, postoperative oronasal communication, and fistula formation. The cartilaginous nasal septum is separated from the nasal groove of the maxilla to facilitate its manipulation later.

\subsubsection{Extractions and Horizontal Osteotomies}

As per surgical plan, maxillary premolars are extracted on each side. Then, a reciprocating saw or piezo-surgical saw is used to perform horizontal osteotomies. These bone cuts should run posteriorly from each side of the piriform rim, including the lateral maxillary walls and the lateral nasal cavity walls. The nasal mucosa is protected with a curved periosteal elevator. Due care should be taken to avoid injury to the infraorbital nerve during retraction of the upper mucoperiosteal flap. The posterior limit for these osteotomies is the planned vertical osteotomy/ostectomy, usually the first or second premolar (Fig. 69.4a-d).

Figure 69.4b and Fig. 69.5 indicates the horizontal and vertical osteotomies/ostectomies that are performed using a \#701 bur, mini-saw, or piezo. Precise bone removal should be done to ensure an accurate postoperative position and sufficient intersegmental bony contacts.

Meticulous tissue handling is of paramount importance at this stage. Failure to preserve buccal mucosa may lead to an impaired blood supply to the down-fractured maxilla or establishment of an oroantral fistula, in addition to periodontal compromise of the adjacent teeth.

\subsubsection{Final Osteotomy and Down-Fracture of the Premaxilla}

After completion of the planned osteotomies and ostectomies under direct visualization, the final osteotomy is done using an osteotome. Neither a palatal incision nor a mucosal undermining is done at this stage. A palpating finger is positioned on the palatal mucosa, and the transpalatal osteotomy is completed with an osteotome. Down-fracture of the premaxilla is accomplished with a bone hook. Additional transpalatal and nasal ostectomies may be necessary at this stage and should be finalized under direct access gained to the nasal aspect of the down-fractured premaxilla. Careful separation of the mucoperiosteum from the posterior segment of the palate facilitates setback of the anterior segment and prevents it from becoming detached from the anterior segment, compromising the blood supply (Fig. 69.6a, b).

\subsubsection{Midpalatal Osteotomy}

If indicated for transverse widening or narrowing of the premaxilla or closure of a diastema, a midpalatal osteotomy is performed with an osteotome or piezo-surgical saw (Fig. 69.7a, b).

\subsubsection{Fixation}

After completion of the ostectomies, maxillary teeth are placed into a preformed acrylic occlusal wafer, which is wired to the maxillary dentition. Temporary maxillomandibular fixation then is done, and a standard 1.5 or 2.0 maxillary plating system is used at the maxillary buttresses to fixate the bone segments in their planned postoperative position (Fig. 69.8a-c).

\subsubsection{Closure}

After thorough irrigation of the surgical site with saline, the mucosal incisions are closed with 3-0/4-0 vicryl suture. If indicated, alar cinch and V-Y closure of the buccal incision are performed at this stage. Maxillomandibular fixation is removed at the end of the procedure. The maxillary surgical wafer may be kept in place for 6 weeks for additional stability of the maxillary segments and occlusal guidance (Fig. 69.9a, b). 


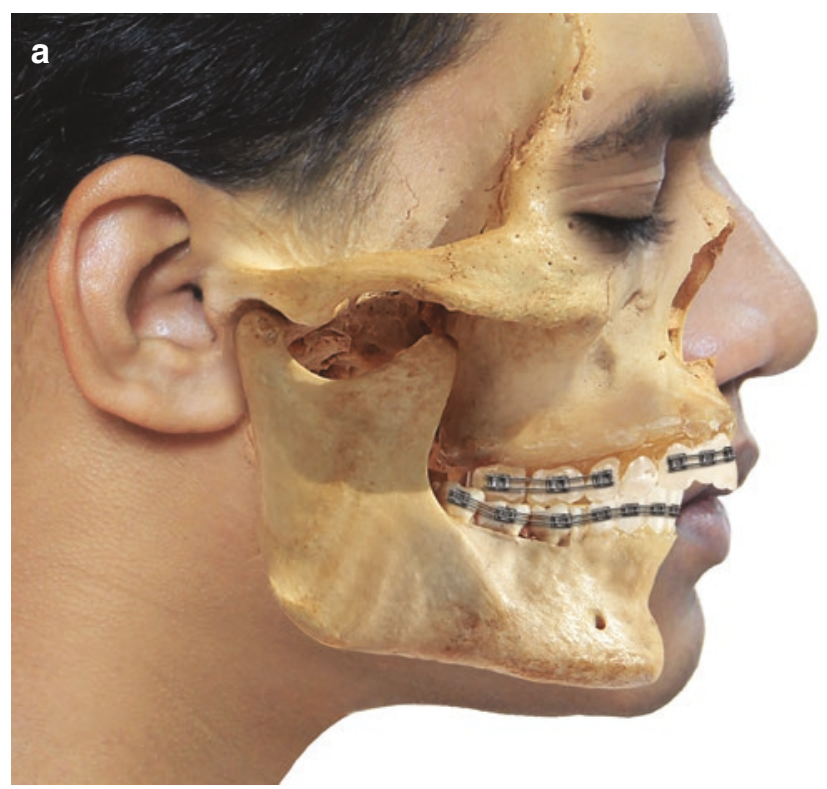

\section{b}
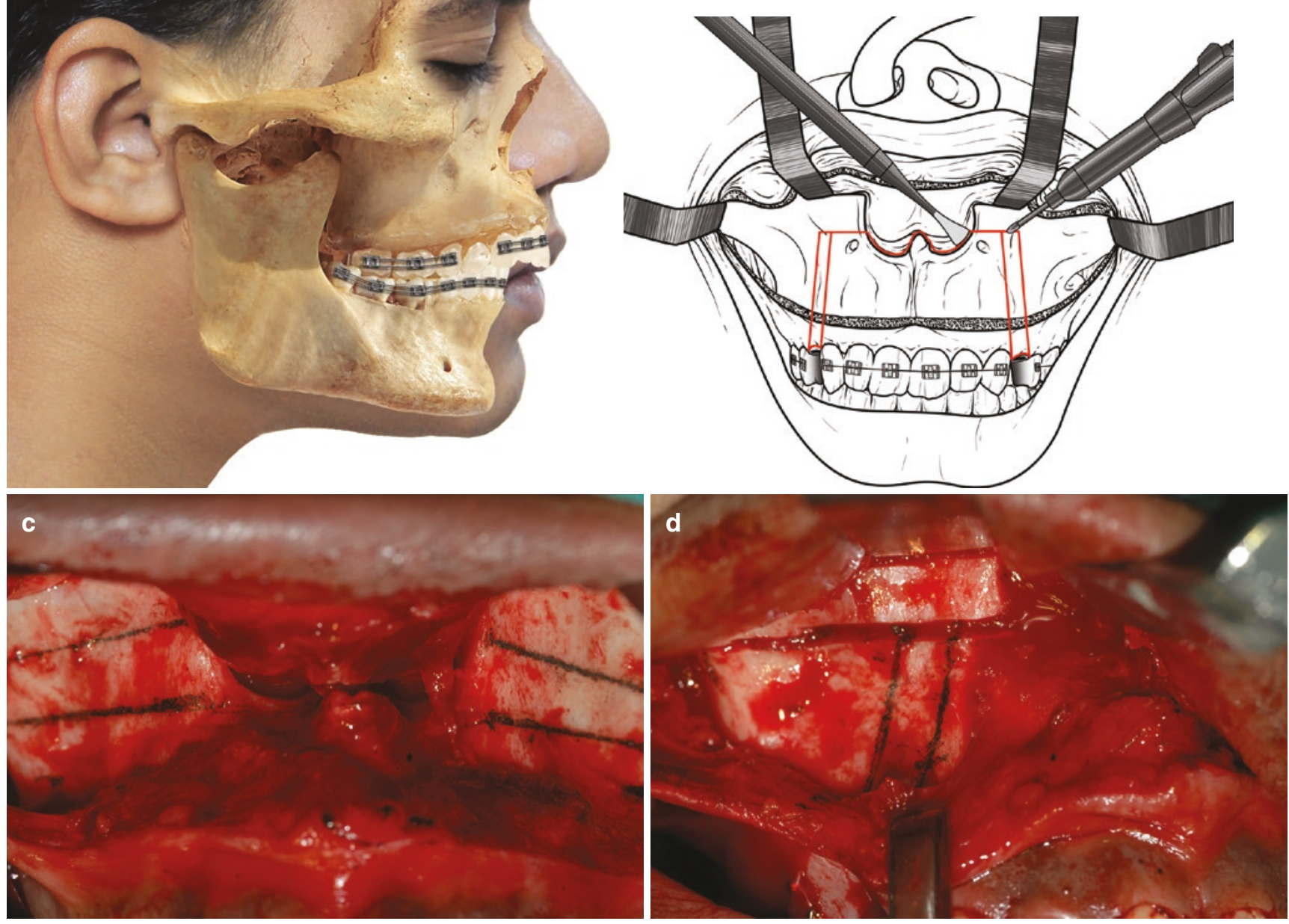

CAssociation of Oral and Maxillofacial Surgeons of India

Fig. 69.4 (a-d) Epker's modificaiton of Cupar's down-fracture anterior maxillary osteotomy. (a) Anterior maxillary excess with first premolar to be extracted, not bonded othodontically, (b) vestibular incision (5 mm superior to mucogingival junction). Osteotomy marked, which includes a horizontal cut beginning at the pyriform rim, going lateral

above the apices of the anterior teeth and vertical cuts to complete the bone removal at the site of the extraacted premolar, (c, d) Osteotomy marking with autoclaved pencil and cuts for anterior maxillary segmental osteotomy. (see Fig. 69.10a2 for clinical profile view) 


\subsection{Le Fort I Osteotomy}

\subsubsection{Operative Technique (Video 69.2)}

There are many acceptable modifications to the Le Fort I osteotomy, and the sequence of steps may vary from surgeon to surgeon. Figures $69.10 \mathrm{a}, \mathrm{b}$ and $69.11 \mathrm{a}, \mathrm{b}$ demonstrate a patient who has undergone a Lefort 1 with anterior maxillary osteotomy and mandibular subapical osteotomy for addressing her Vertical Maxillary Excess and dento-alveolar protrusion. The following is a description of the authors' preferred approach.

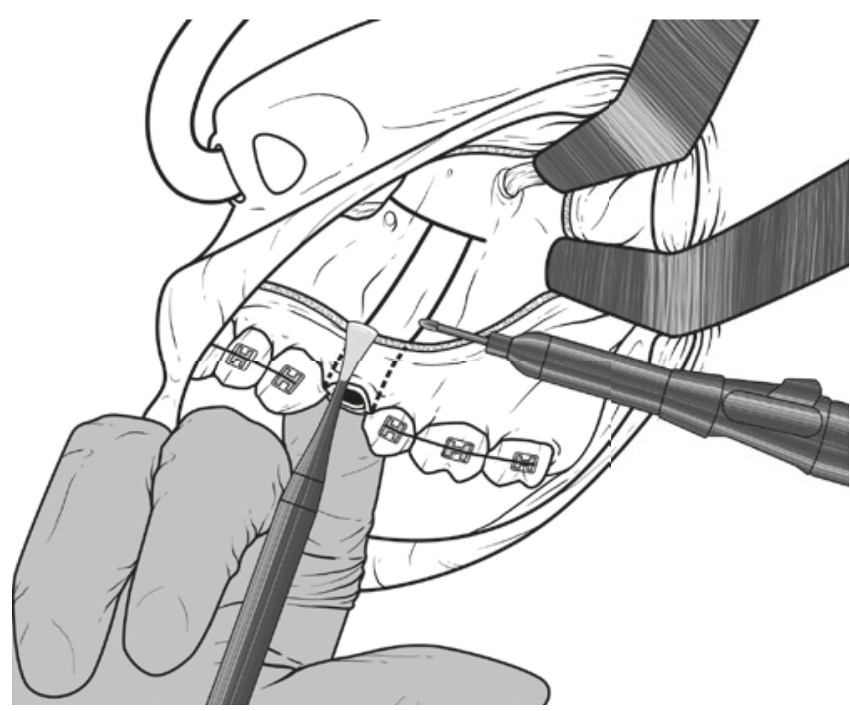

CAssociation of Oral and Maxillofacial Surgeons of India

Fig. 69.5 Horizontal and Vertical Osteotomy Cuts ( $5 \mathrm{~mm}$ superior to mucogingival junction) Osteotomy marked, Horizontal cut $5 \mathrm{~mm}$ above the canine root tip, Vertical osteotomy marked approximate mesiodistal width of premolar
Anaesthetic and Positioning Considerations:

Anaesthetic and positioning considerations must be followed as previously discussed in the anterior segmental maxillary osteotomy technique.

\subsubsection{External Reference Marker}

An external reference marker is placed at the nasion to facilitate proper positioning of the maxilla in the vertical plane (Fig. 69.12a). Common techniques include insertion of a Kirschner wire or a bone fixation screw. Less invasive methods include marking with a skin scribe, a suture or tape, but these may be less reproducible due to skin mobility at the site. Occasionally a soft tissue landmark such as the medial canthus can also be used as a guide to measure from the incisal edge of the anterior teeth (Fig. 69.12b)

External reference points have been shown to be superior to internal references (lines or burr holes placed on the maxilla above and below the osteotomy), which are prone to inaccuracy due to the complex three-dimensional movement of the maxilla [43, 44]. Preoperative measurements are then obtained from the reference site to reproducible midline and lateral maxillary landmarks, typically the maxillary dental midline and the bilateral canine cusp tips or orthodontic brackets.

\subsubsection{Surgical Exposure}

Local anesthesia with vasoconstrictor is infiltrated labially and buccally from the pterygoid plate region, forward to the midline bilaterally. A full-thickness mucosal and periosteal

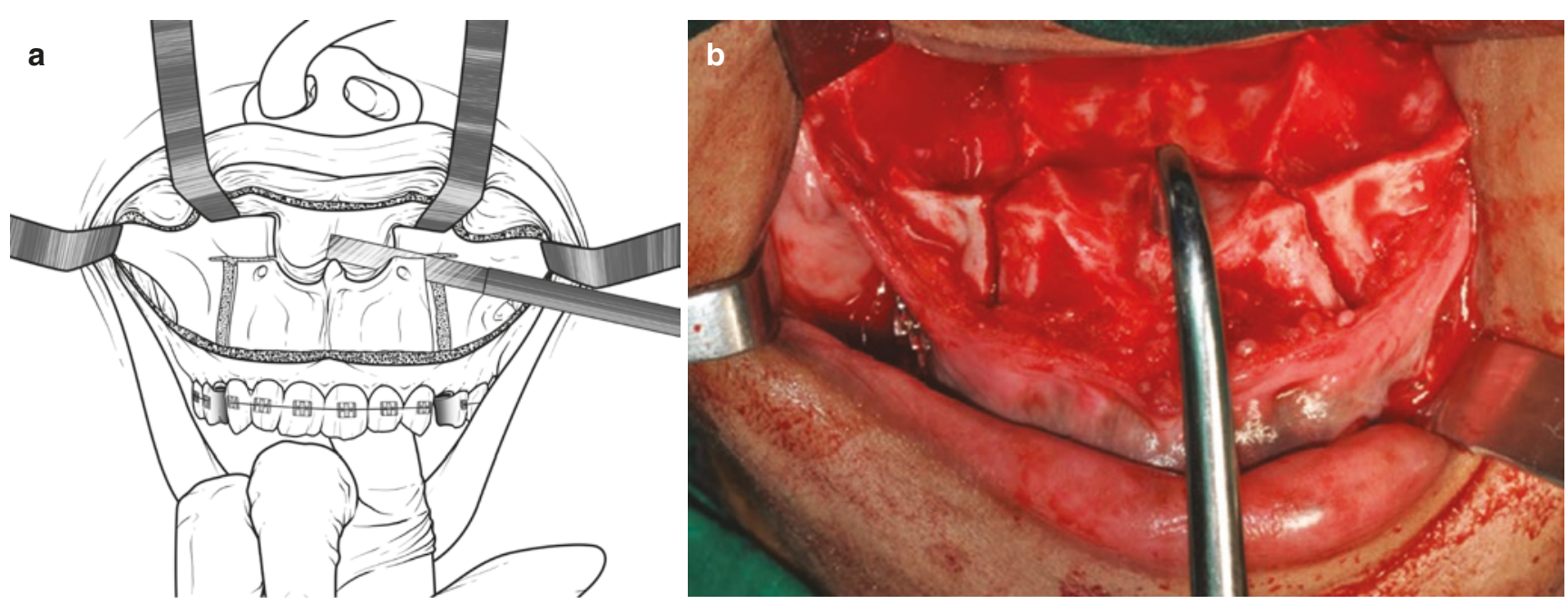

CAssociation of Oral and Maxillofacial Surgeons of India

Fig.69.6 (a, b) Final palatal bone cut with osteotome, palatal mucosa protected with non-dominant hand for tactile sensation 

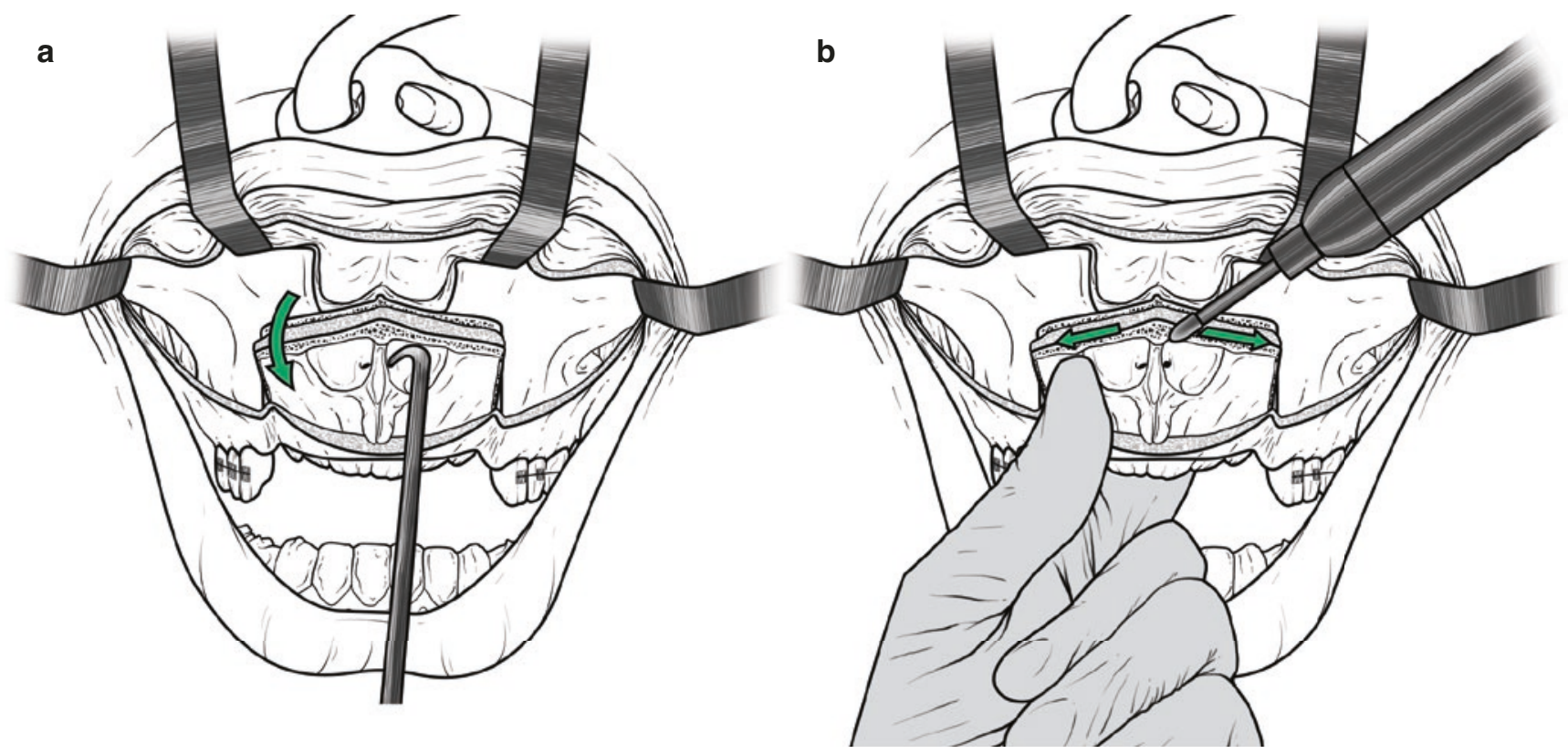

CAssociation of Oral and Maxillofacial Surgeons of India

Fig. 69.7 (a) Down-fracture anterior segment of maxilla and maintaining palatal mucosa. (b) Midline or paramidline osteotomy for horizontal movement
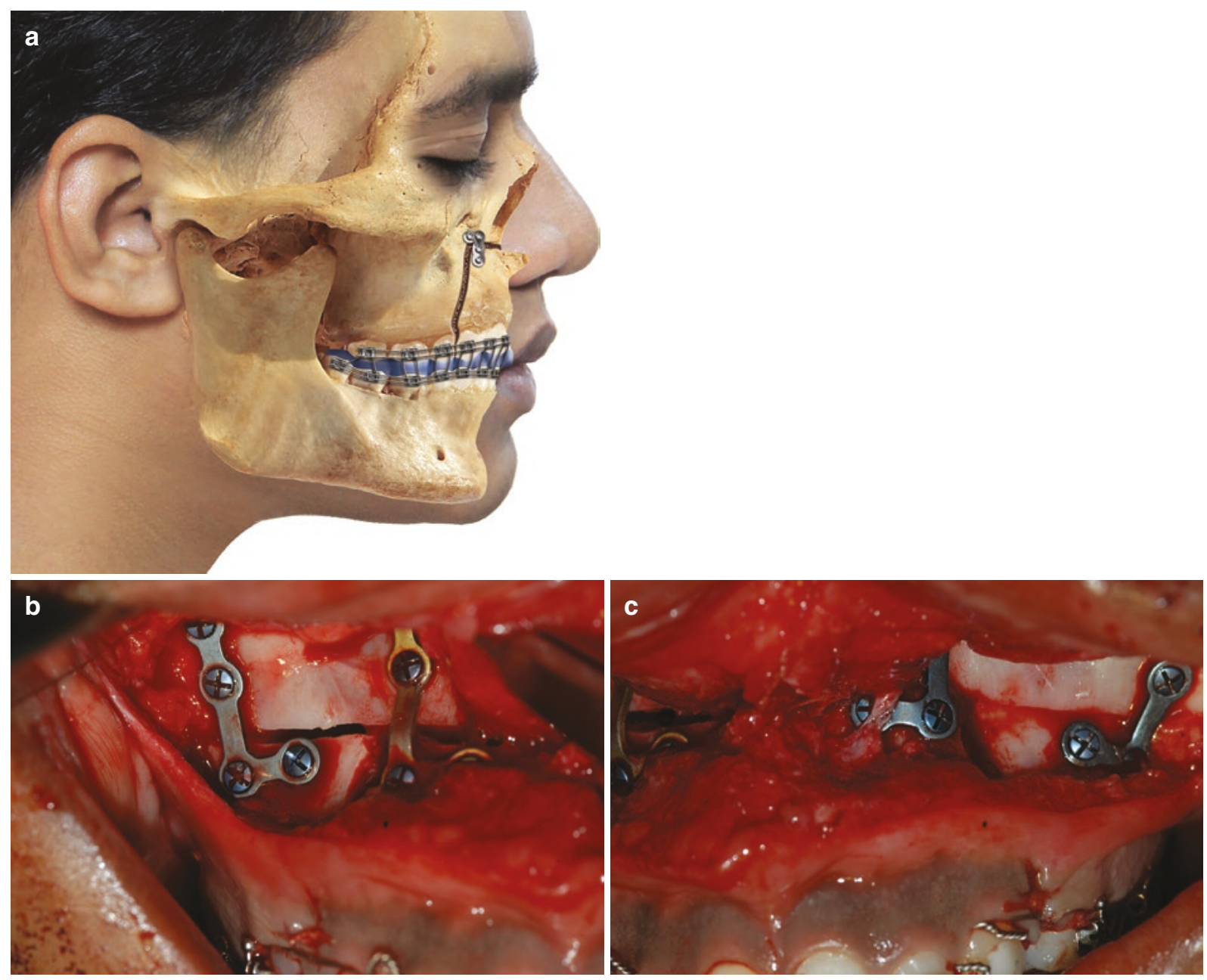

CAssociation of Oral and Maxillofacial Surgeons of India

Fig. 69.8 (a-c) Maxillary plating system used at the maxillary buttresses and pyriform region to fixate the bone segments in their planned postoperative position in case of Le Fort I with AMO, (b) right side (c) left side 

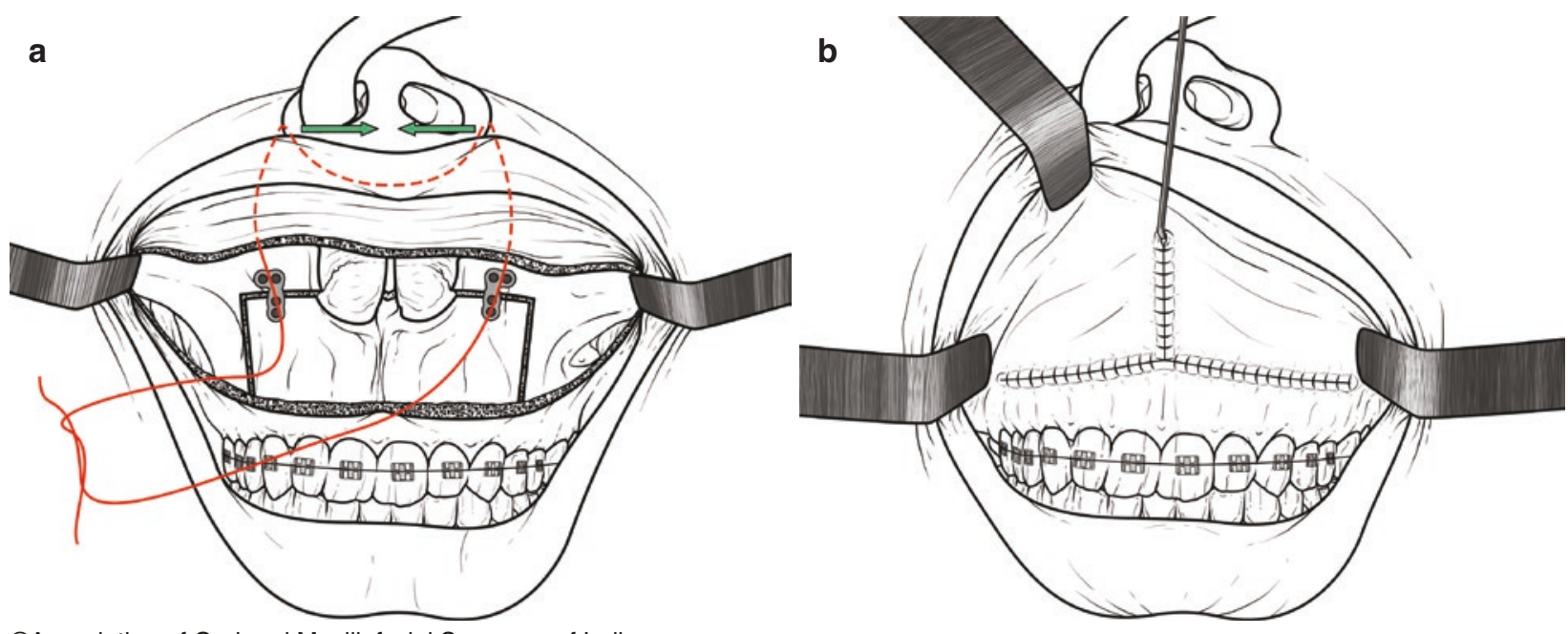

CAssociation of Oral and Maxillofacial Surgeons of India

Fig. 69.9 (a, b) (a) Alar cinch placement to control alar base, (b) V-Y closure of mucosa to maintain upper lip length
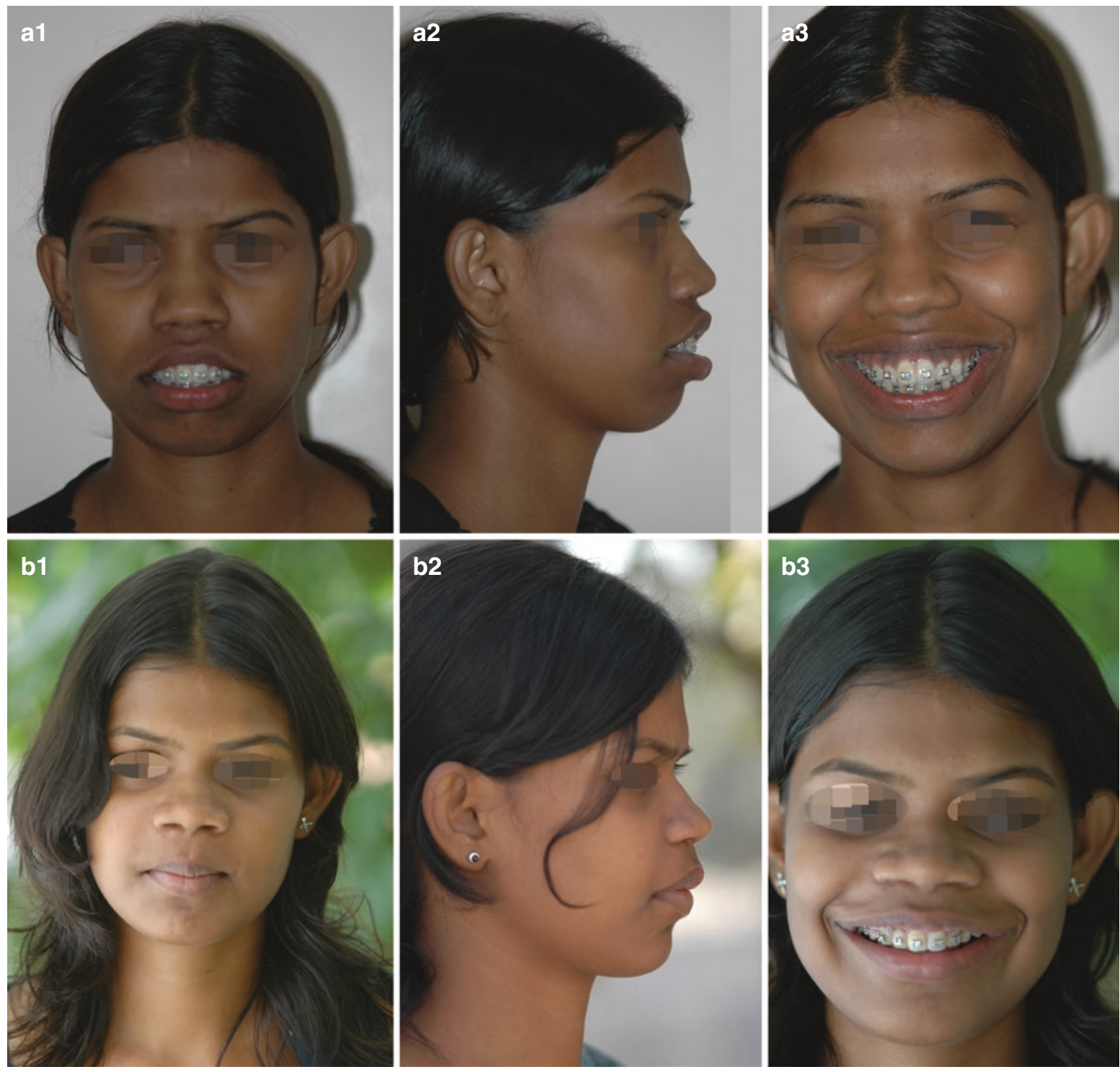

(C)Association of Oral and Maxillofacial Surgeons of India

Fig. 69.10 (a, b) (a1, a2, a3) Pre-surgical images of the patient. (b1, b2, b3) Post Le Fort I and anterior maxillary osteotomy images of the patient 

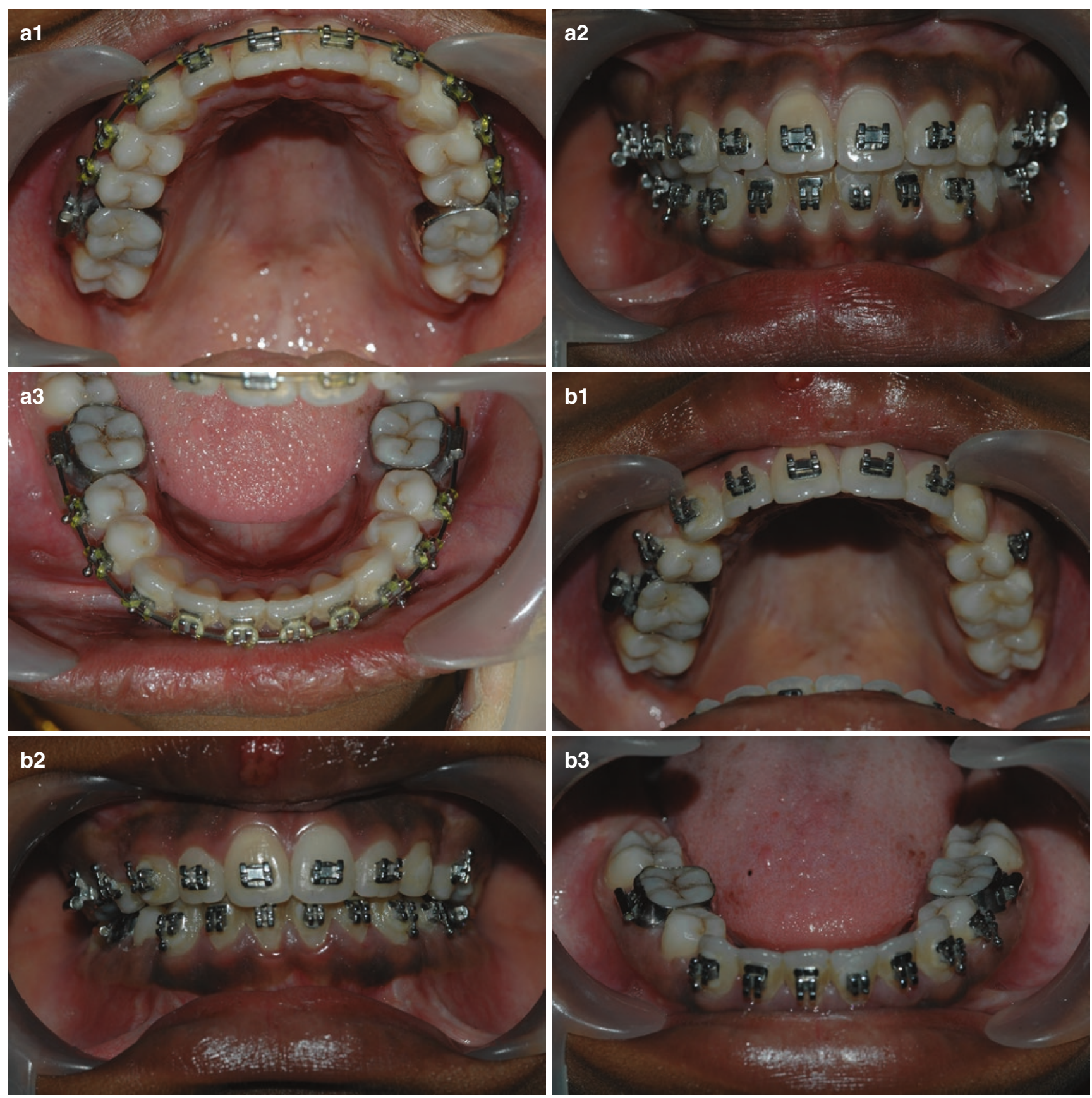

(c)Association of Oral and Maxillofacial Surgeons of India

Fig. 69.11 (a, b) Intra oral photos of the same patient as in Fig. 69.10. (a1, a2, a3) Pre-surgical images of the occlusion. (b1, b2, b3) Post anterior maxillary osteotomy images of the occlusion. A mandibular sub-apical osteotomy was also done for this patient (b2, b3)

incision is made in the soft tissue extending from the buttress of the zygoma on the either side, 3-4 $\mathrm{m}$ above the mucogingival junction with attention in the midline to a V-shaped incision to allow for aesthetic closure [45, 46] (Fig. 69.13). The incision can be made with a scalpel or electrocautery Colorado needle. While layered incisions serve no advantage for the dissection, electrocautery seems to control some hemorrhage at the time of the incision.
Retraction is maintained with down-turned Obwegeser retractors, and the superior mucoperiosteal flap is elevated with a \#9 Molt periosteal elevator. The anterior nasal spine, piriform rim, infraorbital foramen, lateral maxillary wall, and zygomaticomaxillary junction are exposed. Exposure of the posterior maxillary wall and pterygomaxillary junction is next performed with a Molt periosteal elevator, placed parallel to the maxillary teeth and advanced posteriorly below 

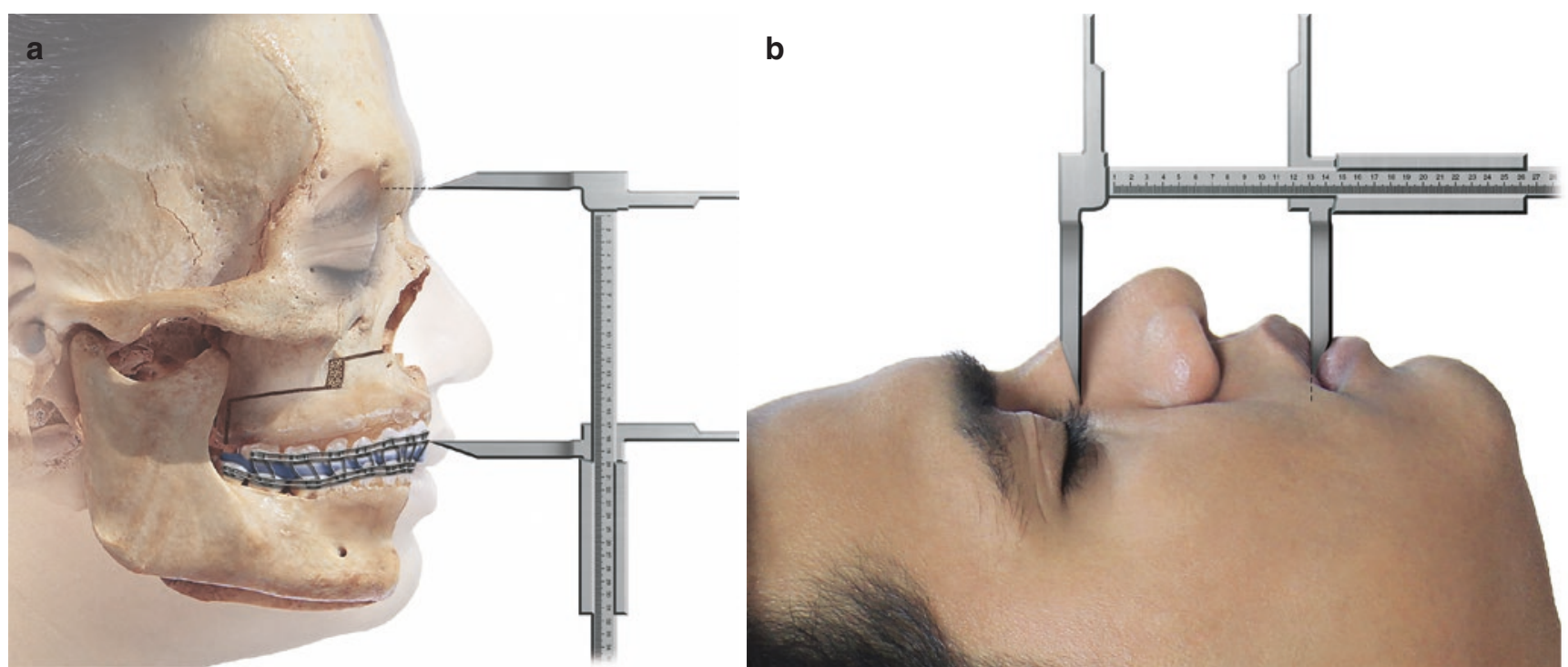

CAssociation of Oral and Maxillofacial Surgeons of India

Fig.69.12 (a, b) (a) External reference marker (skeletal landmark). A stable extraoral reference point is established with a 0.035 -inch K-wire placed in the nasion. A caliper is used to measure the vertical distance from the K-wire to the brackets of the central incisor teeth, and these

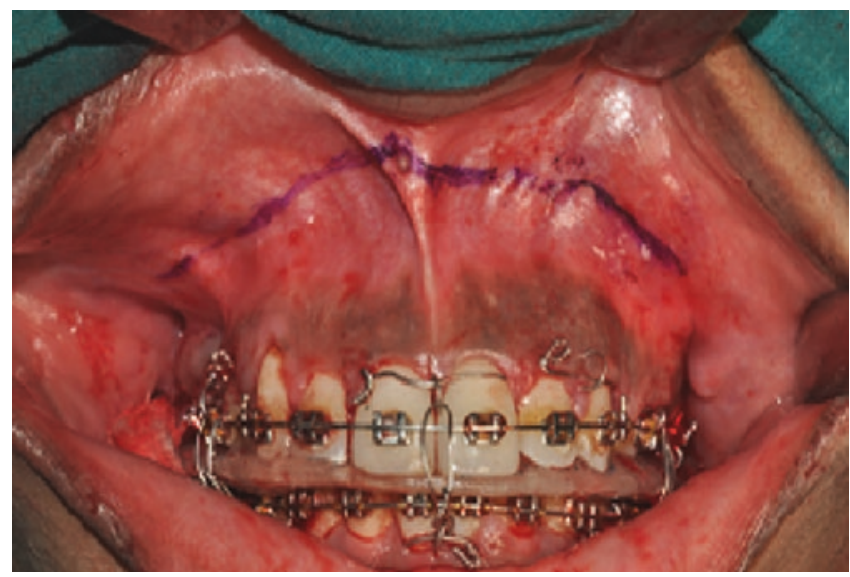

CAssociation of Oral and Maxillofacial Surgeons of India

Fig. 69.13 Maintain a small inverted "V" shape over the midline frenum, with the lateral extension of the incision being $5 \mathrm{~mm}$ above the muco-gingival junction, from first molar one side to the other

periosteum until the pterygomaxillary junction is encountered. The periosteal elevator on the bone and in a subperiosteal plane is maintained with angulation as it proceeds posteriorly to incline inferiorly or toward the hamular process of the sphenoid bone. This alleviates the potential problem of entering the pterygomaxillary fissure and concomitant increased hemorrhage [23, 47].

The nasal/septal mucosal dissection is performed after the bilateral maxillary osteotomies have been completed and involves elevation of the nasal mucosa with a curved freer elevator to the posterior palatine bone (Fig. 69.14). measurements are recorded. (b) A extraoral reference point at medial canthal (soft tissue landmark). A caliper is used to measure the vertical distance from medial canthal to the brackets of the central incisor teeth

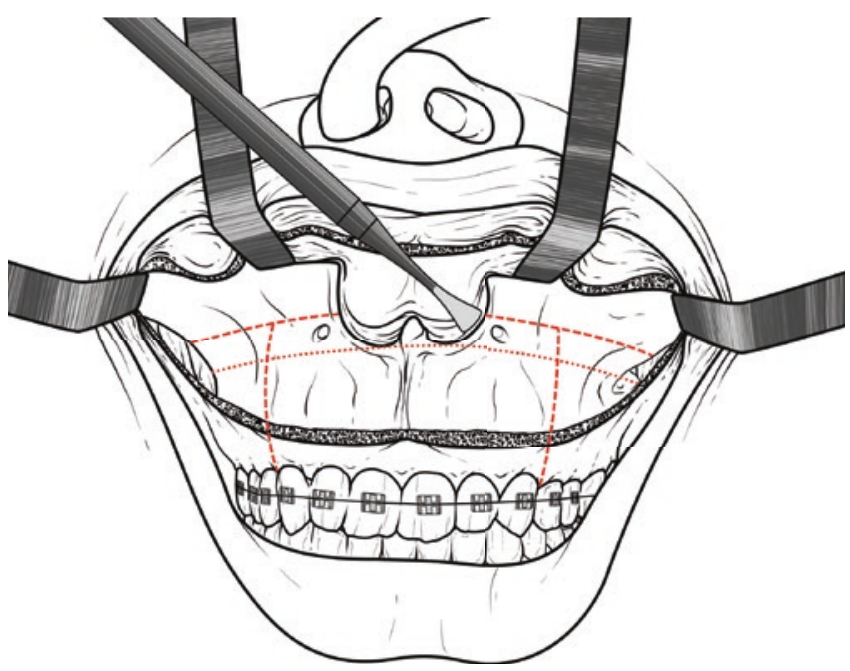

CAssociation of Oral and Maxillofacial Surgeons of India

Fig. 69.14 Exposure of the maxilla is achieved with a full horizontal vestibular incision superior to the mucogingival junction. With appropriate retraction, the infraorbital nerves, piriform rims, posterior maxilla, and anterior nasal spine will be identified

As may be preferred by some surgeons, reference marks are placed vertically in the lateral wall of the maxilla, or bone reference holes are placed a standardized distance apart (15 $\mathrm{mm}$ seems to be a reasonable distance) vertically in the buttress and in the pyriform rim region (Fig. 69.15) [48-50]. 
Alternatively, a non-threaded Kirschner wire or Steinmann pin is placed in the nasal dorsum, and a reference measurement is taken from that Kirschner wire to the anterior dentition to allow for determination of the amount of superior repositioning of the anterior maxilla [51, 52].

With the use of a Tessier caliper, the vertical distance (height) between the medial canthus and the mid-maxillary incisor crown is measured on the left and right sides and recorded; this generally measures between 55 and $70 \mathrm{~mm}$

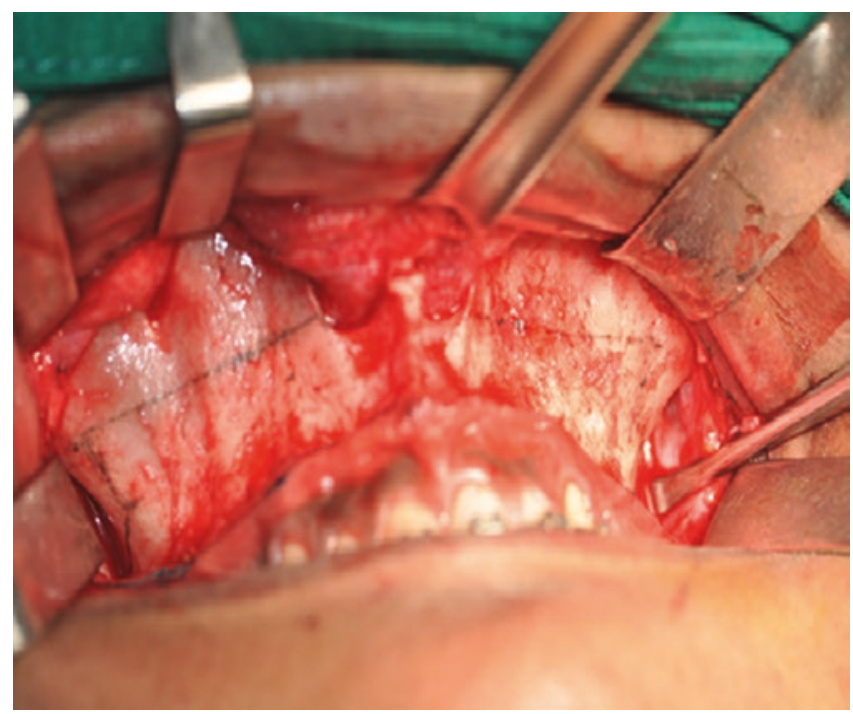

(c)Association of Oral and Maxillofacial Surgeons of India

Fig. 69.15 Marking of osteotomy cuts, horizontal cut minimum of $5 \mathrm{~mm}$ above the apices of the teeth, step or sloping downward and backward toward to maxillary pterygoid plates or Le Fort I level with stepladder cut
(Fig. 69.12). This is a reproducible relative measure of the anterior vertical maxillary height [53].

\subsubsection{Bony Osteotomies}

\subsubsection{Lateral Osteotomies}

A 701 straight fissure bur or reciprocating saw creates the lateral maxillary osteotomy from the lateral nasal rim to the zygomaticomaxillary junction. The osteotomy starts 3-4 m above the nasal floor and is carried to the depth of the maxillary sinus, back to the pterygomaxillary junction, approximately 30-35 $\mathrm{mm}$ above the bracket on the first molar tooth. Cuts are made at least $5 \mathrm{~mm}$ above the roots of the teeth and can be made higher as needed. A vertical step at the first molar is carried inferiorly for 5-10 mm (step osteotomy permits grafting in the zygomaticomaxillary buttress area subsequently, if required) [54], and then it is continued in a horizontal plane to the posterior maxilla ending in front of the pterygomaxillary junction (Fig. 69.16a, b).

\subsubsection{Pterygoid Plate Separation}

A 6- to 8-mm-wide, curved osteotome is placed in the pterygomaxillary junction, with the leading edge angled inferior, medial, and anterior. It is positioned in the junction with the horizontal osteotomy centered over the middle of the osteotome.

A finger can be placed palatally at the junction of the hamulus with the tuberosity, and the mallet is used to drive the chisel through the junction. The end of the osteotome should be palpated on the palatal side as it comes through the junction, but it should not penetrate through
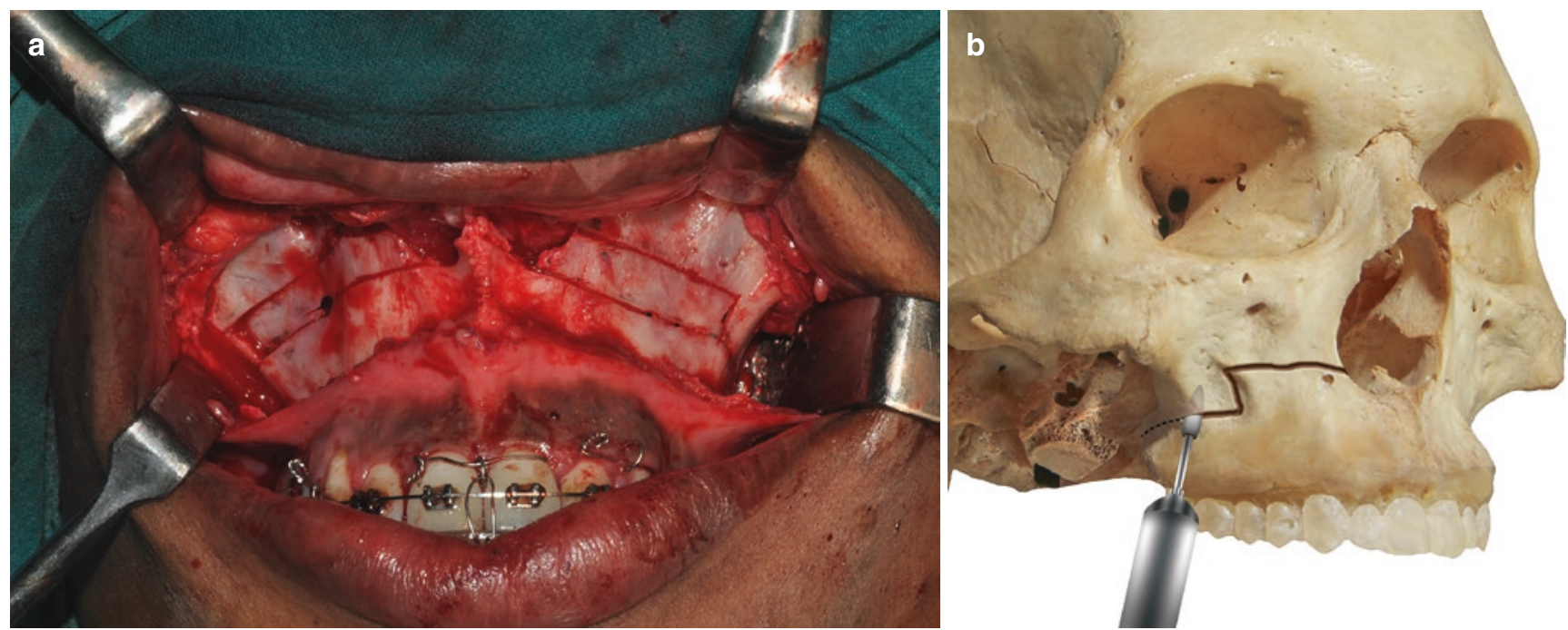

CAssociation of Oral and Maxillofacial Surgeons of India

Fig.69.16 (a, b) (a) The lateral maxillary wall osteotomy is carried posteriorly from the piriform rim to the pterygomaxillary junction, (b) with a vertical step ladder cut in the first molar region. The osteotomy is placed at least $5 \mathrm{~mm}$ superior to the root apices 


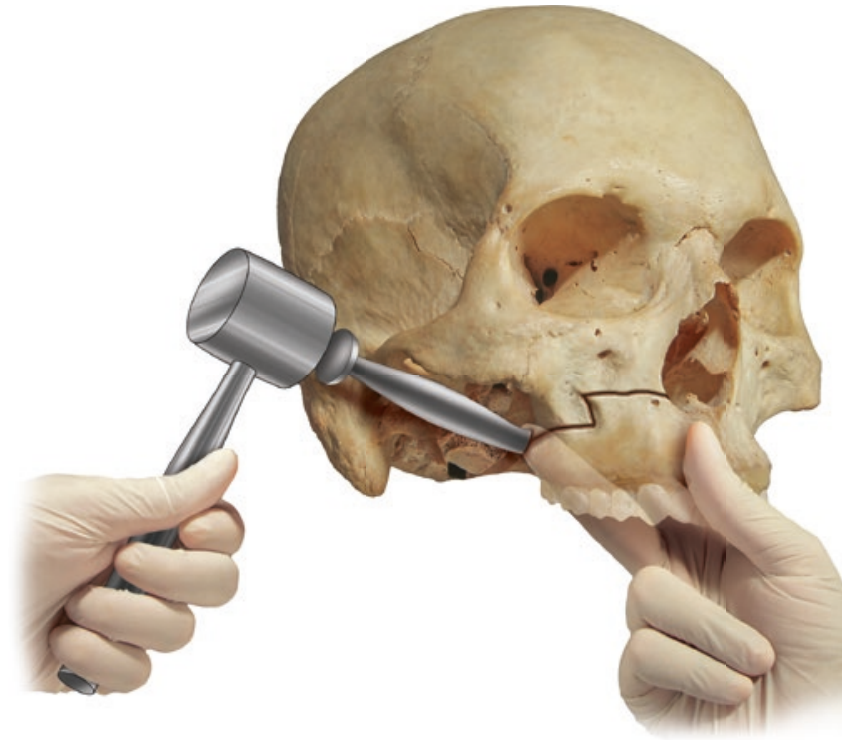

CAssociation of Oral and Maxillofacial Surgeons of India

Fig. 69.17 A curved osteotome is placed in the pterygomaxillary junction, with the superior edge of the osteotome just above the horizontal osteotomy. A finger is placed on the palatal side of the junction, and the osteotome is gently tapped through the junction until palpated on the palatal side, without perforating the soft tissue

the palatal tissue. There should be minimal resistance to separation, and if significant resistance is encountered, the osteotome position should be evaluated and repositioned (Fig. 69.17).

The scientific literature cites examples of damage to the cranial nerves during the Le Fort I osteotomy [55-58].

\subsubsection{Lateral Nasal Wall and Septal Osteotomies}

A small safe-sided osteotome initiates the lateral nasal osteotomy at the piriform rim in the anterior extension of the lateral maxillary osteotomy. A mallet drives the osteotome posterior, parallel to the nasal floor, below the inferior turbinate. One must take care not to go beyond 25 and $30 \mathrm{~mm}$ in depth during osteotomy. The lateral nasal wall diverges (widens) posteriorly, and the osteotome must follow that divergence. Minimal resistance will be encountered until the pyramidal process of the palatine bone is encountered. At this resistance point, the osteotome can be driven another few millimeters to influence the fracture plane through this structure during down-fracture (Fig. 69.18). The nasal septum osteotomy is next performed with a guarded U-shaped osteotome. The osteotome is introduced at the top of the nasal spine and is driven inferiorly and posteriorly along the nasal floor to separate the maxilla and palatine bone from the septum (Fig. 69.19).

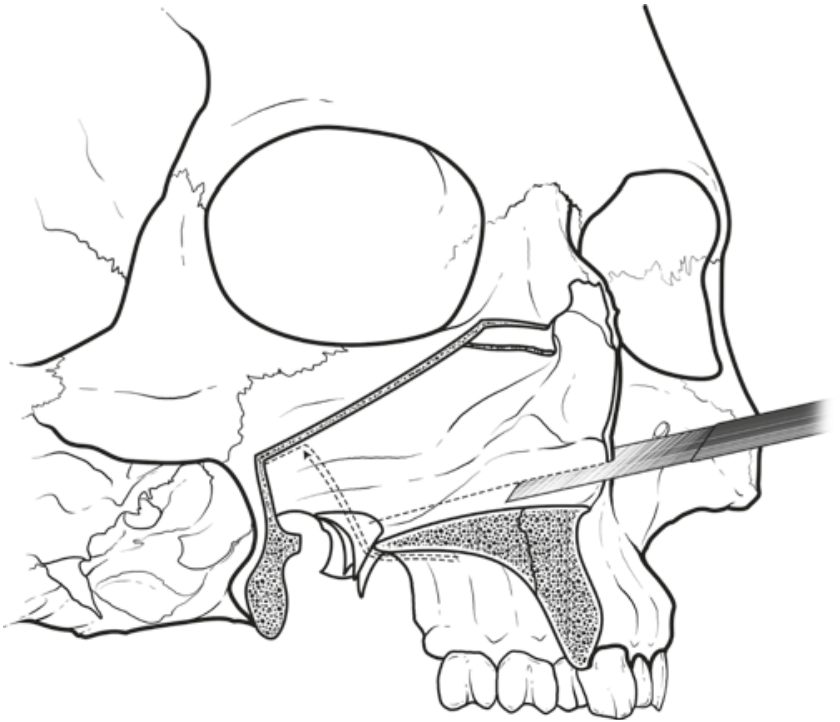

CAssociation of Oral and Maxillofacial Surgeons of India

Fig. 69.18 The lateral nasal wall osteotomy is completed from the inferior piriform rim to the anterior portion of the pyramidal process of the palatine bone. Care is taken to avoid a complete osteotomy through the pyramidal process in order to prevent injury to the greater palatine artery and nerve. The right maxilla has been removed to show the desired cross-section clearly

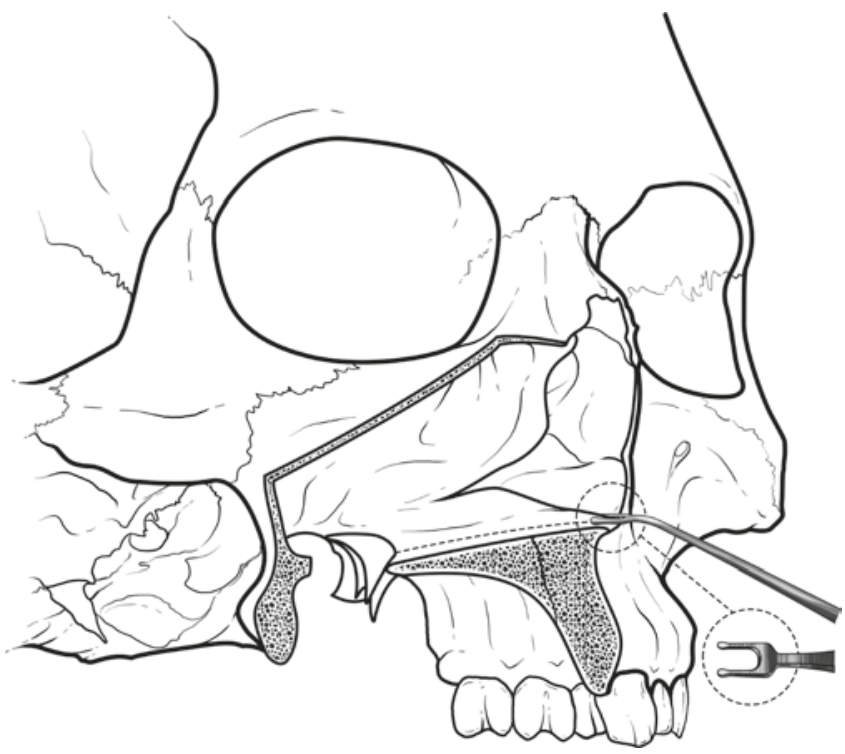

CAssociation of Oral and Maxillofacial Surgeons of India

Fig. 69.19 The septal osteotomy is completed from the anterior nasal spine through the vomer bone posteriorly, with the guarded prongs on the septal osteotome angled inferiorly. Care is taken to retract the nasal mucosa to minimize injury and bleeding to the soft tissue. The right maxilla has been removed to show the desired cross-section clearly

\subsubsection{Down-Fracture and Mobilization}

Once the osteotomy cuts have been completed, some mobility should be readily evident, and down-fracturing be easily 


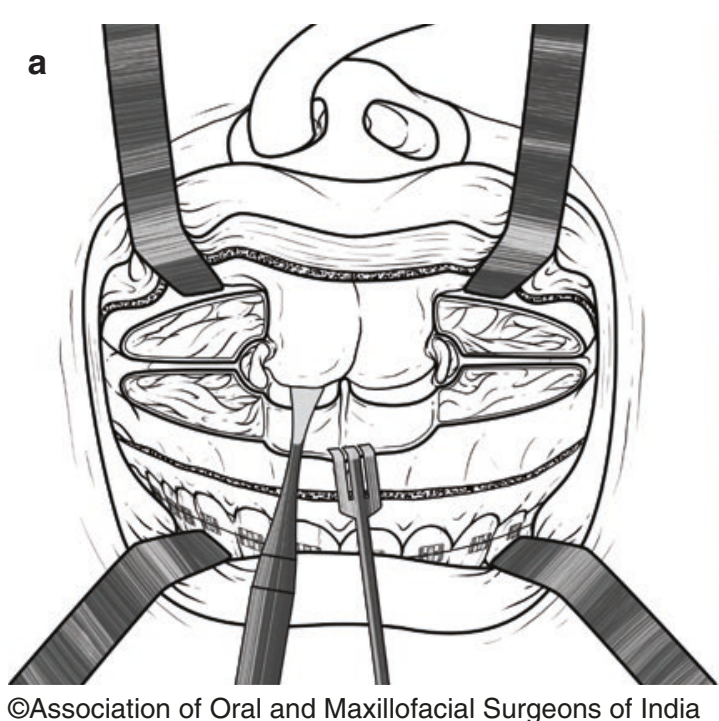

Fig.69.20 (a, b) (a) Once the maxilla is mobilized, the nasal mucosa can be completely freed from the maxilla in the piriform rim region, (b)

The greater palatine nerve and artery can be visualized and protected

done with either bilateral manual digital pressure in the canine fossa or with instrumentation support at the piriform rim. Slowly separate the maxilla by pulling the anterior portion inferiorly while observing the nasal mucosa to avoid tears. If significant resistance is encountered, revise the osteotomy cuts thoroughly to ensure complete separation. To avoid complications related to pterygomaxillary disjunction, we prefer to extract maxillary third molar and make a vertical osteotomy cut through the socket connecting the horizontal cut on the posterolateral surface of maxilla.

Precious et al. (1991) did a study of 138 consecutive Le Fort I osteotomies with successful down-fracture of the maxilla by digital pressure alone (with no serious complications except transient epistaxis that responded to local packing) $[59,60]$.

Once the down-fracture is completed, place a Seldin elevator or tongue depressor behind the tuberosity, and pull the posterior maxilla forward. This will fully mobilize the maxilla from its attachments. For large advancements, freeing the tissue from the nasal side of the posterior maxilla in the soft palate area will provide significantly more forward mobility. In addition, in repeat maxillary surgery, mobilizing the maxilla will most likely be more difficult, and time must be spent freeing hard and soft tissue attachments to ensure passive movements and surgical stability.

\subsubsection{Removal of Posterior Interferences}

Removal of posterior interferences should be done immediately after down-fracture which will make it easier to set the maxillary position later. The maxillary bony septum is reduced most easily with a bur. The lateral nasal wall can be during posterior bone removal from the lateral nasal wall area (yellow arrows) (also see Fig. 65.12a)

reduced with a rongeur, bur, or reciprocating saw. While protecting the descending palatine nerve and artery with a curved freer (Fig. 69.20a, b), the pyramidal process of palatine bone is most safely reduced with the reciprocating saw or bone file. Sometimes a thin spatula osteotome can be used. Finally, the posterior tuberosity, anterior pterygoid plate, and posterior lateral maxillary wall can be reduced with a bur or reciprocating saw (Fig. 69.21). If the superior movement of the maxillary is more that 6 or $7 \mathrm{~mm}$, a partial inferior turbinectomy may be indicated to allow a passive impaction. The nasal mucosa is incised with a scalpel blade along its inferior surface in an anterior-posterior direction. The inferior half of the turbinate is grasped with a large curved hemostat, and a dean scissor is used to excise this portion. Complete removal of the inferior turbinate is rarely necessary and can result in unpleasant clinical side effects. Electrocautery is used to coagulate the incised edge of the turbinate to minimize bleeding. The nasal mucosa is then sutured with a running 4-0 vicryl suture.

\subsubsection{Placement of Surgical Guide}

A prepared surgical guide is necessary to ensure accurate positioning of the maxilla. The guide is generally ligated to the upper teeth with 26-28 gauge wire. The upper and lower teeth are then wired together with 26-28 gauge wire, elastics, or power chain (Fig. 69.22).

\subsubsection{Removal of Anterior Interferences}

With the maxilla now fixed to the mandible, it is rotated into position by applying posterior and superior pressure on the 


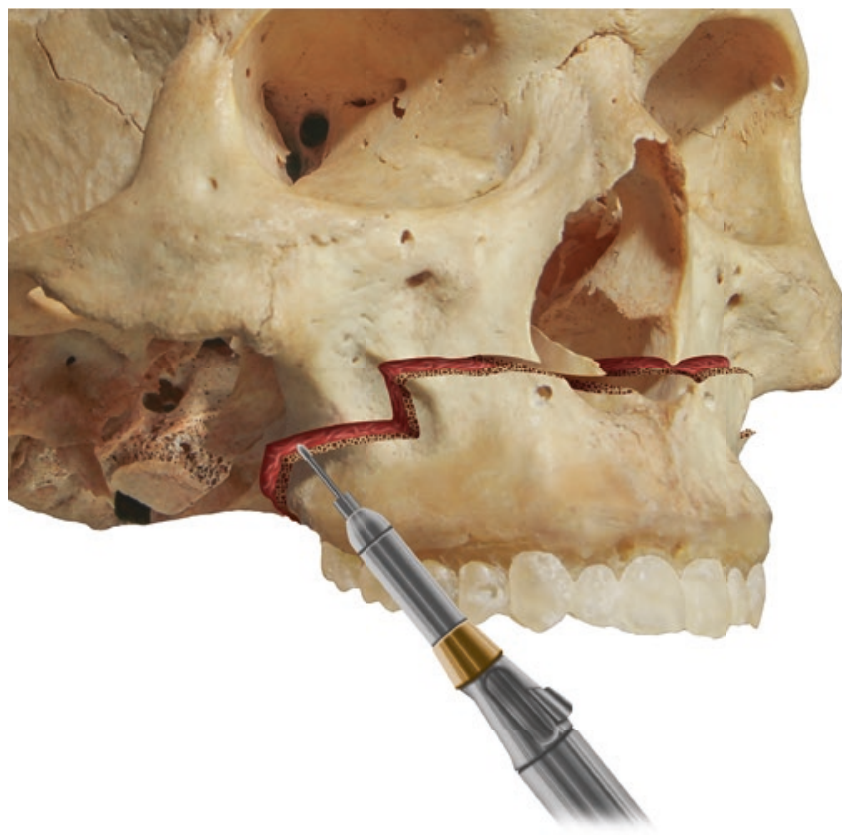

CAssociation of Oral and Maxillofacial Surgeons of India

Fig. 69.21 Posterior interferences are initially removed from the posterior septum, lateral nasal walls, pyramidal processes of the palatine bones, and lateral maxillary walls. This allows for passive seating of the maxilla without posterior pivoting

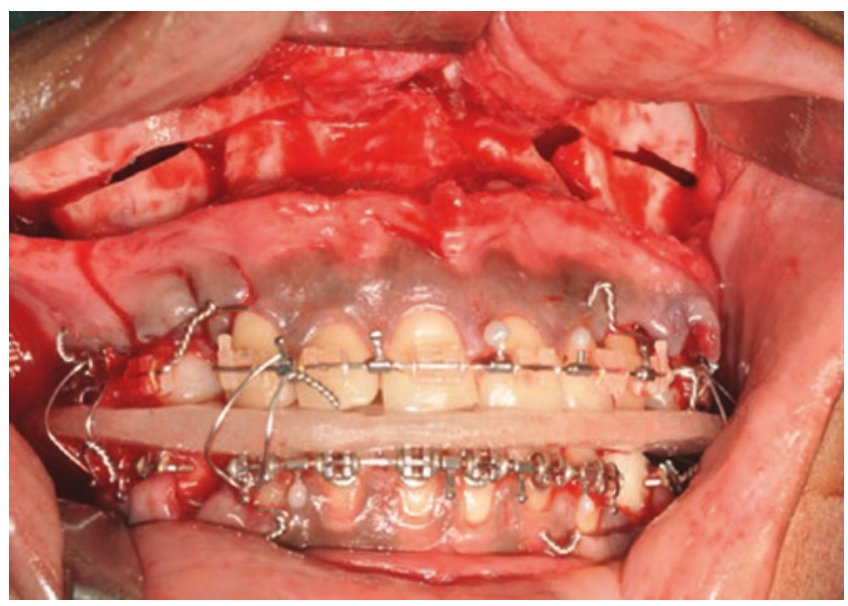

CAssociation of Oral and Maxillofacial Surgeons of India

Fig. 69.22 Placement of surgical guide and achieve desire stable occlusion. The lefort I osteotomy and AMO cuts are visible

mandible. To properly rotate the mandible, the surgeon places two fingers at the gonial notch regions of the mandible and the thumb of the same hand at the chin. Upward pressure is exerted with the two fingers at the gonial notches, and the thumb exerts a posterior and downward pressure. This "triangular" finger formation ensures full seating of the condyles during mandible rotation and maxillary positioning. The surgeon then rotates the mandible and maxilla upward, keeping pressure on the two fingers and thumb (Fig. 69.38a-c). Upward rotation is

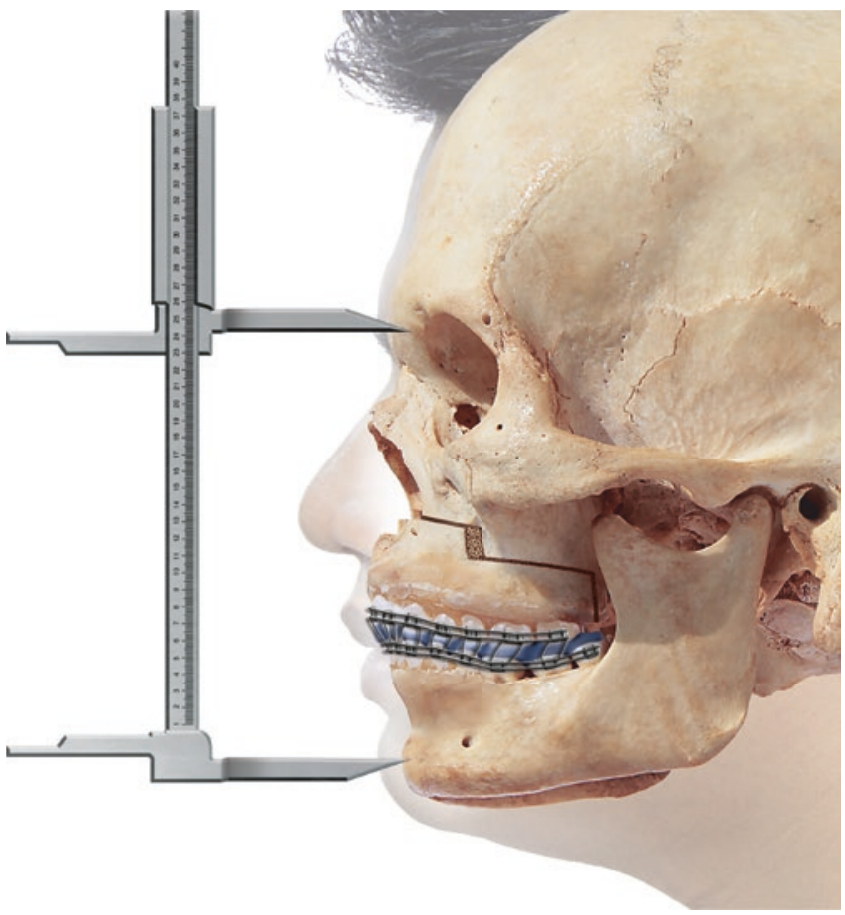

CAssociation of Oral and Maxillofacial Surgeons of India

Fig. 69.23 The maxilla is rotated into place and anterior interferences are removed to ensure full seating of the condyles at the desired vertical position. Seating of the condyles of the mandible is achieved with superior pressure at the gonial notches and posterior pressure at the chin. Once the correct vertical maxillary positioning is achieved, the mandibular-maxillary complex can be reproducibly rotated with the condyles in the fossa without any bone or soft tissue pre maturities (Also see Fig. 69.12a, b)

stopped as soon as the first contact is detected, and this interference is reduced accordingly. Anterior interferences can be easily reduced with a bur. The caliper is used to check the vertical distance from the anterior brackets to the K-wire and interferences are reduced accordingly. Closely observe the nasal septum for early inferences and deviation. When all the bony interferences have been completely removed, utilizing the "triangular" finger formation, the mandible and maxilla can be easily rotated up into a stable reproducible position, with the condyles fully seated (Fig. 69.23).

\subsubsection{Fixation, Grafts, and Final Measurements}

With the maxilla positioned, four miniplates are accurately bent to passively fit across the osteotomy in the piriform and anterior buttress areas of the maxilla. Typically, there are two fixation holes above and below the osteotomy in each bone plate, for placement of four screws. Thin bone or large bone gaps may require more fixation screws in each plate or even require additional plates. Bone grafts can be adapted into the 


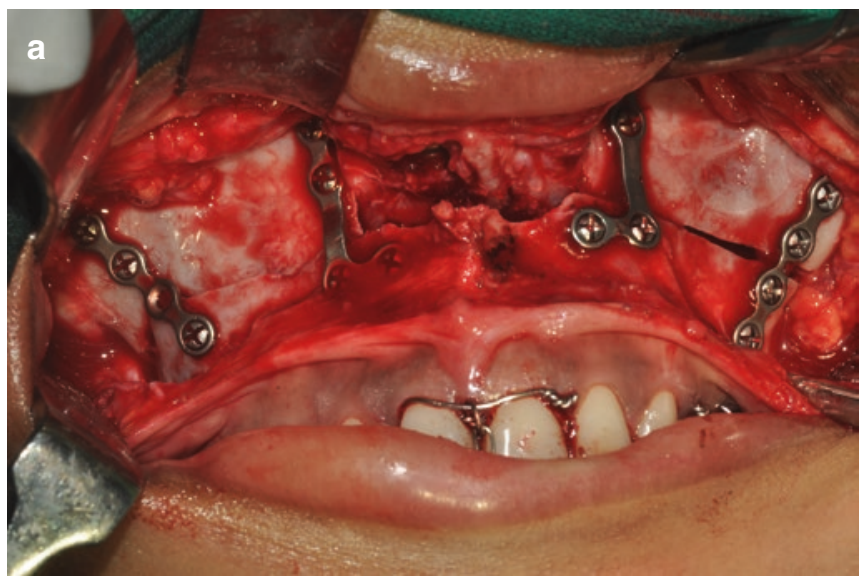

CAssociation of Oral and Maxillofacial Surgeons of India

Fig. 69.24 (a, b) (a) Rigid fixation with four plates provides vertical and horizontal stability to the maxilla. The nasal septum should be free of deviation, and the occlusion should be reproducible once interdental fixation is released. Bone plates are used to stabilize the osteotomy bilaterally at the nasomaxillary and zygomaticomaxillary buttress

osteotomy gaps, and press-fit into position, or rigidly fixed if necessary [61]. Once the fixation has been competed, final measurements with calipers are made to confirm proper vertical placement (Fig. 69.24a, b).

\subsubsection{Checks to Be Made Before Plate Fixation of the Maxilla}

1. Ensure there are no bony interferences.

2. Check that the teeth are occluding into the splint correctly (particularly posteriorly, ensure the tongue is out of the way) and the condyles are seated correctly.

3. Check there are no soft tissue/septal interferences.

4. Check the nasal septum is in center (suture or cut groove into anterior nasal spine). Ensure that tears in the nasal mucosa if any are sutured.

5. Check any septal adjustment and piriform aperture bony adjustments have been made.

6. Make sure the maxillary dental midline and transverse maxillary occlusal plane cant are correct.

7. Ensure facial appearance, incisor exposure and aesthetics are optimal.

8. Check occlusion.

Once the maxillary fixation is completed, the intermaxillary fixation is released. The mandible is hinged with the condyles fully seated using the "triangular" finger formation. Retractors should be used to hold the cheeks away from the posterior teeth, and the mandible is rotated upward such that the teeth fit into the maxillary splint. The tongue

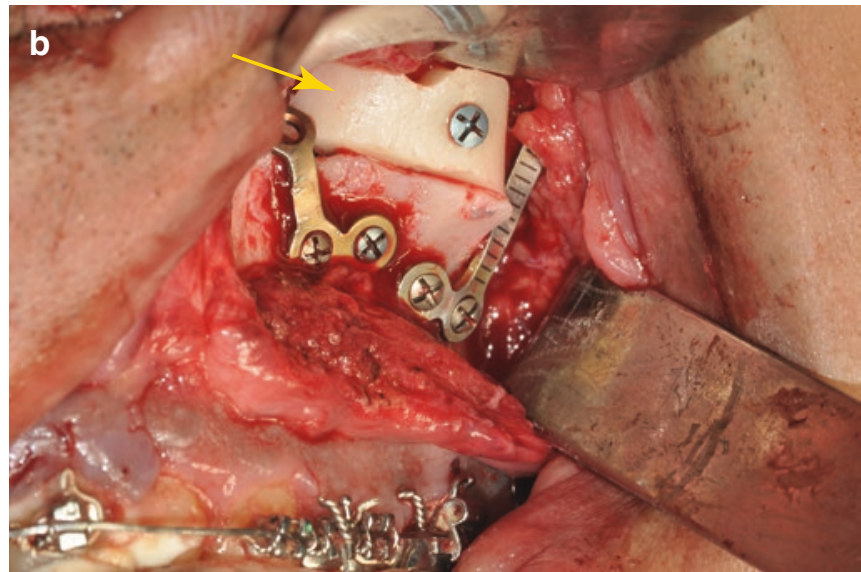

areas. (b) Autogenous bone grafts have been adapted and fixated in the osseous gaps to optimize bone healing and minimize postsurgical relapse. Grafting may be indicated in complex movements, especially large advancements and down grafting cases (yellow arrow)

is also manipulated out of the way if it is interfering with closure. There should be a smooth closure into the splint without any shifting or deviation of the occlusion. Contact should occur simultaneously in the anterior and posterior areas.

\subsubsection{Closure}

Proper closure occurs in three steps.

\subsubsection{Nasal Cinch Suture (Alar-Base Suture) [62]}

With the dissection and exposure of the paranasal musculature during Le Fort I osteotomy, the nasal cinch suture provides appropriate repositioning of the soft tissue to minimize postoperative nasal base widening. A slowly resorbing suture (e.g., 2-0 polyglycolic acid) is placed from an intraoral approach into the alar base bilaterally, pulling the alar bases toward each other when tightened (Fig. 69.25a, b). If properly done, tightening should result in an equal or shorter alar base width when compared to the preoperative width. This will frequently result in an immediate upturned appearance of the nose, a protruded positioning of the upper lip, and edema. These immediate changes are transient and will disappear within a few weeks. Following healing, the procedure results in minimal widening of alar base from the preoperative measurement (Fig. 69.26a, b).

\subsubsection{V-Y Closure [63]}

Typical movements of the maxilla and normal healing of the circumvestibular incision can result in lip shortening, 

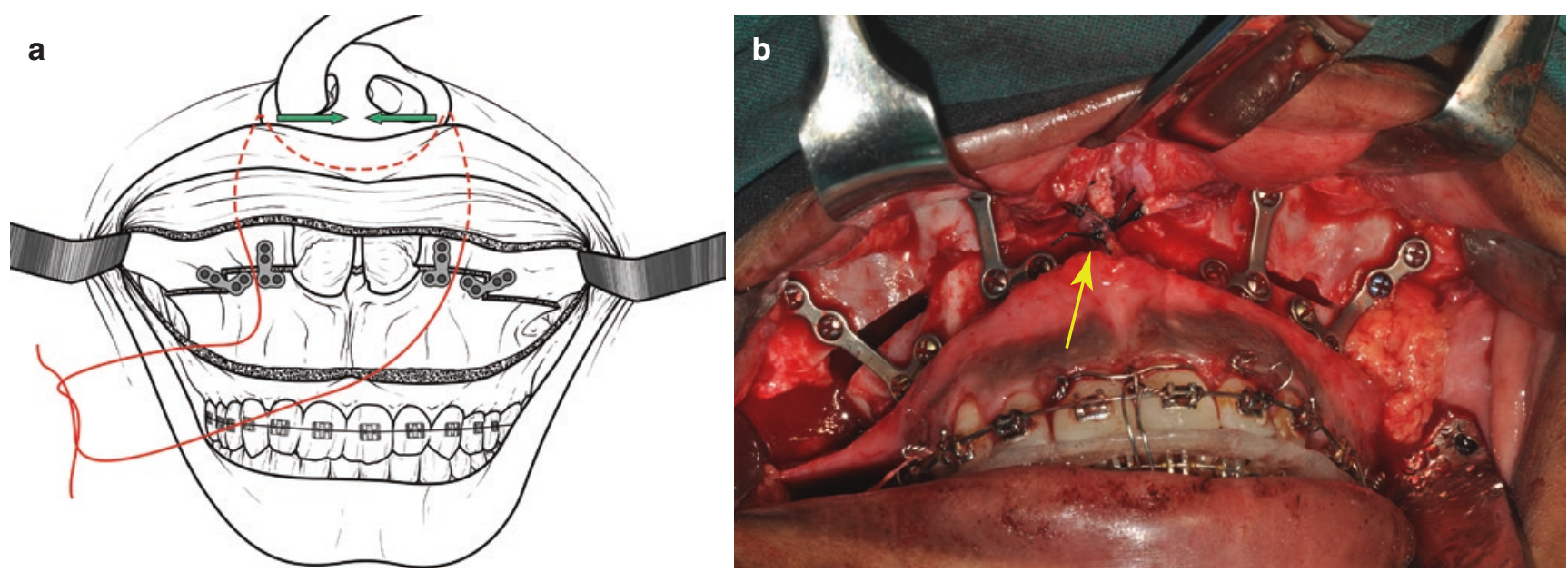

CAssociation of Oral and Maxillofacial Surgeons of India

Fig.69.25 (a, b) An alar base cinch suture controls the alar base width and counteracts postsurgical widening of the alar base. Care is taken to correctly place the suture in the fibro adipose tissue and transverse nasa- lis muscle at the lateral nasal base, allowing medial positioning of the alar base during suture tying (yellow arrow)
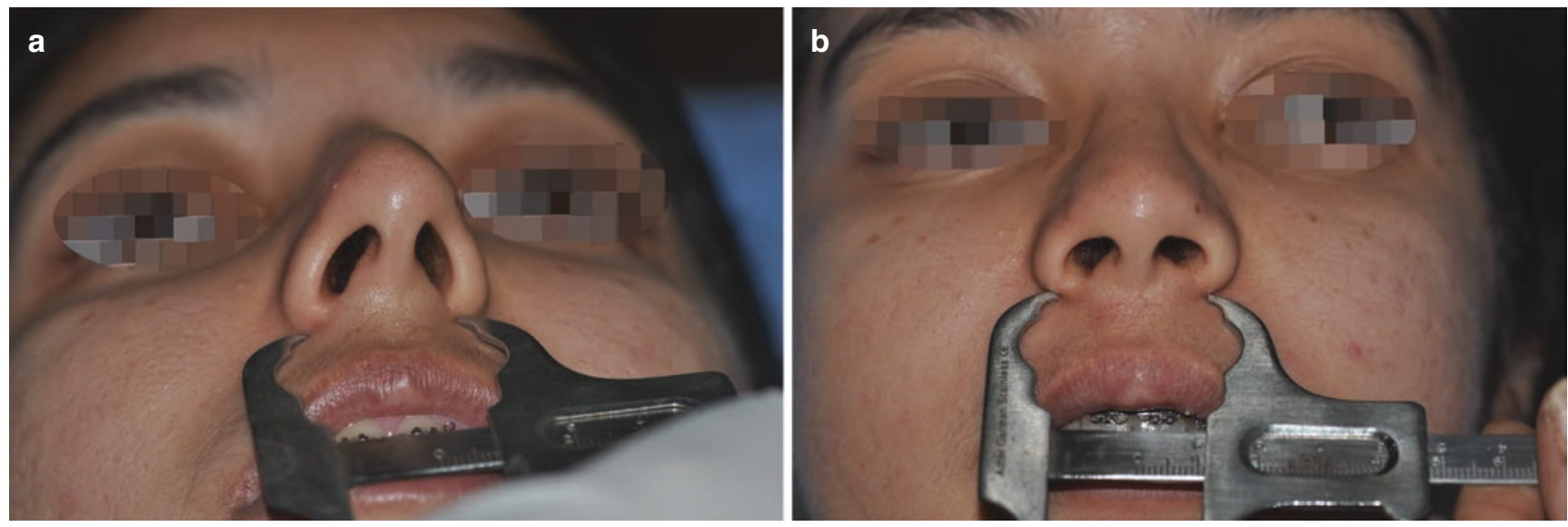

CAssociation of Oral and Maxillofacial Surgeons of India

Fig. 69.26 (a, b) Measuring the alar base pre-surgically (a) and post-surgically (after edema subsides and soft-tissue settles) (b) and confirming that the size remains same

lip thinning, and decreased vermillion show. The Le fort I incision transects various components of the midface musculature, including the transverse part of the nasalis muscle, the myrtiformis muscle), and the levator anguli oris muscle.

It is important to correctly suture the deep muscular layers in proper anatomic orientation, so that the facial contour may be maintained [64].

The V-Y closure is performed to combat these undesirable changes. With the use of a skin hook, the tissue of the midline vestibular incision is grasped and pulled superiorly. Using a resorbable suture (e.g., 4-0 vicryl), the incision is closed vertically by grasping the tissue $1 \mathrm{~cm}$ away from the midline on either side of the skin hook and advancing these edges together by tightening the suture. This provides for a $1 \mathrm{~cm} \mathrm{V-Y} \mathrm{closure.} \mathrm{The} \mathrm{remaining} \mathrm{closure} \mathrm{is} \mathrm{completed} \mathrm{with}$ either a continuous suture or interrupted sutures. The closure generally requires four or five throws of the suture (Fig. 69.27, Fig. 69.9b).

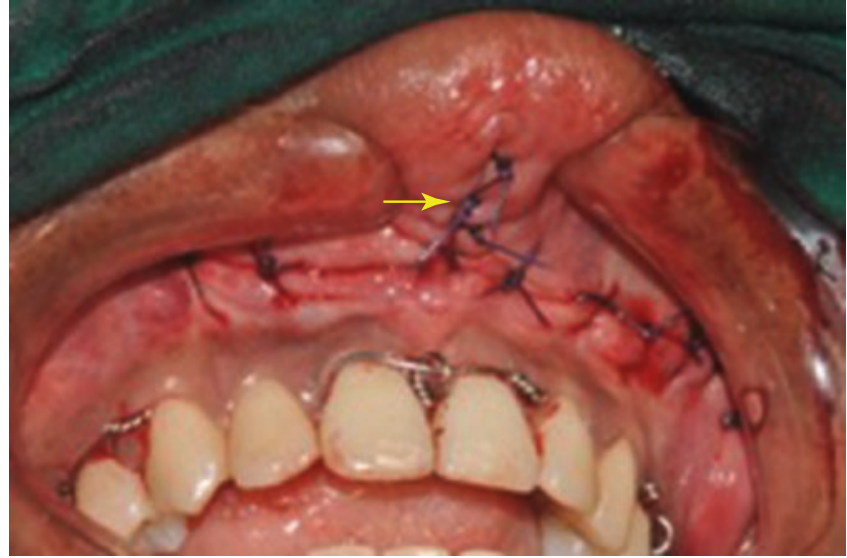

CAssociation of Oral and Maxillofacial Surgeons of India

Fig. 69.27 Vestibular soft tissue closure is performed with a running resorbable suture. A midline V-Y closure provides support to the upper lip and rolls the vermillion upward and outward, gives fullness to the lip, and makes a prominent white-roll. Closure is started posteriorly and moved anterior to bring the labial side mucosa forward, which is then, closed in the midline in the form of an inverted "Y" (yellow arrow) 

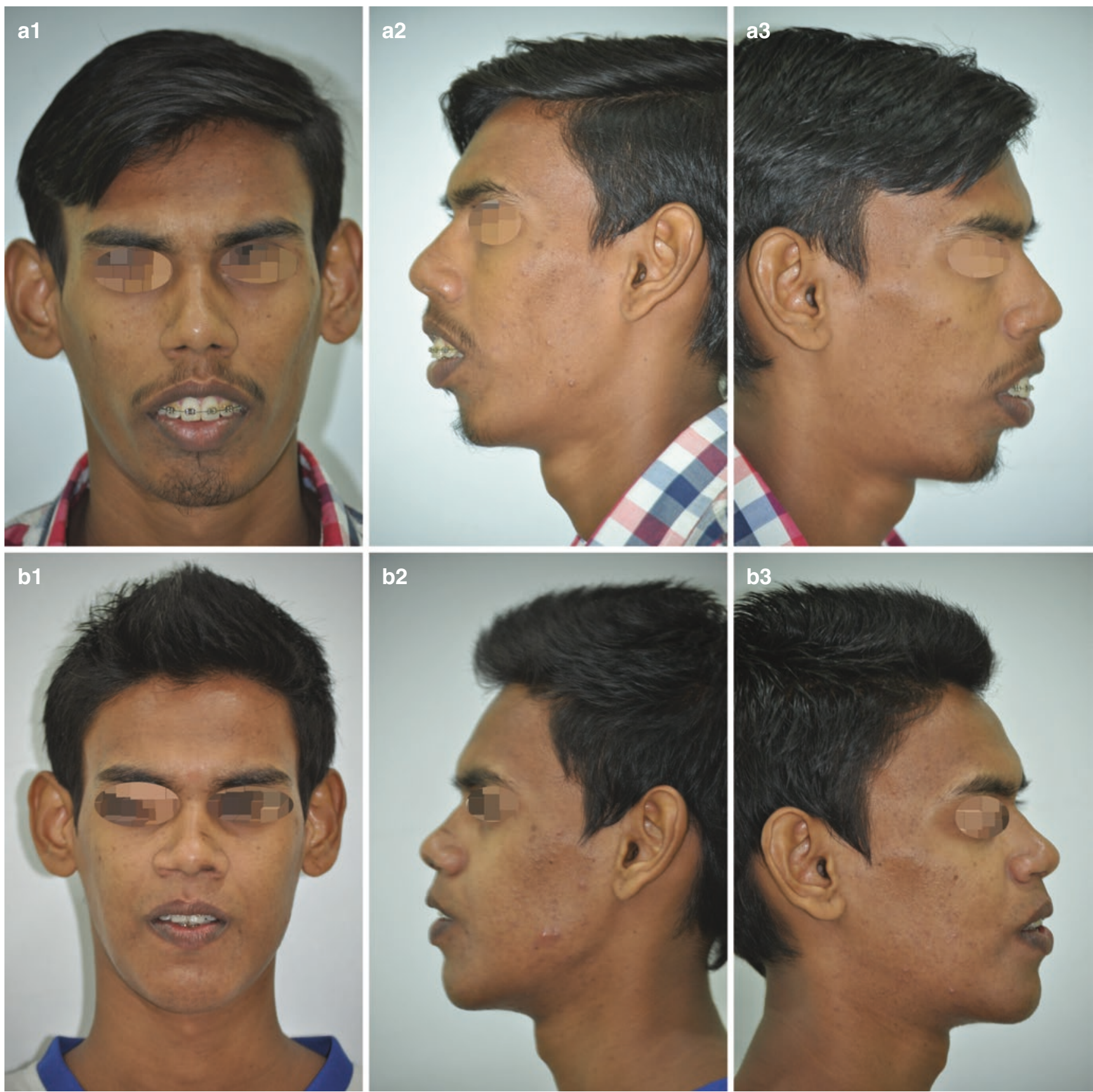

CAssociation of Oral and Maxillofacial Surgeons of India

Fig.69.28 (a, b) A case of vertical maxillary excess treated with superior positioning of the maxilla showing frontal, right lateral and left lateral views. (a1, a2, a3) Pre-surgical photos of the patient; (b1, b2,

\subsubsection{Vestibular Closure}

The remaining vestibular closure continues from the posterior portion of the incision. A running resorbable suture (e.g., 4-0 vicryl) is passed in a simple running fashion. Figures 69.10, 69.11, 69.28a, b, 69.29a, b, 69.30a, b and 69.32a, b depict the results achieved by the technique described above for different clinical indications. Figure 69.31 demonstrates steps involved in peforming a Lefort I osteotomy in a bimaxillary setting. b3) post-surgical photos of patient (Also see Figs. 69.29 and 69.39 for the full case series images)

\subsection{Quadrilateral (Quadrangular) Osteotomy}

This high-level osteotomy is a variant of the Le fort I osteotomy and extends up to the lower part of the zygoma, to a point just below the infraorbital nerve bilaterally.

The indications for this osteotomy are midface retrusion, including excessive scleral exposure. 

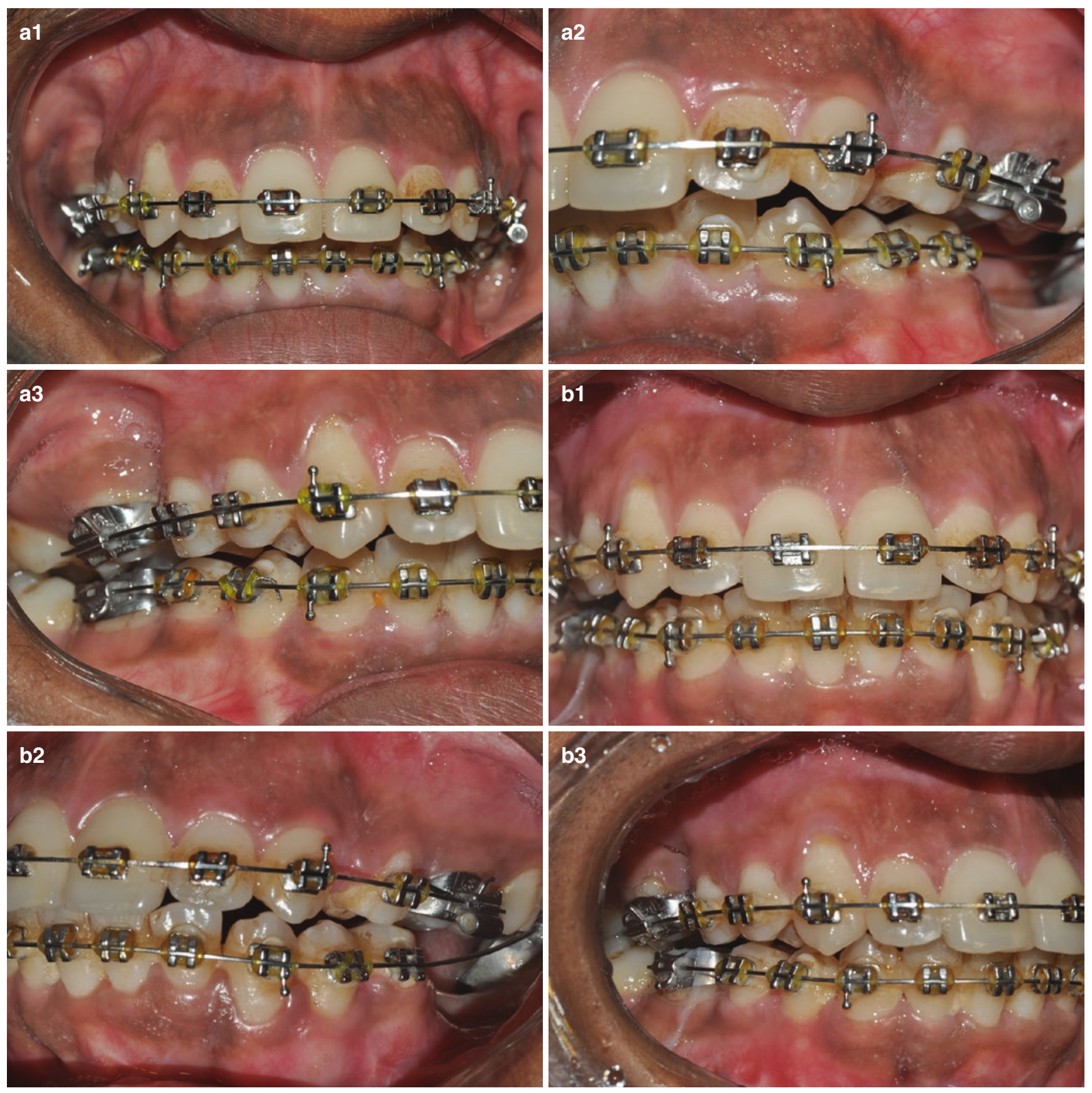

CAssociation of Oral and Maxillofacial Surgeons of India

Fig. 69.29 (a, b) (a1, a2, a3) Pre-surgical occlusion of the same patient as in Fig. 69.28, treated with LeFort I superior repostioning. (b1, b2, b3) Post-surgical occlusion of the same patient

The benefits of the quadrangular osteotomy are that it improves the appearance of midfacial retrusion and flattening and improves zygomatic prominence and support for the lower eyelid. This osteotomy has minimal surgical morbidity and has acceptable outcomes. This may therefore be considered, especially in Asian patients, as a viable treatment alternative for midfacial advancement without augmentation of the malar region [65].

If the cuts are made from high to low a significant inferior movement of the maxilla can be achieved thus reducing the necessity for an interpositional bone graft (which would be required following a maxillary set down) and alloplastic onlay grafts for the zygomatic regions. It is more stable than conventional inferior positioning of the maxilla as there is good bone contact with native bone and no bone graft. This osteotomy also produces less rotation of the nasal tip than the conventional Le Fort I osteotomy. However, it is important to recognize that if there is a mild facial asymmetry in the maxillary region, this asymmetry can be emphasized with this high-level cut as the maxilla is advanced. The surgical technique is the same as for the conventional Le Fort I osteotomy, but significant sharp dissection of the masseter muscle from 

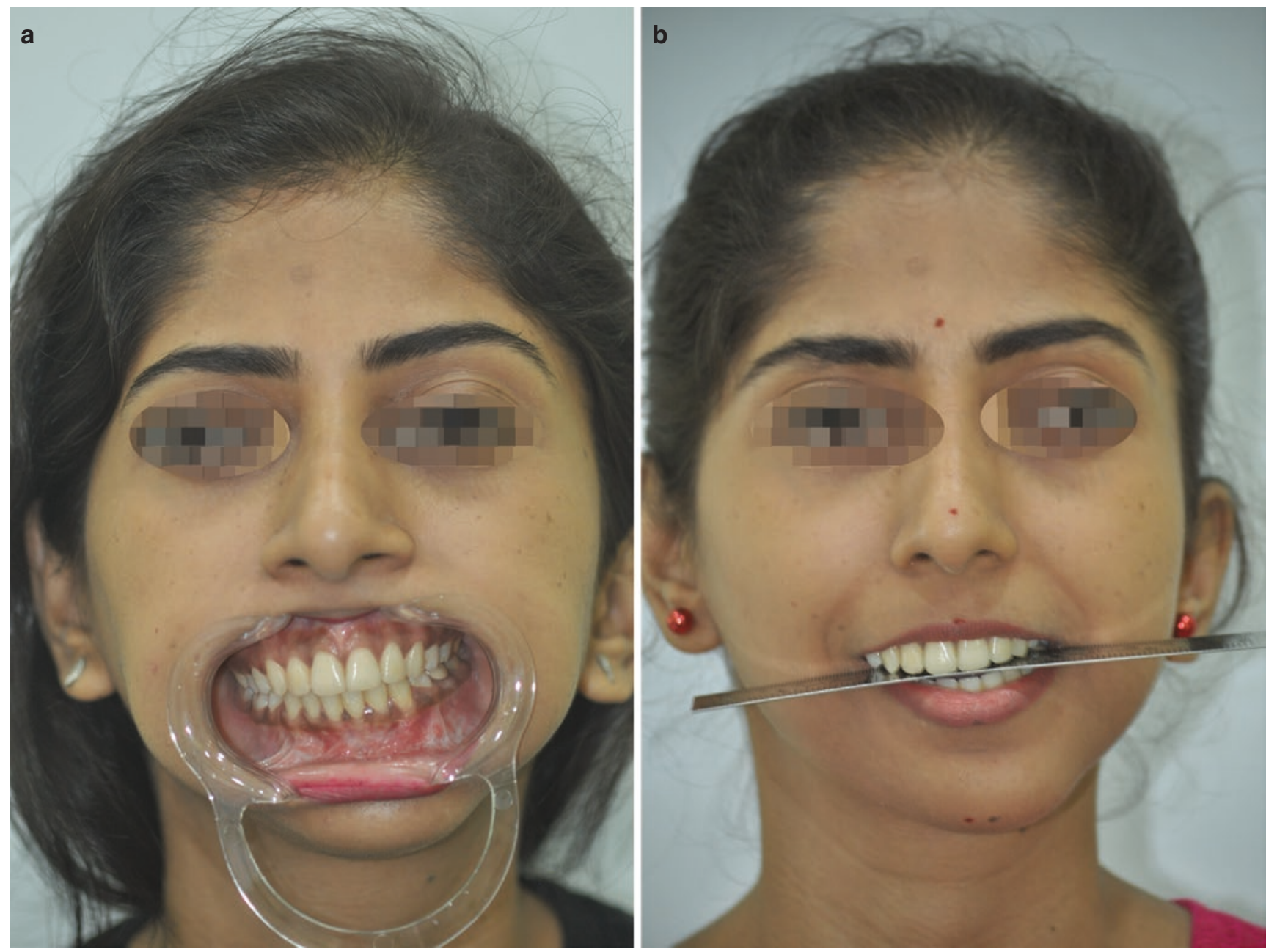

CAssociation of Oral and Maxillofacial Surgeons of India

Fig.69.30 (a, b) Patient with maxillary occlusion cant and asymmetry (also see Figs. 69.31, 69.32 and 69.40)

the zygoma is required to expose the prominence of the zygomatic bone. The bony cuts are demonstrated in Fig. 69.33. The cuts are made just below the infraorbhital nerves.

The bone over the zygomatic prominence is thick, and control over the shape of the cuts is easier using a burr and a saw. This ensures that the bony cut does not propagate upward to the cranial base but instead is directed downward to the normal pterygomaxillary disjunction level. The other steps to complete the bony cuts and down-fracture the Le Fort I cut are made as above. Fixation is with miniplates. However, care must be taken to ensure the plates are not palpable in the infraorbital regions.

\subsection{Surgically Assisted Rapid Palatal Expansion (SARPE)}

SARPE is a combination of orthodontic and surgical techniques to expand the maxillary arch. This is ideal in patients with of transverse maxillary deficiency, where the palatal suture has completely fused. This concept initially was met with skepticism but later was repopularized through the works of several clinicians, including Issacson and Ingram [66] and Haas [67], as a viable method of treating maxillary transverse deficiency. SARPE is indicated in cases where skeletal maturity has been achieved, transverse maxillary deficiency is present, excessive display of buccal corridors when smiling, and presence of anterior dental crowding. It has been shown that the midpalatal suture undergoes ossification at a wide range of ages [68]. In general, SARPE is recommended for patients who are over 16 years of age [69]. Nonsurgical expansions can be a reasonable consideration for patients younger than 12 years of age.

Before starting the surgery, it is important to confirm the secure placement of the appliance and also the presence of the device key to activate the appliance.

This procedure follows Le Fort I single piece osteotomy.

The maxilla is not down-fractured. Relieving of the osteotomies present at the zygomaticomaxillary buttresses is done, as this allows clearance during separation. The midline 

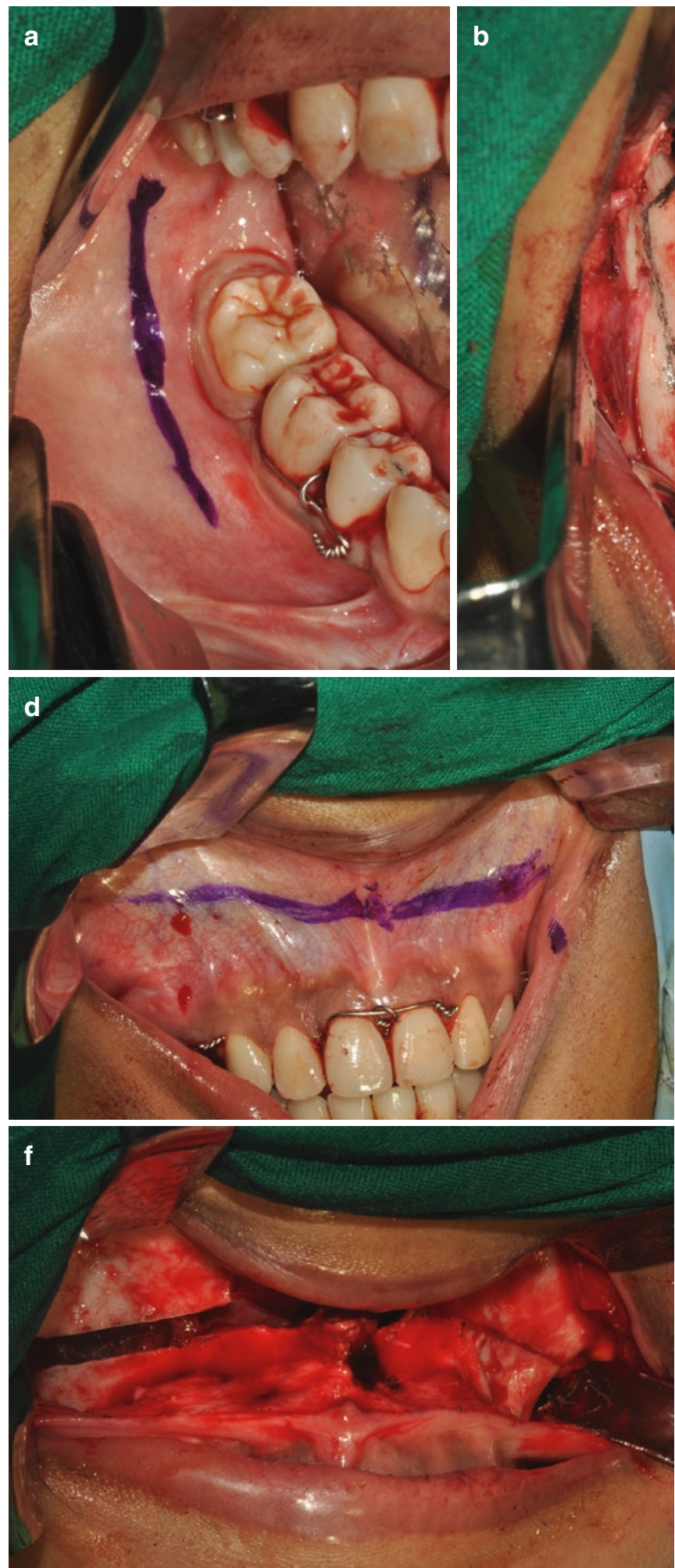

Fig. $69.31(\mathbf{a}-\mathbf{m})$ Surgical procedure for correcting the maxillary occlusion cant (also see Figs. 69.30, 69.32 and 69.40). (a-c) Sagittal split osteotomy cuts. (d) Incision marking for le fort Osteotomy. (e, f) Osteotomy cuts marked and made for asymmetric superior repositioning of maxilla. (g) Down-fracture of maxilla. (h) Superior repositioning
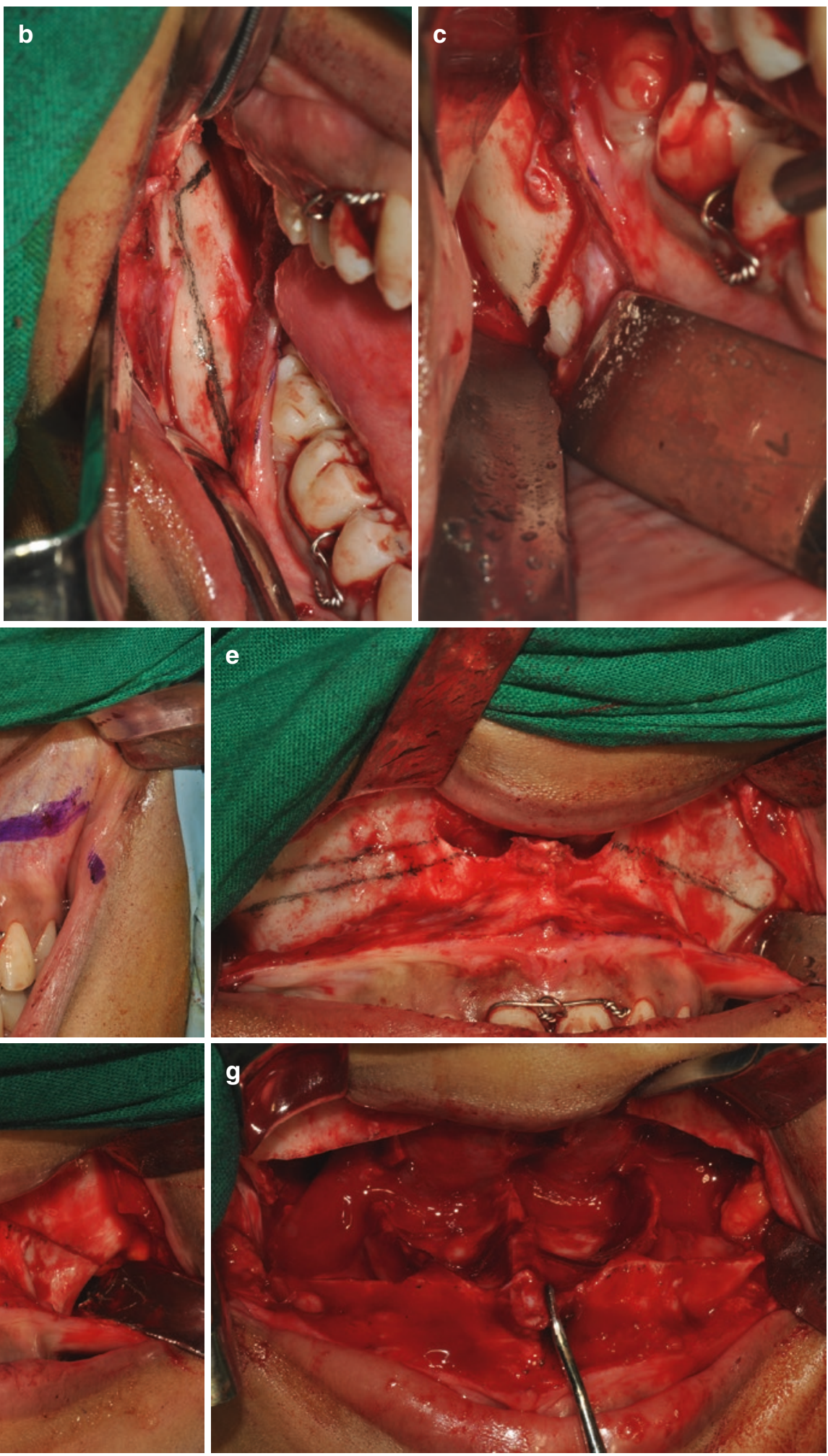

of maxilla. (i) Fixation of maxilla with mini plates and screws. (j) Open bite on right side of occlusion because of asymmetric superior repositioning. (k) Unilateral sagittal split osteotomy of mandible split and fixed with mini plates and screws. (l) New Occlusion achieved. (m) Closure of wound done 

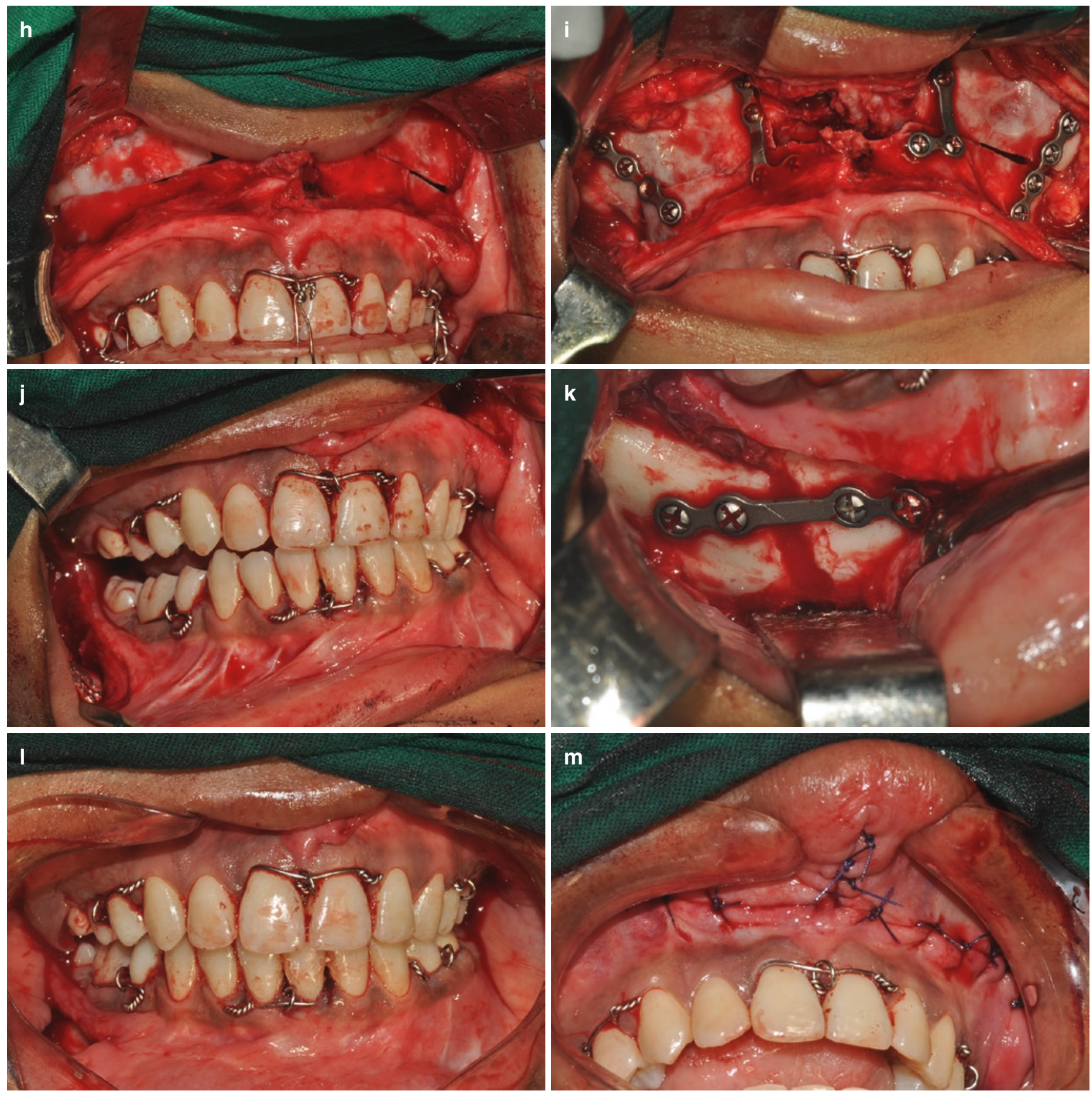

CAssociation of Oral and Maxillofacial Surgeons of India

Fig. 69.31 (continued)

gingiva is elevated to expose the alveolus. The midline osteotomy is carried out using a sagittal or piezo saw from the piriform rim of the nose, to the alveolus. The mid-palatal suture osteotomy is completed with chisels. The zygomaticomaxillary buttresses clearance is confirmed intraoperatively by activating the palatal appliance (Fig. 69.34a-c). The remainder of the procedure is according to Le Fort 1 single piece osteotomy [70].

\section{Salient Features of SARPE}

1. SARPE is usually performed on arches that are $V$ shaped.

2. The scope of orthodontics is limited in masking a skeletal transverse discrepancy that is greater than $5 \mathrm{~mm}$. A segmental Le Fort expansion cannot be carried out for movements greater than $7 \mathrm{~mm}$. If a significant amount of maxillary expansion is required, presumably greater than 

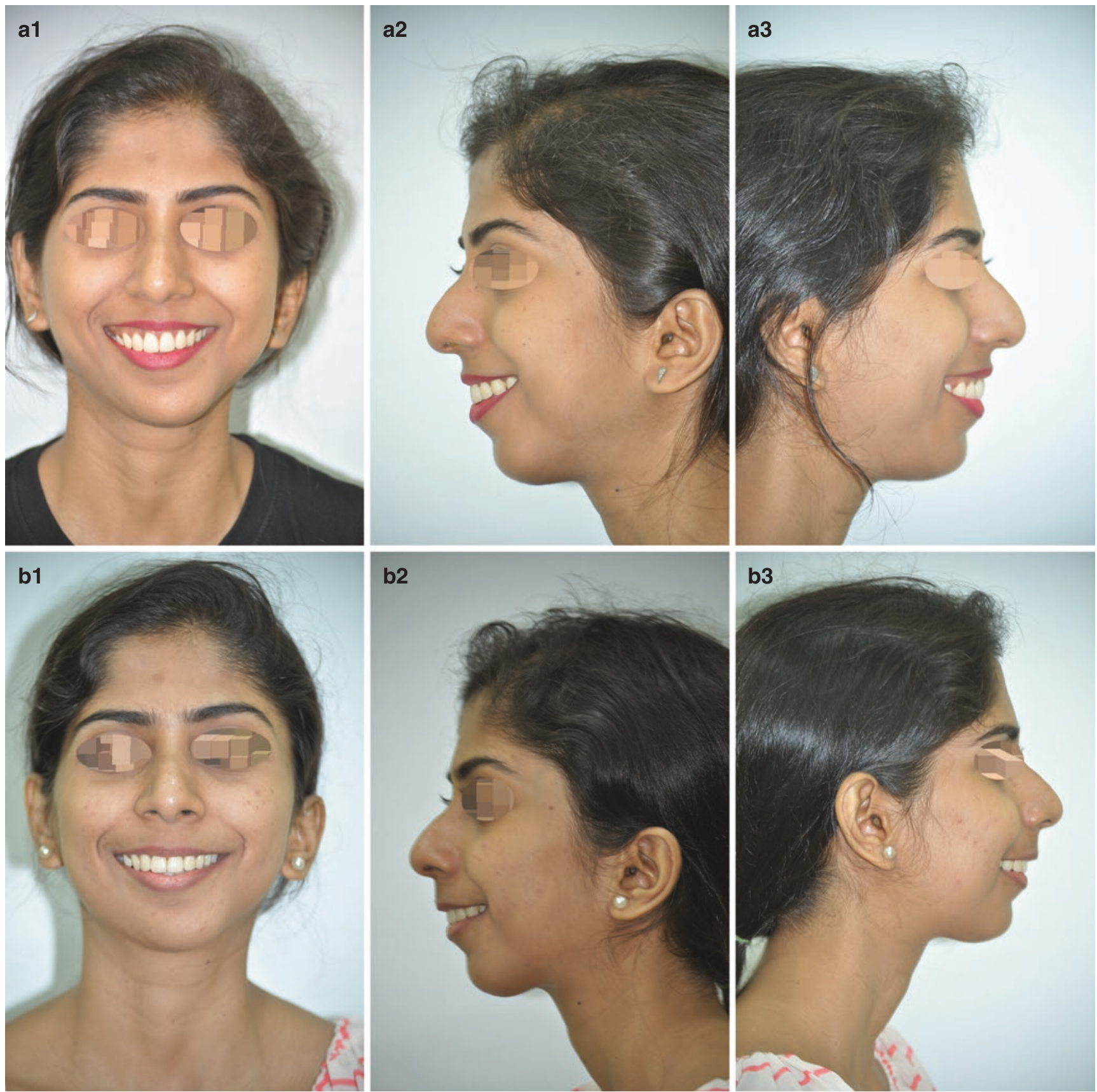

CAssociation of Oral and Maxillofacial Surgeons of India

Fig. 69.32 (a, b) (a1, a2, a3) Pre-surgical pictures of patient with cant; (b1, b2, b3) postoperative asymmetric superior repositioning of maxilla and unilateral sagittal split osteotomy of the mandible to close the open bite created (Also see Figs. 69.30, 69.31 and 69.40)

$7 \mathrm{~mm}$, a SARPE procedure is preferred as it would offer more stability.

3. An IOPA X-ray is taken to ensure that sufficient space exists for an interdental osteotomy.

4. Osteotomies performed during a Le Fort I are replicated for the SARPE procedure, without down-fracturing the maxilla.
5. Pterygoid plates are separated for the posterior expansion of maxilla.

6. The zygomaticomaxillary buttresses offer greatest resistance to maxillary expansion. Activation of the palatal appliance must be done within the operating room. This will ensure that the maxilla is able to expand bilaterally, in a symmetric fashion, with no interferences. 
Fig. 69.33 It is important to continue the saw or cut with a fissure bur through the inferior part of the zygomatic arch and extend it inferiorly and posteriorly to enable the important back cut to the pterygoid plates. This reduces the possibility of unwanted propagation of fractures to the cranial base

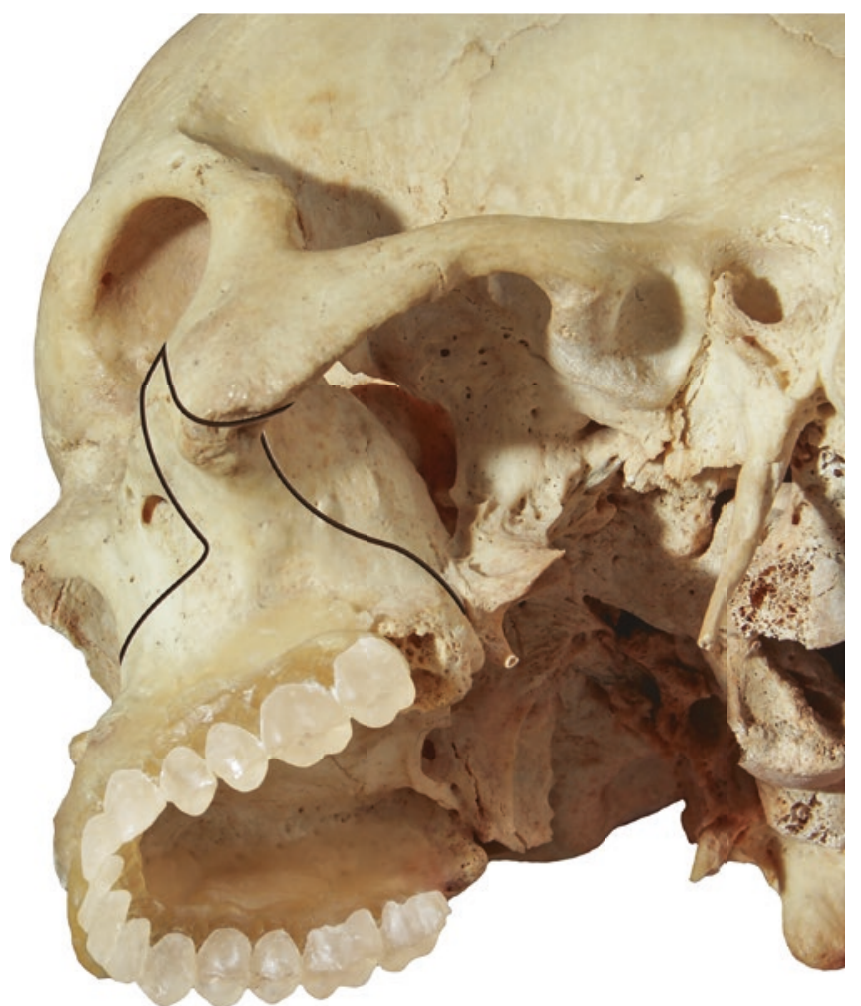

CAssociation of Oral and Maxillofacial Surgeons of India
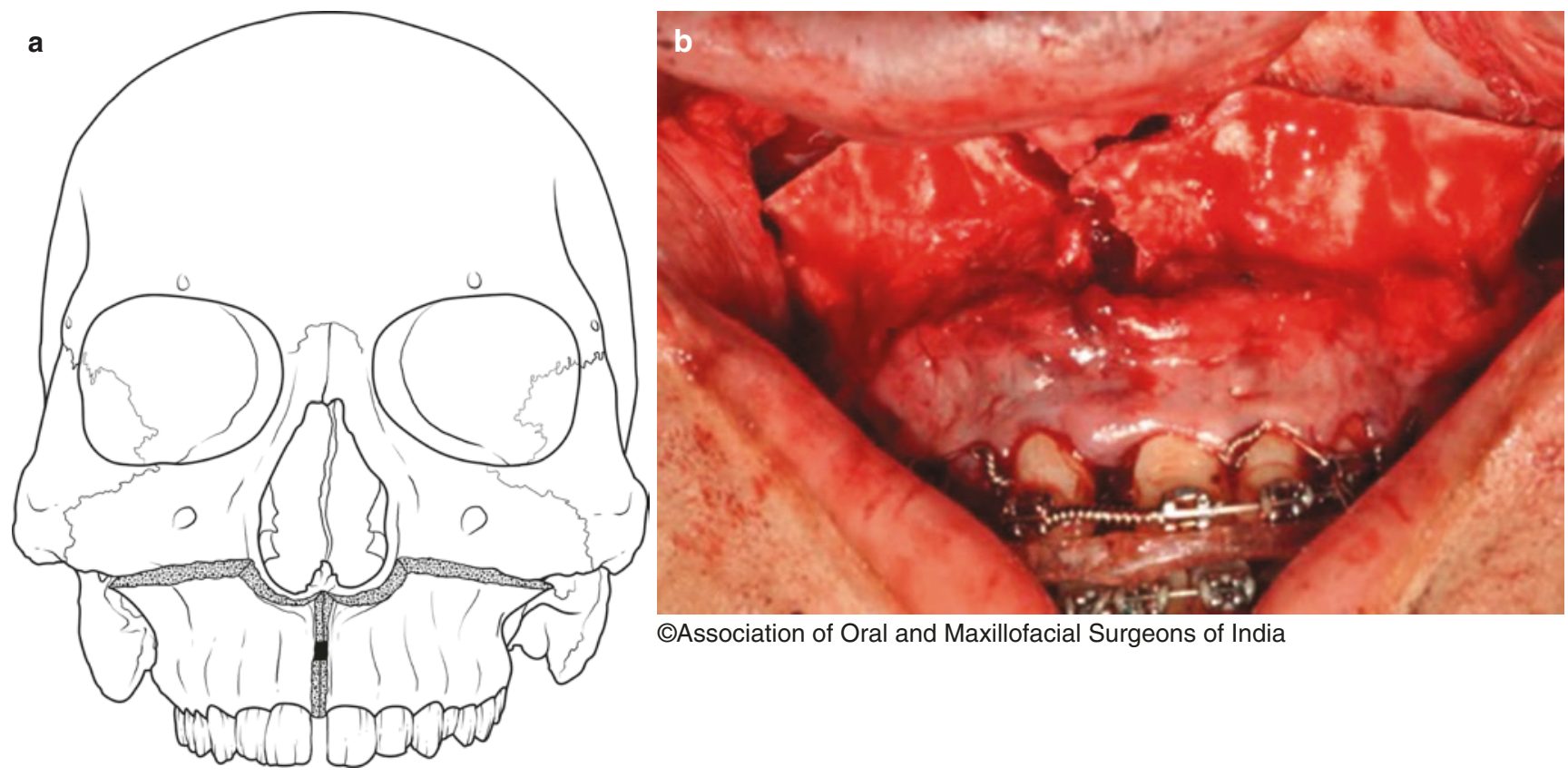

CAssociation of Oral and Maxillofacial Surgeons of India

Fig. 69.34 (a) Maxilla down-fracture, paramedial osteotomy, palatal expansion device in situ, and checking for the horizontal segmental movement. (b) Midline palatal osteotomy, device for palatal expansion, (c) Tooth- borne Haas \& Hyrax Appliance 


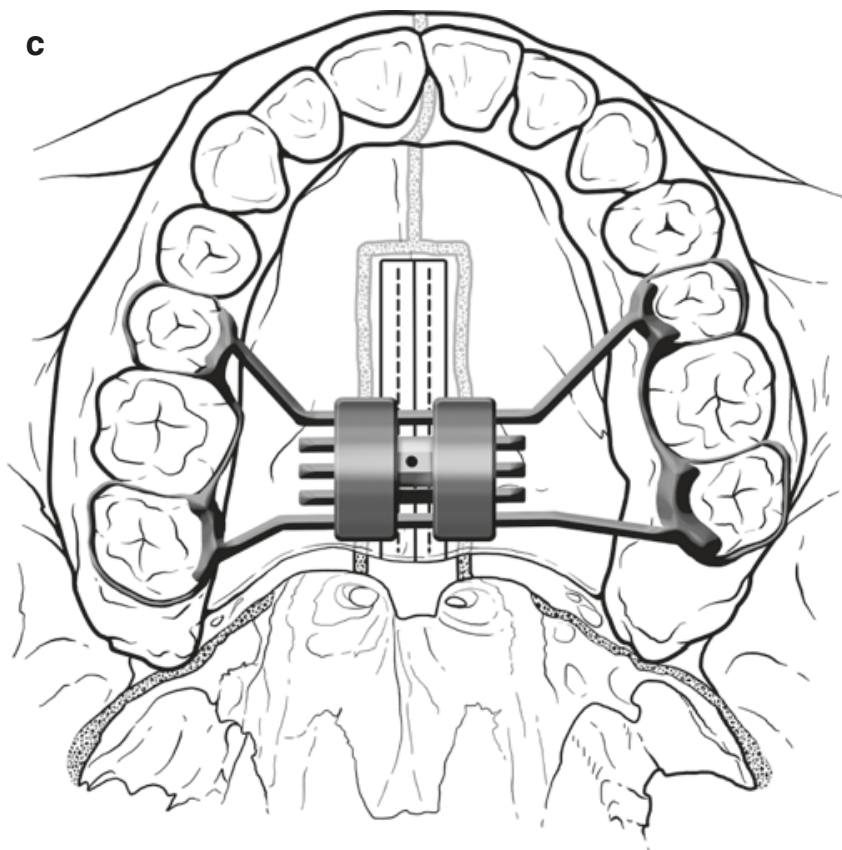

Fig. 69.34 (continued)

7. Overcorrection is recommended to allow for relapse. This is because maximum instability is associated with transverse maxillary expansion.

8. Either a tooth-borne appliance (Haas and Hyrax appliance) or a bone-borne palatal appliance may be used. The tooth-borne appliances may be more acceptable for patients, as they are less invasive and more hygienic. The disadvantage of these appliances is that they can create an occlusal tipping effect at the level of the alveolar bone and teeth. This may be minimized by engaging at least three posterior teeth. On the other hand, a bone-borne appliance offers better control over orthopedic movements at the level of the palate, but it requires a steep palatal vault for anchorage and is more invasive [71, 72].

\subsection{Sequence of Bimaxillary Surgery} (Fig. 69.31a-m)

A single surgical procedure can be employed to correct skeletal deformities of the mandible and the maxilla as well. The surgeon generally determines the preferred sequence. The authors personal preference is provided below.

1. The mandibular bony cuts are usually performed first, without splitting the mandible. This is followed by completion of the maxillary osteotomy, repositioning and fixation. In the past, fixation was only by trans-osseous wiring. Hence, when the mandible was performed first, its position was arbitrary as it incorporated the mobile proximal fragment (due to the TMJ) based on which the final maxillary position was determined. To avoid this the maxilla was completed first.

2. The mandible is exposed, and the bony osteotomy cuts are completed. However the formal split is not completed.

3. The maxilla is exposed, osteotomy completed and fixed in its final position.

4. The split for the mandible is completed, followed by the reposition of the mandible to the desired position. The mandible is then stabilised and fixed in its final position. This eliminates the possibility of any undesired maxillary movement as the movement of the maxilla is completed based on a stable intact mandible.

5. Finally, the genioplasty cuts are stabilized.

6. The same order must be considered during model surgery and when fabricating the intermediate and final splints for guidance.

The authors personal preference has been detailed above. Alternatively, mandibular splitting may be performed first, and an intermediate splint may be used to to fix the mandible to the unoperated maxilla. The maxilla may then be stabilized to the operated and repositioned mandible. However, it must be noted that stabilization and fixation of the mandible are more challenging than for the maxilla. Rigid fixation may be more challenging if an improper or misdirected split occurs. The procedure may even need to be aborted altogether. However, by stabilizing the maxilla first, the mandible can use appropriately positioned maxilla for stabilization. Therefore, we have always preferred to complete the maxillary surgery before mandibular surgery.

Having listed a general guide above, we reiterate that no dogma should be given regarding the sequence of maxillary or mandibular surgery. Proper planning and preparation will in turn logically dictate the sequence, which must be kept flexible [73].

\subsection{Soft Tissue Changes with Le Fort I Osteotomy}

Changes in the jaw position in turn lead to changes in the position of soft tissues such as the lips, cheeks, and nose [74]. The lips may show thinning, reduced vermillion show, and may lack adequate lip support [46]. The nasal tip may be upturned, the alar base width may increase, and the nasolabial angle may widen [75] (Fig. 69.35a-c). Soft tissue swelling 

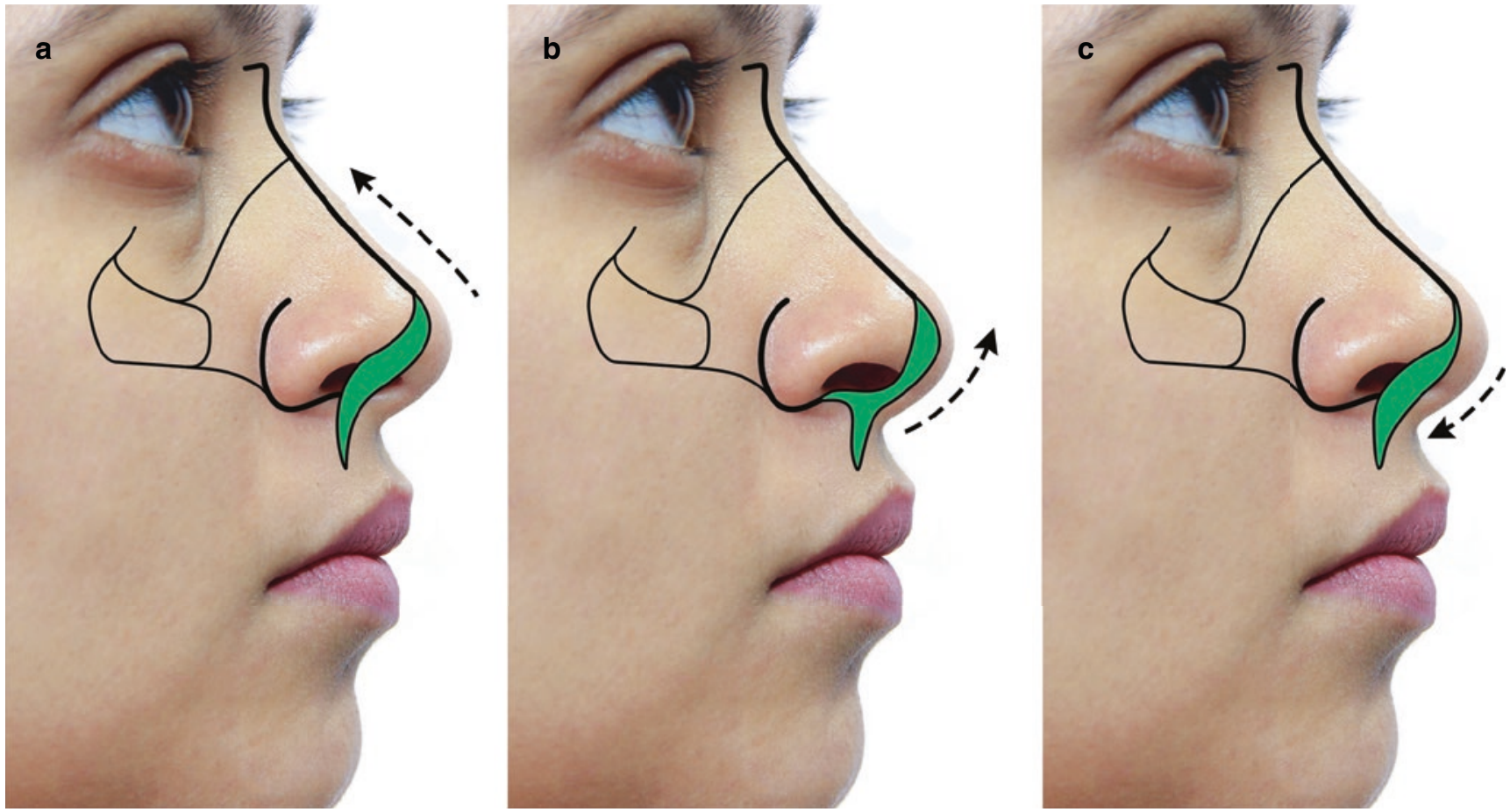

CAssociation of Oral and Maxillofacial Surgeons of India

Fig. 69.35 (a-c) (a) reduction of a strip along the caudal septum will shorten the nose; (b) reduction involving the nasal tip as shown will increase the nasolabial angle; (c) wedge reduction predominantly at the septal base will reduce the nasolabial angle

may take up to a year to resolve, so these changes may not be apparent immediately [76]. In some regions, such as the subnasale, and the lips, greater than $10 \%$ change has been documented over 5 years [4]. Nasal changes are quite complex and are therefore unpredictable. Both the structure of the nose (including nasal cartilage connective tissue, anterior nasal spine, and the other nasal cartilages) and the degree of movement of the maxilla play a role in nasal changes. Other patient-related factors, including thickness and morphology of the soft tissue, postoperative healing, age, and ethnicity, can also affect nasal changes, which may either be favorable or unfavorable or beneficial. The nasal width alone increases predictably in Le Fort I osteotomies, and the increase in width depends on the extent of maxillary movement. Adjunctive procedures to limit widening of the nasal width may be performed intraoperatively. These include alar cinch suture and piriform aperture sculpting. Alternatively, the changes may be accepted and later procedures can be performed if necessary. The disadvantage of this is the need for an additional surgical procedure, e.g., alar wedge resection rhinoplasty. The alar cinch suture and V-Y closure (ACVY) is efficient and less invasive in controlling nasolabial changes. Its long-term results need to be evaluated. One study showed that the alar base cinch suture reduced the inter-alar width to its preoperative width following a Le Fort I osteotomy. The suture was stable when evaluated at 12 months and 3 years postoperatively [77]. There have been studies comparing nasal and maxillary vermilion morphology after Lefort osteotomies by simple primary closure, Single VY closure and Double VY closure. The results indicated that better aesthetics are seen in double VY closure cases (See Hackney et al. 1989, Ledezma et al. 2014, in Additional reading provided). However a systematic review in 2014 couldn't reach a conclusion regarding the efficacy of various methods of closure in Lefort Osteotomies.

\subsection{Specific Considerations}

1. Attempts to study the nasal changes resulting from maxillary movements have demonstrated very variable results. The general consensus is that nasal changes are unpredictable after Le Fort I osteotomy [78].

2. The ascending pharyngeal artery and ascending palatine artery maintain blood perfusion to the down-fractured maxilla.

3. Impacted, unerupted, or erupted wisdom teeth may be removed during the Le Fort I surgery. The curved pterygoid osteotome must be placed posterior to the impacted teeth or through the socket. The technique of pterygoid separation through the socket of the third molar was described by Trimble et al in 1983 (Refer additonal reading).

4. If posterior bony interferences are present, they may cause condylar displacement, condylar distraction, asym- 
metrical jaw movements (deviations), malocclusion, and aberrant maxillary position.

5. If the maxilla is not mobilized sufficiently prior to fixation, this may hinder optimal advancements.

6. The zygomaticomaxillary and nasomaxillary buttresses consist of thick struts of bone and are ideal for securing fixation [79].

7. Blood loss is variable but rarely warrants transfusion. A review of over 500 osteotomies concluded an average loss of just under $300 \mathrm{~mL}$, greater for bimaxillary osteotomies and less for single jaw surgery [80].

\subsubsection{Adjustment to the Anterior Nasal Spine and Piriform Aperture}

Mommaerts et al. reported that the anterior nasal spine is a significant component of nasal tip projection and may be reduced to limit the degree of nasal tip rotation [81]. Betts et al. also stated that changes in the lateral part of the piriform aperture significantly affected the soft tissue of the nasal base and nasal tip projection [82].

It is important not to remove too much of the septum as this can produce a retracted columella, which is a potentially unattractive feature.

Osseous recontouring of the nasal crest of the maxilla and/or resection of a portion of the caudal extent of the cartilaginous septum is recommended to keep interference at bay. Placement of a suture through the anterior nasal spine and cartilaginous septum to prevent its displacement upon removal of the nasoendotracheal tube is beneficial.

\subsubsection{Effect of Changing the Inclination (Slope) of the Osteotomy Cut}

If the osteotomy cut is made in a parallel direction to the occlusal plane and the maxilla is advanced, the maxillary incisor exposure will increase but the face height will not change. However, if the osteotomy cut starts high posteriorly and slopes downwards toward the piriform aperture, the maxilla will move down the slope as it is advanced, thus increasing the maxillary incisor exposure. The mandible will subsequently rotate in a clockwise direction and the lower anterior face height will increase (Fig. 69.36a, b). The opposite is true for the osteotomy cuts that start low posteriorly and slopes upward toward the piriform aperture (Fig. 69.37a, b).

\subsubsection{Impacted Wisdom Teeth}

If an impacted maxillary wisdom tooth is indicated for removal, this is done through the sinus floor. Using a rotary drill with a rosette bur, the bone from the sinus floor, which lies above the impacted tooth, is removed. Next, a tapered fissure bur is used, and the bone just adjacent to the impacted tooth is removed. The impacted wisdom teeth may also be sectioned if necessary

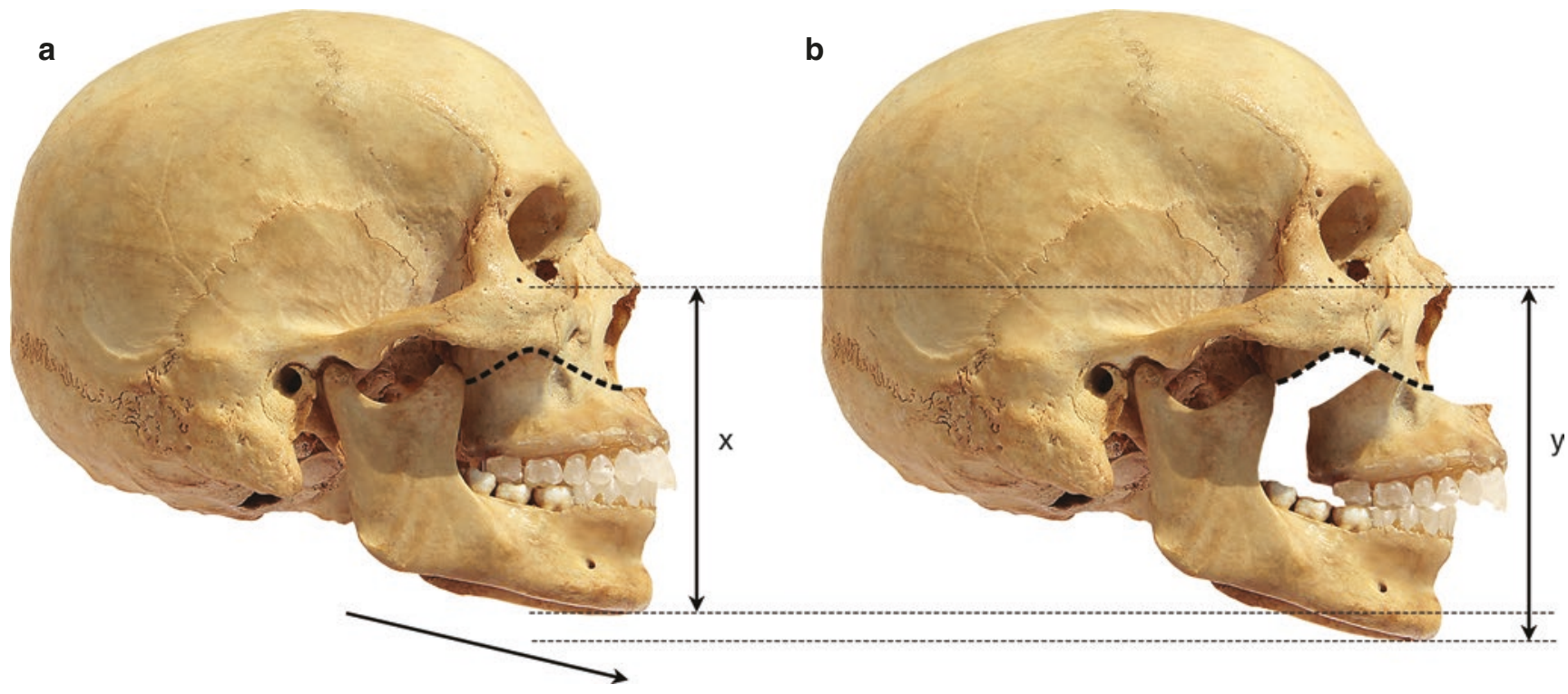

CAssociation of Oral and Maxillofacial Surgeons of India

Fig. 69.36 (a, b) Diagram showing effects of the inclination (high to low postero-anteriorly) of the osteotomy cut when advancing the maxilla-(a) osteotomy inclination to increase incisor exposure and poten- tially increase lower face height, (b) advancement of maxilla producing increase of lower facial height due to downward ramp effect 


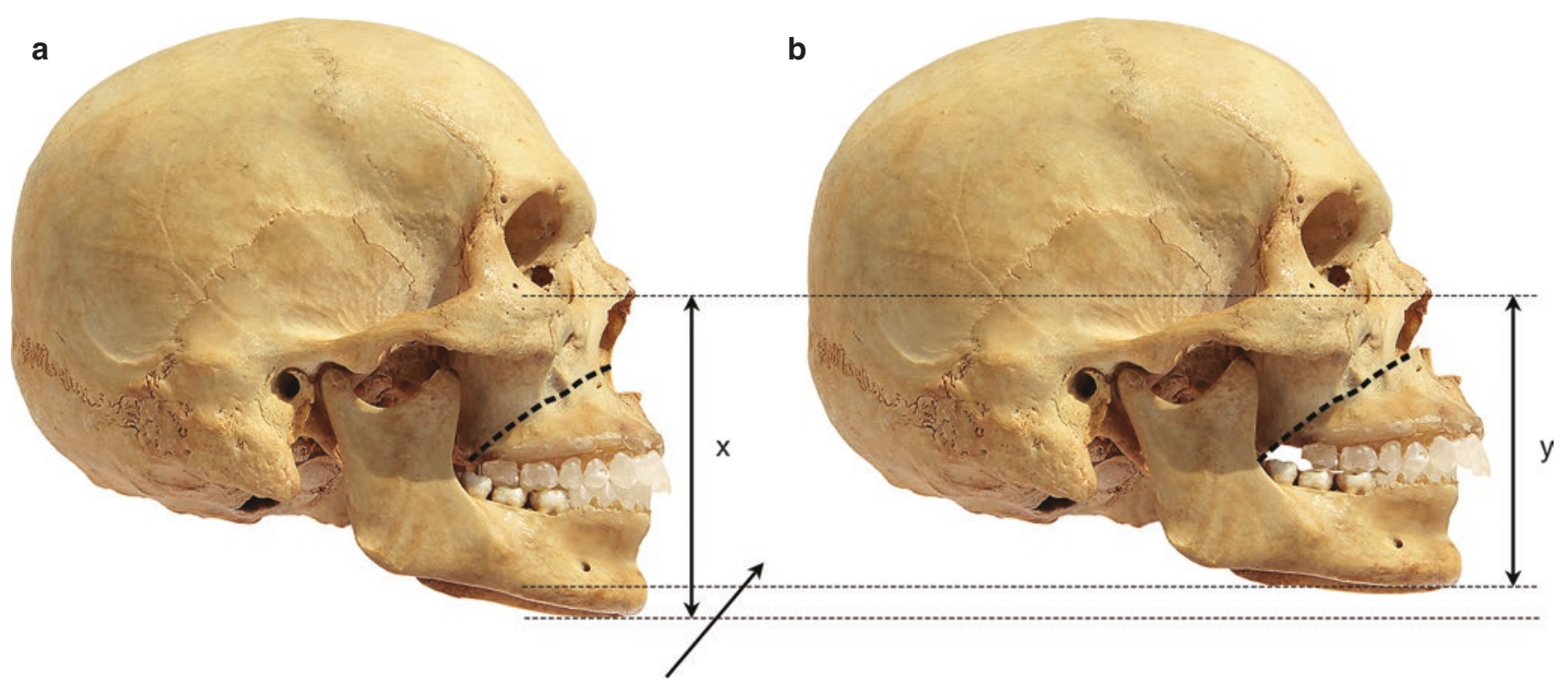

CAssociation of Oral and Maxillofacial Surgeons of India

Fig. 69.37 (a, b) Diagram showing effects of the inclination (low to high postero-anteriorly) of the osteotomy cut when advancing the maxilla-(a) osteotomy inclination to reduce incisor exposure and poten-

to aid in removal; this usually depends on the developmental stage. The tooth is delivered using a dental elevator. Rarely, perforation through the palatal mucosa may occur.

\subsubsection{Erupted Wisdom Teeth}

If the maxillary wisdom tooth is completely erupted, this may be extracted prior to down-fracture. This will allow the operator to have a stable "workbench" during extraction. In order to maintain the blood supply to the down-fractured maxilla, the adjacent palatal and labial mucosa must be preserved carefully at the time of extraction.

\subsubsection{Considerations of Pre-operative Difficulties}

The pre-surgical workup and planning of patients who require corrective jaw surgery required detailed analysis of clinical features, study models, and plane radiographs. Radiographic analysis includes comprehensive assessment of lateral cephalograms, postero-anterior cephalograms, and orthopantomograms. The need for multiple individual planar views has been replaced by the advent of cone beam technology.

\subsubsection{Considerations of Operative Difficulties}

Horizontal osteotomy of the maxilla should result in a clean pterygomaxillary separation to subsequently allow for tially reduce lower face height, (b) advancement of maxilla producing reduction of lower facial height due to upward ramp effect

down-fracture and mobilization. At this step, the pterygoid plates should ideally remain intact and attached to the skull base. However, in some exceptional cases, such as patients with cleft maxilla, the pterygoid plates are unusually thick and well buttressed. On the other hand, some patients have thin and almost translucent pterygoid plates [83]. Pterygomaxillary synostosis (fusion) may be seen in up to $12 \%$ of all patients [21].

If the pterygoid plates fracture at a lower level, this may cause difficulties in down-fracture and mobilization, because of the attachment of the pterygoid musculature. On the other hand, if the plates fracture at a higher level, the fracture may propagate into and along the skull base, which can potentially cause neuro-ophthalmic complications.

On postoperative CT scans, the incidence of pterygoid plate fracture after a Le Fort I osteotomy was found to range from 58 to $75 \%$ [84, 85]. However, despite this high incidence, the incidence of fractures propagating to the skull base/orbit is low [83].

Lanigan et al. carried out a study on unfixed fresh cadavers and found that $26 \%$ of cases were "difficult downfracture." They stated that this was probably due to the presence of "thick bony maxillary walls" [83].

These authors stated that if a difficult down-fracture was encountered after a routine Le Fort I osteotomy, then the posterior walls of the maxilla must be sectioned completely using an osteotome. Alternatively, sectioning through the tuberosity could be performed, using a micro-oscillating saw or straight osteotome, as this would avoid the thick posterior walls and aid in pterygomaxillary separation. However, these authors have stated that it would not be possible to totally prevent 
untoward fractures that could occur during pterygomaxillary disjunction and down-fracture. We emphasize that thorough CBCT imaging should be undertaken preoperatively, as this would familiarize the surgeon with the maxillary morphology.

The following maneuvers may help if the surgeon finds difficulty in down-fracture following osteotomy and disjunction:

1. Revise the osteotomy cuts at all accessible sites, including anteromedial antral, lateral antral, and superior-nasal crest.

2. The maxilla may be "hinged down" to directly visualize the posterior maxilla, after which the cuts in this region may be completed, using a straight $4 \mathrm{~mm}$ osteotome.

3. Down-fracture can then be undertaken under direct vision.

O'Regan and Bharadwaj stated that an osteotome or saw must never be used blindly in these situations [86].

\subsubsection{Proper Positioning}

- Proper positioning can be difficult in isolated maxillary surgery, usually due to unrecognized posterior bony interferences.

- With an unrecognized posterior interference and inadequate effort or improper seating of the condyles, the maxilla can rotate around this interference, resulting in an anterior open bite after release of intermaxillary fixation. The maxillomandibular complex should be rotated with pressure seating the condyles in the glenoid fossa (Fig. 69.38a, b, c).

- Looking for the posterior interferences and eliminating them will result in the intended postoperative occlusion. Prior to any attempt to position the maxilla, effort is devoted to removing bone in the most likely areas of potential posterior interference, that being the area posterior to the second molar and along the perpendicular process of the palatine bone.

- Whether or not there is a potential for interference in the region of the pterygoid plates, per se, depends upon the
Fig. 69.38 (a-c) (a) The proper method for condylar seating at the time of maxillary positioning prior to fixation. Posterior prematurities are best appreciated with this method. (b) Pressure on the chin to push the anterior aspect of the maxillary osteotomy together may rotate the condyles inferiorly and posteriorly while maxillary fixation is applied. (c) Upon release of intermaxillary fixation, the condyles may return to the fosse, and an open bite may appear. Unfortunately, this open bite may not appear immediately, especially if postoperative elastics are used to "guide" the occlusion
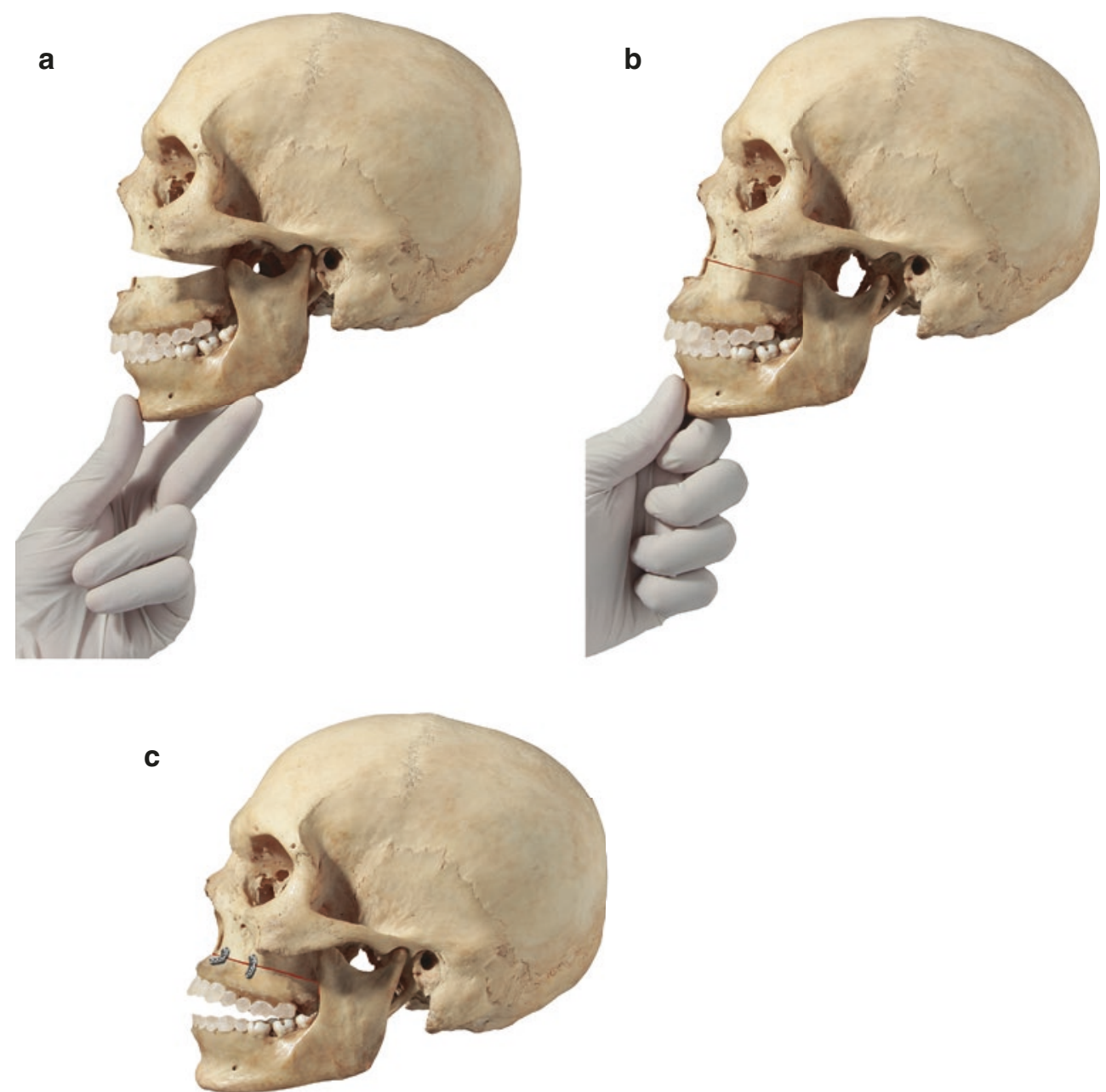

(C)Association of Oral and Maxillofacial Surgeons of India 
surgical move. This is much less likely with advancement than it is with other moves such as impaction.

- It is often easiest to adapt the plates for fixation with Le Fort osteotomy and initially secure them only to the inferior fragment. Once all the plates are properly bent and secured to the inferior fragment, the maxillomandibular complex and condyles can be positioned with great care, and the shape and bending of the plates critically evaluated and secured to the superior fragment in succession, while the maxillomandibular complex is held in position.

\subsubsection{Nutritional Support}

Orthognathic surgery throws up many physiological challenges. These include postoperative facial swelling and catabolism which increase the nitrogen requirements. If these are not met, wound healing may be compromised. A diet fortified with macro- and micronutrients and adequate hydration is therefore essential [87].

Mandibular movements may be restricted in the postoperative period, owing to facial swelling and pain. Meeting the daily nutritional needs and hydration requirements (Table 69.1) may therefore be difficult. Studies have shown that in 6 weeks following surgery, patients can lose between 3.1 and $6.8 \mathrm{~kg}$ of weight [88].

It is important to adapt the diet to suit these needs, to promote wound healing, and to minimize postoperative complications. Another important factor in patient recovery is the patient's mood. Adequate nutrition and hydration will serve to improve the patient's mood, thereby diminishing postoperative irritability or depression [89]. Dietician assessment of nutritional status is essential to ensure that the above goals are achieved.

The modification of the diet is a sequential process. This aims at reducing the masticatory forces on the underlying healing bone, which in turn optimizes the conditions for healing.

1. The first 7 days following surgery should consist of a diet rich in energy and protein. This must be in a liquid form, and foods may be completely blended in a food processor to a smooth liquid consistency.

2. After the first week, patients can start consuming food with a small spoon or fork. It is still advised to minimize

Table 69.1 Recommended postoperative nutrition requirements for patients above 16 years, undergoing orthognathic surgery [87]

\begin{tabular}{l|l|l|l} 
& Energy $(\mathrm{kcls})$ & Protein $(\mathrm{g})$ & Fluid $(\mathrm{ml})$ \\
Male & 2500 & $1 \mathrm{~g} / \mathrm{kg} /$ day & $35 \mathrm{~mL} / \mathrm{kg} /$ day \\
Female & 2000 & $1 \mathrm{~g} / \mathrm{kg} /$ day & $35 \mathrm{~mL} / \mathrm{kg} /$ day
\end{tabular}

chewing, and foods may be mashed. The high-energyhigh-protein diet must be continued.

3. After the second week, light chewing may be done, and a soft diet is recommended. The jaw muscles may fatigue easily at first, but gradually the muscles adapt to the new position. The soft diet is continued for two months, after which regular diet may be resumed [87, 90-98].

\subsubsection{Complications}

1. Hardware failure: Unstable orthoappliance, splints/wafer, must be tried separately on each arch pre-operatively. Hardware exposure or fracture, palpable hardware, and loosening of screws are certain complications in hardware failure. Management involves removal of hardware with or without replacement, depending on the amount of bone union and time duration after surgery.

2. Unanticipated fracture of maxilla: A occlusal splint with a palatal vault extension is essential to counter this complication.

3. Hemorrhage: Bleeding commonly occurs from the descending palatine artery and pterygoid plexus. Injury to pterygoid plexus may happen while performing pterygomaxillary disjunction. This may lead to arteriovenous malformations which may cause life-threatening bleeding $2-4$ weeks post-surgery. It needs to be managed with selective embolization. Hemorrhage may occur in patients with undiagnosed bleeding disorders.

4. Deviated nasal septum: This can occur when inferior septoplasty is inadequate during superior repositioning of the maxilla. It is managed postoperatively with adjunctive septoplasty.

5. Damage to apices of teeth: The horizontal osteotomy should be placed at least $5 \mathrm{~mm}$ above the apices of the maxillary teeth to avoid damage to the apices.

6. Malunion and nonunion: This can occur if fixation is inadequate fixation or has failed.

Rigid fixation with plates provides the initial stability until bone has united. Bone first unites in the pterygoid region [99]. The most stable maxillary movement is superior repositioning, followed by advancement, and the least stable is inferior repositioning. However, the studies looking at the inferior positioning of the maxilla have been based on the need for bone grafting. Studies have reported relapse rates for maxillary superior repositioning of the maxilla ranges from a mean of $0-18 \%$ for the anterior maxilla and $6-7 \%$ for the posterior maxilla. Relapse rates for maxillary advancement range from 5 to $15 \%$. As with most orthognathic surgery, relapse is greater with increase in the maxillary advancement. With inferior maxillary reposition- 
ing (using bone grafts), there may be $28 \%$ anterior relapse and up to $70 \%$ posterior relapse [100]. Nonunion is rare and probably associated with failure of the initial plate fixation and poor bony contact. If this persists for greater than 6 months, further surgery with rigid fixation and autogenous bone grafting is recommended [101]. Maxillary advancement and posterior and superior movements are shown to be stable, whereas inferior and transverse movements are unstable [99-110]. The use of autogenous bone grafts and/or hydroxyapatite has been proposed to improve the stability of inferior repositioning of the maxilla [101, 111-117].

7. Unfavorable aesthetic result: This results from poor treatment planning or unrealistic patient expectations.

8. Infection: Infection may occur in rare cases and is managed with systemic antibiotics with or without placement of a drain and the causative hardware removal. Septic complications have been recorded in $1.1 \%$ of osteotomy operations [55].

9. Dental problems: As a result of the osteotomy cut, the maxillary teeth lose their nerve supply. Generally, the nerve supply is re-established after 18 months to 2 years [118]. The teeth maintain their viability from the collateral blood supply. Patients should be warned that their teeth and gingivae may be numb for up to 2 years [119]. Osteotomy cuts should be a minimum of $5 \mathrm{~mm}$ above the root apices to avoid complications.

10. Trigeminocardiac reflex (TCR): The stimulation of trigeminal nerve branches during Le Fort I osteotomy can be a possible cause of the TCR, and transient cessation of the procedure is adequate to allow the heart rate and blood pressure to normalize and dysrhythmia to stop [120].

\subsection{Recent Advances (Refer Figs. 66.21 and} 78.51)

(a) Virtual planning in Orthognathic Surgery: the last decade has seen a tremendous evolution in the field of surgical planning. Computer Assited Virtual Surgical Planning and the use of CAD-CAM designed splints have significantly improved intra-operative accuracy of maxillary repositioning in orthognathic surgery [121].

(b) Waferless Orthognathic Surgery: Another technique which has created a paradigm change is the design of custom-fabricated cuttiing stents and patient specific implant for fixation, which help not only perform the osteotomy but also fix the segment in the desired position without the use of occlusal wafers [122].

\subsection{Conclusion}

The development of modern maxillary orthognathic surgical procedures had diverse historical origins and contributions. With advancement in technique and the introduction of safe hypotensive anesthesia, the Le Fort I osteotomy has been increasingly utilized over the last four decades. Over the years, various modifications of the osteotomies, ORIF methods and bone grafting to the mobilized maxilla, have continued to evolve and progress. The Le Fort I osteotomy of the maxilla is one of the core procedures in orthognathic surgery for the management of facial skeletal deformities. The surgery, often used in conjunction with the bilateral sagittal split osteotomy, is used to correct functional and cosmetic irregularities in all three planes of space and can be utilized in the treatment of a wide range of malocclusions. Traditionally, the surgery has been known for its low technical difficulty and dependable results. Changes in the soft tissue of the nose, lips, and cheeks due to this surgical procedure need due consideration.

The risk of complications is higher in patients with segmental Le Fort 1 osteotomies or anterior movements greater than $9 \mathrm{~mm}$. Efforts to minimize maxillary movement (e.g., with two-jaw surgery) are recommended to reduce complications. An emphasis should be placed on proper pre-surgical orthodontics and solid pre-surgical planning to ensure predictable and stable results. It is also imperative to plan and provide for optimal nutrition as Orthognathic surgery throws up many physiological challenges that may compromise the nutritional status including catabolism, postoperative facial swelling, and increased nitrogen requirements to promote wound healing. The premise of maxillary orthognathic surgery is therefore a multidimensional approach through planning, execution, and postoperative management.

Disclosure Authors have no financial conflicts to disclose. Authors have written consent and reconfirmation from the patients for the use of clinical pictures.

\subsection{Case Scenarios}

\section{Case Scenario 1 (Figs. 69.28, 69.29 and 69.39a-h)}

(A) Chief Complaints

Gummy smile

Long face

Deficient chin

Protruding upper front teeth

\section{(B) Postoperative Result}

Competent lips

Normal chin projection

Balanced face 

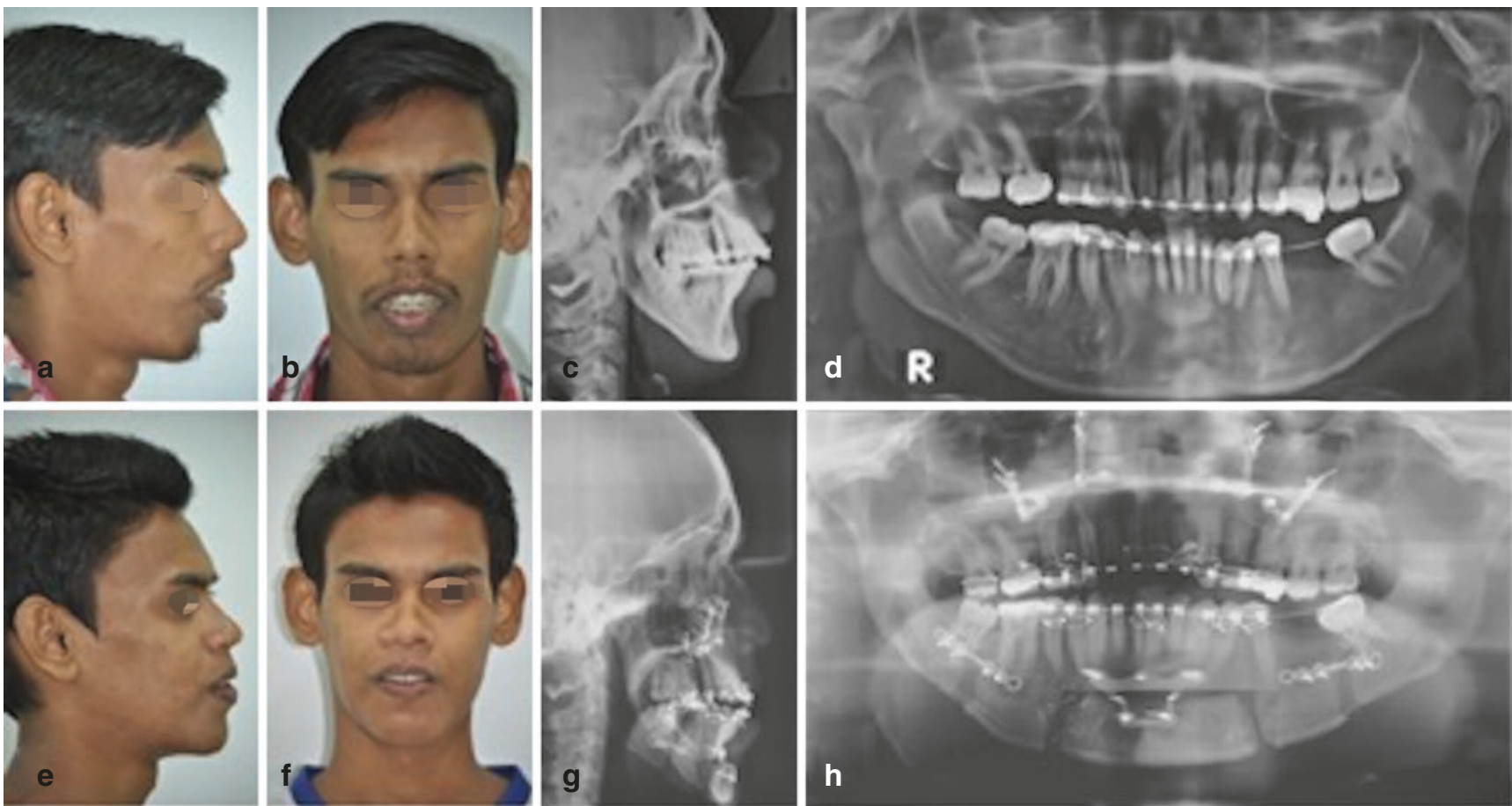

CAssociation of Oral and Maxillofacial Surgeons of India

Fig. $69.39(\mathbf{a}-\mathbf{h})$ Vertical maxillary excess with mandibular deficiency. Treatment: Le fort I with superior repositioning of maxilla; bilateral sagittal split ramus osteotomy advancement; advancement genioplasty. (a) Pre-operative profile picture; (b) pre-operative frontal view; (c) pre-operative lateral cephalogram. (d) Pre-operative OPG; (e) postoperative lateral profile; (f) postoperative frontal view; (g) postoperative lateral cephalogram; (h) postoperative OPG showing the implants and the osteotomy cuts in mandible. (Also see Fig. 69.28)
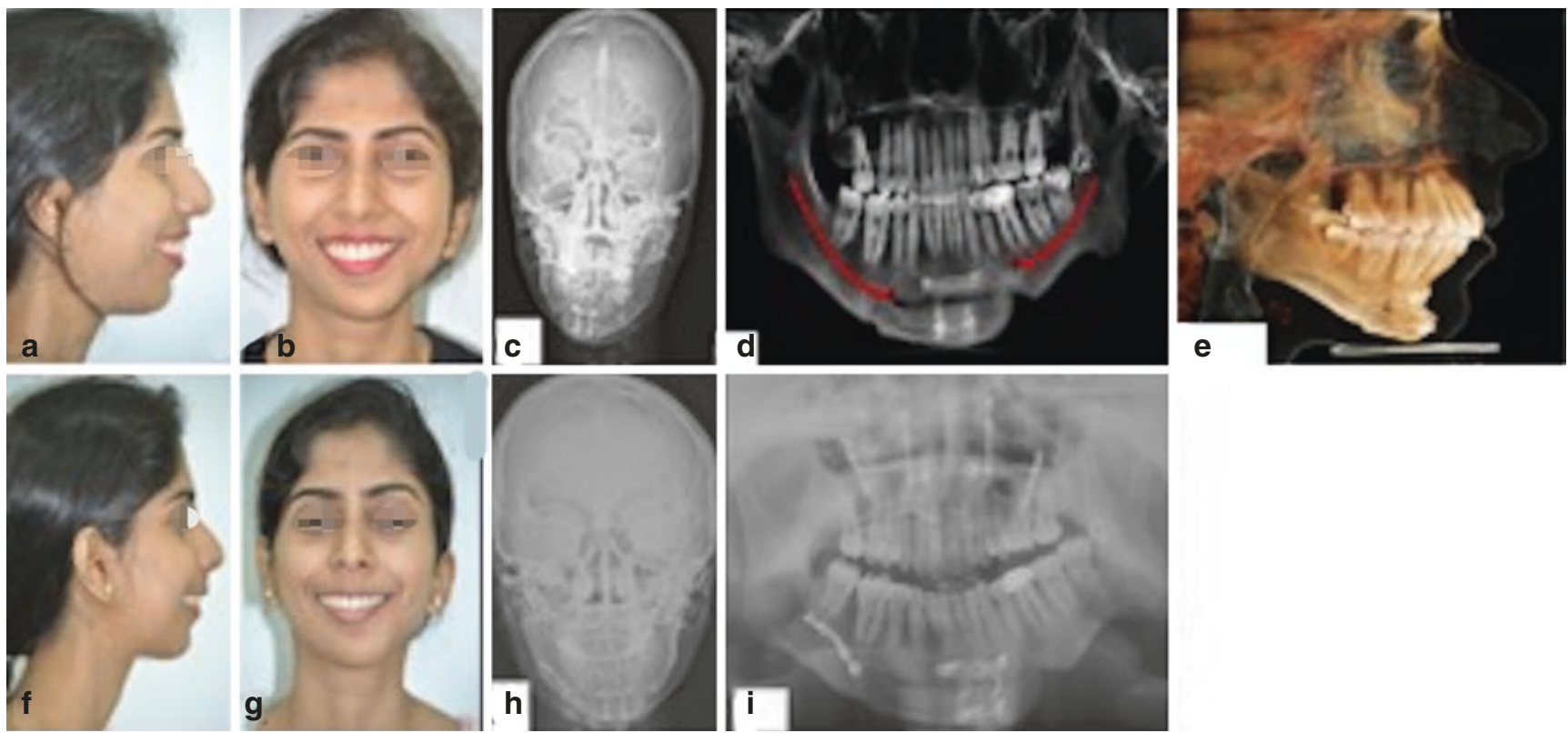

CAssociation of Oral and Maxillofacial Surgeons of India

Fig.69.40 (a-i) Facial asymmetry with maxillary occlusal cant, deviation of chin (surgery for left TMJ ankylosis and genioplasty done previously elsewhere). Treatment: Le fort I osteotomy for correction of maxillary occlusal cant; right unilateral sagittal split ramus osteotomy to close the open bite. (a) Pre-operative profile picture; (b) pre-opera- tive frontal view; (c) pre-operative PA skull; (d) pre-operative OPG; (e) pre-operative lateral cephalogram; (f) postoperative profile picture; (g) postoperative frontal view; (h) postoperative PA skull; (i) Post-operative OPG (Also see Figs. 69.30, 69.31 and 69.32) 


\section{Surgical Procedure}

Le fort I osteotomy for superior repositioning of maxilla

Bilateral Sagittal Split Ramus osteotomy for advancement of mandible

Advancement genioplasty

Later rhinoplasty was done.

Case Scenario 2 (Figs. 69.30, 69.31, 69.32, and 69.40a-i)

\section{Chief Complaints}

Facial asymmetry

Deviation of chin to left

Incisal/occlusion cant (Fig. 69.30)

Facial asymmetry was secondary to ankylosis of left TMJ. Left side treated with costochondral graft when patient was younger.

\section{Pre-operative Findings}

Occlusal cant

Asymmetry of face

The patient presented with occlusal canting visible at the anterior region. This needed to be addressed as it is clinically evident and may affect visual cosmesis.

Judge the incisal cant by drawing an imaginary interpupillary line and its inclination with incisal cant represented by the metal scale held in incisors

\section{Surgical Plan (Figs. 69.31 and 69.32)}

Le Fort I osteotomy for superior repositioning of maxilla on right side by $5 \mathrm{~mm}$

Sagittal split osteotomy on right side of mandible to match mandible to maxilla

\section{References}

1. Comte A. The positive philosophy of Auguste Comte. Freely translated and condensed by Harriet Martineau (1855). London: George Bell \& Sons; 1896.

2. Von Langenbeck B. Beitrange zur osteoplastik. In: Goschen A, editor. Die osteoplastiche resektion des oberkierers. Deutsche Klinik. Berlin: Reimer; 1859.

3. Cheever D. Displacement of the upper jaw. Med Surg Rep Boston City Hosp. 1870;1:156.

4. Cheever D. Nasopharyngeal polypus, attached to the basilar process of occipital and body of the sphenoid bone successfully removed by a section, displacement, and subsequent replacement and reunion of the superior maxillary bone. Boston Med Surg. 1867:8:162.

5. Moloney F, Worthington P. The origin of the Le Fort I maxillary osteotomy: Cheever's operation. J Oral Surg. 1981;39:731-4.

6. Halvorson EG, Mulliken JB. Cheever's double operation: the first Le Fort I osteotomy. Plast Reconstr Surg. 2008;121:1375-81.
7. Le Fort R. Etude experimentale sur les fractures de la machoire superieure. Rev Chir. 1901;1:208, 260, 479.

8. Le Fort R. Experimental study of fractures of the upper jaw (paper of 1901 translated by Paul Tessier). Plast Reconstr Surg. 1972;50:497-506.

9. Wassmund M. Frakturen und luxationen des gesichtsschädels. Leipzig: Meusser; 1927.

10. Axhausen G. Zur behandlung veralteter disloziert geheilter oberkieferbruche. Dtsch Zahn Mund Kieferheilk. 1934;1:334-9.

11. Wassmund M. Frakturen und Lurationen des Gesichtsschadels. Berlin: Meusser; 1927.

12. Axhausen G. Zur Behandlung veralteter desloziert verheilter Oberkieferbrunche. Dtsch Zahn Mund Kieferheilk. 1934;1:334.

13. Schuchardt D. Ein Beitrag zur chirurgeschen Kieferorthopadie unter Berucksichtigung ihrer Bedertung fur die Behandlung angeborener und erworbener Kieferdeformitaten bei Soldaten. Dtsch Zahn Mund Kieferheilk. 1942;9:73.

14. Willmar K. On Le Fort I osteotomy: a follow-up study of 106 operated patients with maxillo-facial deformity. Scand J Plast Reconstr Surg. 1974;12(Suppl 12):11-68.

15. Obwegeser H. Surgery of the maxilla for the correction of prognathism. SSO Schweiz Monatsschr Zahnheilkd. 1965;75:365-74.

16. Obwegeser HL. Surgical correction of small or retrodisplaced maxillae. The "dish-face" deformity. Plast Reconstr Surg. 1969;43:351-65.

17. Bell WH. Biologic basis for maxillary osteotomies. Am J Phys Anthropol. 1973;38:279-89.

18. Aziz SR, Marchena JM, Puran A. Anatomic characteristics of the infraorbital foramen: a cadaver study. J Oral Maxillofac Surg. 2000;58:992-6.

19. Demas PN, Sotereanos GC. Incidence of nasolacrimal injury and turbinectomy-associated atrophic rhinitis with Le Fort I osteotomies. J Craniomaxillofac Surg. 1989;17:116-8.

20. You ZH, Bell WH, Finn RA. Location of the nasolacrimal canal in relation to the high Le Fort I osteotomy. J Oral Maxillofac Surg. 1992;50:1075-80.

21. Cheung LK, Fung SC, Li T, et al. Posterior maxillary anatomy: implications for Le Fort I osteotomy. Int J Oral Maxillofac Surg. 1998;27:346-51.

22. Choi J, Park H. The anatomy of the maxillary artery in the pterygopalatine fossa. Int J Oral Maxillofac Surg. 1999;28(Suppl 1): 133 .

23. Turvey TA, Fonseca RJ. The anatomy of the internal maxillary artery in the pterygopalatine fossa: its relationship to maxillary surgery. J Oral Surg. 1980;38:92-5.

24. Bell WH. Revascularization and bone healing after anterior maxillary osteotomy: a study using adult rhesus monkeys. J Oral Surg. 1969;27:249-55.

25. Bell WH, Fonseca RJ, Kenneky JW, et al. Bone healing and revascularization after total maxillary osteotomy. J Oral Surg. 1975;33:253-60

26. Bruneder S, et al. Anatomy of the Le Fort I segment: are arterial variations a potential risk factor for avascular bone necrosis in Le Fort I osteotomies? J Craniomaxillofac Surg. 2018;46:1285-95.

27. Salman S, Fattahi T, Fernandes R, Steinberg B. Dynamic analysis of maxillary perfusion during Le Fort I osteotomy using indocyanine green. Int J Oral Maxillofac Surg. 2018;47:1311-5.

28. Oliveira GQV, Rossi MA, Vasconcelos TV, Neves FS, CrusoéRebello I. Cone beam computed tomography assessment of the pterygomaxillary region and palatine canal for Le Fort I osteotomy. Int J Oral Maxillofac Surg. 2017;46:1017-23.

29. Cohn-Stock G. Die Chirurgische Immediatregulierung der Kiefer, Speziell die Chirurgische Behandlung der Prognathie. Vjschr Zahnheilk. 1921:37:320. 
30. Wunderer S. Erfahrungen mit der Operativen Behandlung Hochgradiger Prognathien. Dtsch Zahn Mund Kieferheilk. 1963;39:451.

31. Cupar I. Die chirurgisehe Behandlung der Form- und Stellungsveranderungen des Oberkiefers. Ost Z Stomatol. 1954;51:565.

32. Bell WH. Revascularization and bone healing after anterior maxillary ostectomy. J Oral Surg. 1969;27:249.

33. Bell WH. Correction of maxillary excess by anterior maxillary osteotomy. Oral Surg Oral Med Oral Pathol. 1977;43:323.

34. Gunaseelan R, Anantanarayanan P, Veerabahu M, et al. Intraoperative and perioperative complications in anterior maxillary osteotomy: a retrospective evaluation of 103 patients. J Oral Maxillofac Surg. 2009;67:1269.

35. Rosenquist B. Anterior segmental maxillary osteotomy: a 24-month follow-up. Int J Oral Maxillofac Surg. 1993;22:210.

36. Meyer MW, Cavanaugh CD. Blood flow changes after orthognathic surgery: maxillary and mandibular subapical ostectomy. J Oral Surg. 1976;34:495.

37. Epker NB. Vascular considerations in orthognathic surgery: maxillary osteotomies. J Oral Surg. 1984;57:473.

38. Epker NB. A modified anterior maxillary ostectomy. J Maxillofac Surg. 1977;5:35.

39. Haas Junior OL, Guijarro-Martıínez R, de Sousa Gil AP, da Silva Meirelles L, de Oliveira RB, Hernaíndez-Alfaro F. Stability and surgical complications in segmental Le Fort I osteotomy: a systematic review. Int J Oral Maxillofac Surg. 2017;46:1071-87.

40. Rodrigo C. Induced hypotension during anesthesia with special reference to orthognathic surgery. Anesth Prog. 1995;42:41-58.

41. Zellin G, Rasmusson L, Palsson J, et al. Evaluation of haemorrhage depressors on blood loss during orthognathic surgery: a retrospective study. J Oral Maxillofac Surg. 2004;62:662-6.

42. Carlos E, Monnazzi MS, Castiglia YM, et al. Orthognathic surgery with or without induced hypotension. Int J Oral Maxillofac Surg. 2014;43:577-80.

43. Van Sickels JE, Larsen AJ, Triplett RG. Predictability of maxillary surgery: a comparison of internal and external reference marks. Oral Surg Oral Med Oral Pathol. 1986;61:542-5.

44. Ferguson JW, Luyk NH. Control of vertical dimension during maxillary orthognathic surgery. A clinical trial comparing internal and external fixed reference points. J Craniomaxillofac Surg. 1992;20:333-6.

45. Hackney FL, Nishioka GJ, VanSickels JE. Frontal soft-tissue morphology with double V-Y closure following LeFort I osteotomy. J Oral Maxillofac Surg. 1988;46:850-5.

46. Schendel SA, Williamson LW. Muscle reorientation following superior repositioning of the maxilla. J Oral Maxillofac Surg. 1983;41(4):235-40.

47. Newhouse RF, Schow SR, Kraut RA, et al. Life-threatening haemorrhage from a Le Fort I osteotomy. J Oral Maxillofac Surg. 1982;40(2):117-9.

48. Epker BN, Fish LC. Dentofacial deformities, integrated orthodontic and surgical correction, vol. 1. St Louis: Mosby; 1986.

49. Epker BN. Superior surgical repositioning of the maxilla: longterm results. J Maxillofac Surg. 1981;9(4):237-46.

50. Maloney F, West RA, McNeill W. Surgical correction of vertical maxillary excess: a re-evaluation. J Maxillofac Surg. 1982;10(2):84-91.

51. Johnson DG. Intraoperative measurement of maxillary repositioning: an ancillary technique. Oral Surg Oral Med Oral Pathol. 1985;60(3):266-8.

52. Nishioka GJ, Van Sickels JE. Modified external reference measurement technique for vertical repositioning of the maxilla. Oral Surg Oral Med Oral Pathol. 1987;64(1):22-3.
53. Posnick JC. 15: Sequencing of orthognathic procedures: step-bystep approach. In: Posnick JC, editor. Orthognathic surgery: principles \& practice. St Louis: Saunders; 2014.

54. Bennett MA, Wolford LM. The maxillary step osteotomy and Steinmann pin stabilization. J Oral Maxillofac Surg. 1985;43:307.

55. Kramer FJ, Baethge C, Swennen G, Teltzrow T, Schulze A, Berten $\mathrm{J}$, Brachvogel P. Intra- and perioperative complications of the Le Fort I osteotomy: a prospective evaluation of 1000 patients. J Craniofac Surg. 2004;15:971-9.

56. Aldridge T, Gulati A, Baker N. Theories of acquired blindness following Le Fort 1 osteotomy. Br J Oral Maxillofac Surg. 2013;51:e86.

57. Bays RA, Bouloux GF. Complications of orthognathic surgery. Oral Maxillofac Surg Clin North Am. 2003;15:229-42.

58. Richardson D. Avoiding surgical complications in orthognathic surgery. In: Ward-Booth P, Schendel S, Hausamen J, editors. Maxillofacial surgery. 2nd ed. London: Churchill Livingstone; 2006. p. 1259-74.

59. Breeze $\mathrm{J}$, et al. comReview Is an osteotome necessary for pterygomaxillary dysjunction or dysjunction through the tuberosity during Le Fort I osteotomy? A systematic review. Br J Oral Maxillofac Surg. 2016;54:248-52.

60. Precious DS, Morrison A, Ricard D. Pterygomaxillary separation without the use of an osteotome. J Oral Maxillofac Surg. 1991;49:98-9.

61. Mehra P, Hopkin JK, Castro V, Freitas RZ. Stability of maxillary advancement using rigid fixation and bone grafting: cleft lip versus non-cleft patients. Int J Adult Orthodon Orthognath Surg. 2001;16:193.

62. Muradin MS, Seubring K, Stoelinga PJ, et al. A prospective study on the effect of modified alar base cinch sutures and V-Y closure versus simple closing sutures on nasolabial changes after Le Fort 1 intrusion and advancement osteotomies. J Oral Maxillofac Surg. 2011;69:870.

63. Peled M, Ardekian L, Krausz AA, Aizenbud D. Comparing the effects of V-Y advancement versus simple closure on upper lip esthetics after Le Fort 1 advancement. J Oral Maxiillofac Surg. 2004;62:315

64. Vercruysse H Jr, et al. The effect of a Le Fort I incision on nose and upper lip dynamics: unraveling the mystery of the "Le Fort I lip". J Craniomaxillofac Surg. 2016;44:1917-21.

65. Lee H-J, Park H-S, Kyung H-M, Kwon T-G. Soft tissue changes and skeletal stability after modified quadrangular Le Fort I osteotomy. Int J Oral Maxillofac Surg. 2015;44:356-61.

66. Issacson R, Ingram A. Forces produced by rapid maxillary expansion: forces present during treatment. Angle Orthod. 1964;34:256.

67. Haas AJ. The treatment of maxillary deficiency by opening the midpalatal suture. Angle Orthod. 1965;35:200.

68. Persson M, Thilander B. Palatal suture closure in man from age 15 to 35 years of age. Am J Orthod. 1977;72:42.

69. Epker BN, Wolford LM. Transverse maxillary deficiency dentofacial deformities: integrated orthodontic and surgical correction. St Louis: Mosby; 1980.

70. Spalding PM. Craniofacial growth and development: current understanding and clinical considerations. In: Miloro M, editor. Peterson's principles of oral and maxillofacial surgery. 2nd ed. London: BC Decker; 2004. p. 1051-86.

71. Suri L, Taneja P. Surgically assisted rapid palatal expansion: a literature review. Am J Orthod Dentofac Orthop. 2008; 133:290-302.

72. Verquin M, Daems L, Politis C. Short-term complications after surgically assisted rapid palatal expansion: a retrospective cohort study. Int J Oral Maxillofac Surg. 2017;46:303-8. 
73. Turvey T. Sequencing of two-jaw surgery: the case for operating on the maxilla first. J Oral Maxillofac Surg. 2011;69:2225.

74. Guymon M, Crosby DR, Wolford LM. The alar base cinch suture to control nasal width in maxillary osteotomies. Int $\mathrm{J}$ Adult Orthodon Orthognath Surg. 1988;3:89-95.

75. Betts NJ, Vig KW, Vig P, Spalding P, Fonseca RJ. Changes in the nasal and labial soft tissues after surgical repositioning of the maxilla. Int J Adult Orthodon Orthognath Surg. 1993;8:7-23.

76. Hack GA, de Mol van Otterloo JJ, Nanda R. Long-term stability and prediction of soft tissue changes after LeFort I surgery. Am J Orthod Dentofac Orthop. 1993;104:544-55.

77. Raithatha R, Naini FB, Patel S, Sherriff M, Witherow H. Longterm stability of limiting nasal alar base width changes with a cinch suture following Le Fort I osteotomy with submental intubation. Int J Oral Maxillofac Surg. 2017;46:1372-9.

78. Schendel SA, Carlotti AE. Nasal considerations in orthognathic surgery. Am J Orthod Dentofac Orthop. 1991;100:197-208.

79. Perciaccante VJ, Bays RA. Maxillary orthognathic surgery. In: Miloro M, editor. Peterson's principles of oral and maxillofacial surgery. 2nd ed. London: BC Decker; 2004. p. 1179-204.

80. Moenning JE, Bussard DA, Lapp TH, Garrison BT. Average blood loss and the risk of requiring perioperative blood transfusion in 506 orthognathic surgical procedures. J Oral Maxillofac Surg. 1995;53:880-3.

81. Mommaerts MY, Abeloos JV, De Clercq CA, Neyt LF. The effect of the subspinal Le Fort I-type osteotomy on interalar rim width. Int J Adult Orthodon Orthognath Surg. 1997;12:95-100.

82. Betts NJ, Vig KW, Vig P, Spalding P, Fonseca RJ. Changes in the nasal and labial soft tissues after surgical repositioning of the maxilla. Int J Adult Orthod Orthognath Surg. 1993;8:7-23.

83. Lanigan DT, Guest P. Alternative approaches to pterygomaxillary separation. Int J Oral Maxillofac Surg. 1993;22:131-8.

84. Renick BM, Symington JM. Postoperative computed tomography study of pterygomaxillary separation during the Le Fort I osteotomy. J Oral Maxillofac Surg. 1991;49:1061-5.

85. Robinson PP, Hendy CW. Pterygoid plate fractures caused by the Le Fort I osteotomy. Br J Oral Maxillofac Surg. 1986;24:198-202.

86. O'Regan B, Bharadwaj G. Prospective study of the incidence of serious posterior maxillary haemorrhage during a tuberosity osteotomy in low level Le Fort I operations. Br J Oral Maxillofac Surg. 2007;45:538-42.

87. Gustafsson UO, Scott MJ, Schwenk W, Demartines N, Roulin D, Francis N, McNaught CE, MacFie J, Liberman S, Soop M, Hill A, Kennedy RH, Lobo DN, Fearon K, Ljungqvist O. Guidelines for perioperative care in elective colonic surgery: enhanced recovery after surgery (ERAS) society recommendations. Clin Nutr. 2012;31:783-800.

88. Robinson RC, Holm RL. Orthognathic surgery for patients with maxillofacial deformities. Assoc Periop Regist Nurs. 2010;92:28-52.

89. Hoffman GR, Islam S. The difficult Le Fort I osteotomy and downfracture: a review with consideration given to an atypical maxillary morphology. J Plast Reconstr Aesthet Surg. 2008;61:1029-33.

90. Kendell BD, Fonseca RJ, Lee M. Postoperative nutritional supplementation for the orthognathic surgery patient. J Oral Maxillofac Surg. 1982;40:205-13.

91. Olejko TD, Fonseca RJ. Preoperative nutritional supplementation for the orthognathic surgery patient. J Oral Maxillofac Surg. 1984;42:573-7.

92. Chidyllo SA, Chidyllo R. Nutritional evaluation prior to oral and maxillofacial surgery. NY State Dent J. 1989;55:38-40.
93. Kehlet H. Multimodal approach to control postoperative pathophysiology and rehabilitation. Br J Anaesth. 1997;78:606-17.

94. Fearon KC, Luff R. The nutritional management of surgical patients: enhanced recovery after surgery. Proc Nutr Soc. 2003;62:807-11.

95. Younis J, Salerno G, Fanto D, Hadjipavlou M, Chellar D, Trickett JP. Focused preoperative patient stoma education, prior to ileostomy formation after anterior resection, contributes to a reduction in delayed discharge within the enhanced recovery programme. Int J Colorect Dis. 2011;27:43-7.

96. Aarts MA, Okrainec A, Glicksman A, Pearsall E, Victor JC, McLeod RS. Adoption of enhanced recovery after surgery (ERAS) strategies for colorectal surgery at academic teaching hospitals and impact on total length of hospital stay. Surg Endosc. 2012;26:442-50.

97. Larsson J, Akerlind I, Permerth J, Hornvist JO. The relation between nutritional state and quality of life in surgical patients. Eur J Surg. 1994;160:329-34.

98. Nygren J, Thacker J, Carli F, Fearon KCH, Norderval S, Lobo DN, Ljungqvist O, Soop M, Ramirez J. Guidelines for perioperative care in elective rectal/pelvic surgery: enhanced recovery after surgery (ERAS) society recommendations. Clin Nutr. 2012;31:801-16.

99. Piecuch J, Tideman H, DeKoomen H. Short face syndrome: treatment of myofascial pain dysfunction by maxillary disimpaction. Oral Surg. 1980;49:112.

100. Baker DL, Stoelinga PJ, Blijdorp PA, Brouns JJ. Long-term stability after inferior maxillary repositioning by miniplate fixation. Int J Oral Maxillofac Surg. 1992;21:320.

101. Wardrop RW, Wolford LM. Maxillary stability following downgraft and/or advancement procedures with stabilization using rigid fixation and porous block hydroxyapatite implants. J Oral Maxillofac Surg. 1989;47:336.

102. Proffit WR, Phillips C, Turvey TA. Stability following superior repositioning of the maxilla by LeFort I osteotomy. Am J Orthod Dentofac Orthop. 1987;92(2):151-61.

103. Proffit WR, Turvey TA, Phillips C. Orthognathic surgery: a hierarchy of stability. Int J Adult Orthodon Orthognath Surg. 1996;11:191.

104. Dowling PA, Espeland L, Sandvik L, Mobarak KA, Hogevold HE. Le Fort I maxillary advancement: 3-year stability and risk factors for relapse. Am J Orthod Dentofac Orthop. 2005; 128:560.

105. Louis PJ, Waite PD, Austin RB. Long-term skeletal stability after rigid fixation of LeFort I osteotomies with advancements. Int J Oral Maxillofac Surg. 1993;22:82.

106. Nimkarn Y, Miles PG, Waite PD. Maxillomandibular advancement surgery in obstructive sleep apnea syndrome patients: long-term surgical stability. J Oral Maxillofac Surg. 1995;53:1414.

107. Bishara SE, Chu GW. Comparisons of postsurgical stability of the LeFort I maxillary impaction and maxillary advancement. Am J Orthod Dentofac Orthop. 1992;102:335.

108. Bailey LJ, Phillips C, Proffit WR, Turvey TA. Stability following superior repositioning of the maxilla by LeFort I osteotomy: five-year follow-up. Int J Adult Orthodon Orthognath Surg. 1994;9:163.

109. Emshoff R, Scheiderbauer A, Gerhard S, Norer B. Stability after rigid fixation of simultaneous maxillary impaction and mandibular advancement osteotomies. Int J Oral Maxillofac Surg. 2003;32:137

110. Mogavero FJ, Buschang PH, Wolford LM. Orthognathic surgery effects on maxillary growth in patients with vertical maxillary excess. Am J Orthod Dentofac Orthop. 1997;111:288. 
111. Hedemark A, Freihofer HP. The behavior of the maxilla in vertical movements after LeFort I osteotomy. J Maxillofac Surg. 1978;6:244.

112. Ellis E III, Carlson DS, Frydenlund S. Stability of midface augmentation: an experimental study of musculoskeletal interaction and fixation methods. J Oral Maxillofac Surg. 1989;47:1062.

113. Rosen HM. Definitive surgical correction of vertical maxillary deficiency. Plast Reconstr Surg. 1990;85:215.

114. Major PW, Philippson GE, Glover KE, Grace MG. Stability of maxilla downgrafting after rigid or wire fixation. J Oral Maxillofac Surg. 1996;54:1287.

115. de Mol van Otterloo JJ, Tuinzing DB, Kostense P. Inferior positioning of the maxilla by a LeFort I osteotomy: a review of 25 patients with vertical maxillary deficiency. J Craniomaxillofac Surg. 1996;24:69.

116. Chow J, Hagg U, Tideman H. The stability of segmentalized LeFort I osteotomies with miniplate fixation in patients with maxillary hypoplasia. J Oral Maxillofac Surg. 1995;53:1407.

117. Junger TH, Krenkel C, Howaldt HP. LeFort I sliding osteotomy: a procedure for stable inferior repositioning of the maxilla. $\mathrm{J}$ Craniomaxillofac Surg. 2003;31:92.

118. Gulabivala K, Naini FB. The orthodontic-endodontic interface. In: Gulabivala K, Ng YL, editors. Endodontics. 4th ed. St Louis: Mosby; 2014.

119. El Deeb M, Wolford L, Bevis R. Complications of orthognathic surgery. J Clin Plast Surg. 1989;16(4):825-40.

120. Kiani MT, Tajik G, Ajami M, Fazli H, Kharazifard MJ, Mesgarzadeh A. Trigeminocardiac reflex and haemodynamic changes during Le Fort I osteotomy. Int J Oral Maxillofac Surg. 2016;45:567-70.

121. Chen Z, Mo S, Fan X, et al. A Meta-analysis and Systematic Review Comparing the Effectiveness of Traditional and Virtual Surgical Planning for Orthognathic Surgery: Based on Randomized Clinical Trials. Journal of Oral and Maxillofacial Surgery: Official Journal of the American Association of Oral and Maxillofacial Surgeons. 2020 Sep. https://doi.org/10.1016/j. joms.2020.09.005.

122. Heufelder M, Wilde F, Pietzka S, et al. Clinical accuracy of waferless maxillary positioning using customized surgical guides and patient specific osteosynthesis in bimaxillary orthognathic surgery. Journal of Cranio-maxillo-facial Surgery: Official Publication of the European Association for Craniomaxillo-facial Surgery. 2017;45(9):1578-85.

\section{Additional Readings}

Laster Z, Ardekian L, Rachmiel A, Peled M. Use of the 'shark-fin' osteotome in separation of the pterygomaxillary junction in Le Fort I osteotomy: a clinical and computerized tomography study. Int J Oral Maxillofac Surg. 2002;31(1):100-3.

Cheng LH, Robinson PP. Evaluation of a swan's neck osteotome for pterygomaxillary dysjunction in the Le Fort I osteotomy. Br J Oral Maxillofac Surg. 1993;31(1):52-3.

Stajcić Z. Altering the angulation of a curved osteotome-does it have effects on the type of pterygomaxillary disjunction in Le Fort I osteotomy? An experimental study. Int J Oral Maxillofac Surg. 1991;20(5):301-3.

Trimble LD, Tideman H, Stoelinga PJ. A modification of the pterygoid plate separation in low-level maxillary osteotomies. J Oral Maxillofac Surg. 1983;41(8):544-6.

Perez D, Ellis E 3rd. Sequencing bimaxillary surgery: mandible first. J Oral Maxillofac Surg. 2011;69(8):2217-24.

Hackney FL, Timmis DP, Van Sickels JE. Esthetic evaluation of frontal labial morphology after double V-Y closure following Le Fort I osteotomy. J Oral Maxillofac Surg. 1989;47(12):1277-80; discussion 1281.

Khamashta-Ledezma L, Naini FB. Systematic review of changes in maxillary incisor exposure and upper lip position with Le Fort I type osteotomies with or without cinch sutures and/or VY closures. Int J Oral Maxillofac Surg. 2014;43(1):46-61.

Open Access This chapter is licensed under the terms of the Creative Commons Attribution 4.0 International License (http://creativecommons. org/licenses/by/4.0/), which permits use, sharing, adaptation, distribution and reproduction in any medium or format, as long as you give appropriate credit to the original author(s) and the source, provide a link to the Creative Commons license and indicate if changes were made.

The images or other third party material in this chapter are included in the chapter's Creative Commons license, unless indicated otherwise in a credit line to the material. If material is not included in the chapter's Creative Commons license and your intended use is not permitted by statutory regulation or exceeds the permitted use, you will need to obtain permission directly from the copyright holder. 